\title{
GEOMETRY OF RECENTLY ACTIVE BREAKS ALONG THE SAN ANDREAS FAULT, CALIFORNIA
}

\author{
by
}

D.E. Moore and J. Byerlee

Open-File Report 89-347

This report is preliminary and has not been reviewed for conformity with U.S. Geological Survey editorial standards or with the North American Stratigraphic Code . Any use of trade, firm, or product names is for descriptive purposes only and does not imply endorsement by the U.S. Government. 


\section{ABSTRACT}

Textural examination of fault gouge deformed in laboratory triaxial friction experiments has yielded differences in the degree of development and the orientations of secondary shear sets between the stably sliding and stick-slip samples. In order to determine whether such differences can be identified in real faults, maps of recently active breaks along the San Andreas fault from Point Arena to Cajon Pass have been examined to compare the types and orientations of secondary structures mapped in the creeping and locked sections. The fault was subdivided into 52 geometrically defined segments of uniform average trend that range from 4.6 to $66 \mathrm{~km}$ in length. The orientations and lengths of all secondary fault traces within each segment were then measured and compared to the average trends. Two principal differences between the creeping and locked segments have been identified. First, the angular difference between the strikes of the individual recent breaks and the average trend is $14^{\circ}$ or less in the creeping segments, whereas in the locked segments the maximum angular difference is generally greater than $15^{\circ}$. Second, the ratio of the length of recent breaks with a more westerly (or southerly) strike than the average trend to the length of breaks with a more northerly strike is about 1.38 for the creeping segments as a group and 0.63 among the locked segments. Both secondary faulting characteristics along the San Andreas are consistent with our experimental results. Our study of experimentally deformed gouge therefore provides a possible explanation for the observed San Andreas fault patterns. It is only one of several competing hypotheses, however, the most important alternative being the control of fault orientations by current or pre-existing stress states. Further work is needed to identify the best model.

\section{INTRODUCTION}

A general correlation has long been made between the fracture patterns of natural fault zones and those that develop during laboratory shear box and friction tests (e.g., Tchalenko, 1970; Wallace, 1973; Rutter et al., 1986). Because of this correspondence, the examination of laboratory samples may yield information that will help to explain fault zone behavior. In recent years we have conducted textural studies of fault gouge deformed in many triaxial friction experiments (Moore et al., 1986a, 1988, 1989). A major result of this work is that we have been able to distinguish stably sliding samples from ones that show stick-slip motion on the basis of their textures, in particular the degree of development and the orientations of secondary shear sets. We then wished to determine whether these experimental results could be applied to natural fault zones. To this end, we have studied the surface rupture patterns along the San Andreas fault, with emphasis on a comparison of the creeping and locked sections. This report presents the first results of this study of San Andreas fault geometry, and an evaluation of the results in the light of our laboratory observations.

\section{EXPERIMENTAL BACKGROUND}

For many years, soil scientists have studied the structural features produced during shear box, rotary shear, and Riedel experiments (e.g., Cloos, 1928; Riedel, 1929; 
Morgenstern and Tchalenko, 1967; Mandl et al., 1977) and rock mechanics investigators have examined the textures and structures developed during triaxial friction experiments (e.g., Logan et al., 1979, 1981; Rutter et al., 1986; Logan and Rauenzahn, 1987). A number of secondary shear and fracture orientations have been identified by these workers in the experimentally produced fault zones. Figure 1 summarizes the different types of observed shears and fractures, using the labelling scheme of Logan et al. (1979) and Vialon (1979) along with the additional designation of 'boundary shears' for $Y$ shears that have developed at or near the boundaries between the gouge layer and the enclosing rock cylinder.

We have examined many samples of fault gouge that were deformed during triaxial friction experiments; the fault gouge materials that were used included a granitic rock flour, a pure quartz sand, serpentine, and clayey gouges rich in either illite or montmorillonite (Moore et al., 1986a, 1988, 1989). In the samples that contain subsidiary shears, $R$ (Riedel) and boundary shears (Figure 1) predominate overall. $Y$ shears in the middle of the gouge layer have been found in some of the samples of serpentine gouge. $P$ shears are not uncommon, but in many samples their occurrence is restricted to short segments connecting two $R$ shears or an $R$ and a boundary shear. The initial textural investigations were therefore concentrated on the $R$ and boundary shears rather than the $P$ shears although, as will be discussed later, the observed fracture patterns along the San Andreas have since led to a more serious examination of $P$-shear development in the experimental samples. Tension $(T)$ fractures were not observed in our experiments, which were conducted at high effective pressures, and the major structures with $X$ and $R^{\prime}$ (conjugate Riedel) orientations are the axial planes of kink bands in the clay-rich gouge samples. In the granite and quartz sand gouges, however, some grains of quartz and feldspar contain fractures that have an orientation and sense of offset that are consistent with $R^{\prime}$ fractures.

The friction experiments on these various gouge types were run under a range of temperature, confining pressure, fluid pressure, and velocity conditions, which yielded many samples each of stable and stick-slip motion (Summers and Byerlee, 1977; Byerlee et al., 1978; Moore et al., 1983, 1986a, b). Over 100 run products of the illite-rich gouge were available for study; as a result, this gouge provided the framework for the textural examinations. Detailed descriptions of the illite gouge samples are contained in Moore et al. (1989); a brief summary is provided here. Schematic drawings showing the range of textures developed in the illite gouge are presented in Figure 2. Some samples are pervasively deformed (Figure 2a), and the textures include a clay-mineral alignment, stretched mineral grains, and variously oriented kink bands. The samples characterized by Figure $2 \mathrm{~b}$ contain poorly developed (proto-) shears whose boundaries with the remaining gouge are ill-defined. The gouge between the proto-shears in these samples still shows pervasively developed deformation textures. In Figure 2c, the shears are well developed and have sharply defined boundaries with the adjoining gouge. At least some of the gouge between the shears is undeformed. In the extreme case of localized shear (Figure 2d), all the deformation is concentrated in relatively narrow boundary and $R$ shears, and the rest of the gouge is completely undeformed.

Each of the illite samples was classified as $\mathbf{a}, \underline{b}, \mathbf{c}$, or $\mathrm{d}$, based on the textural diagrams in Figure 2. In addition, the orientations of the $R$ shears, where present, relative to the 

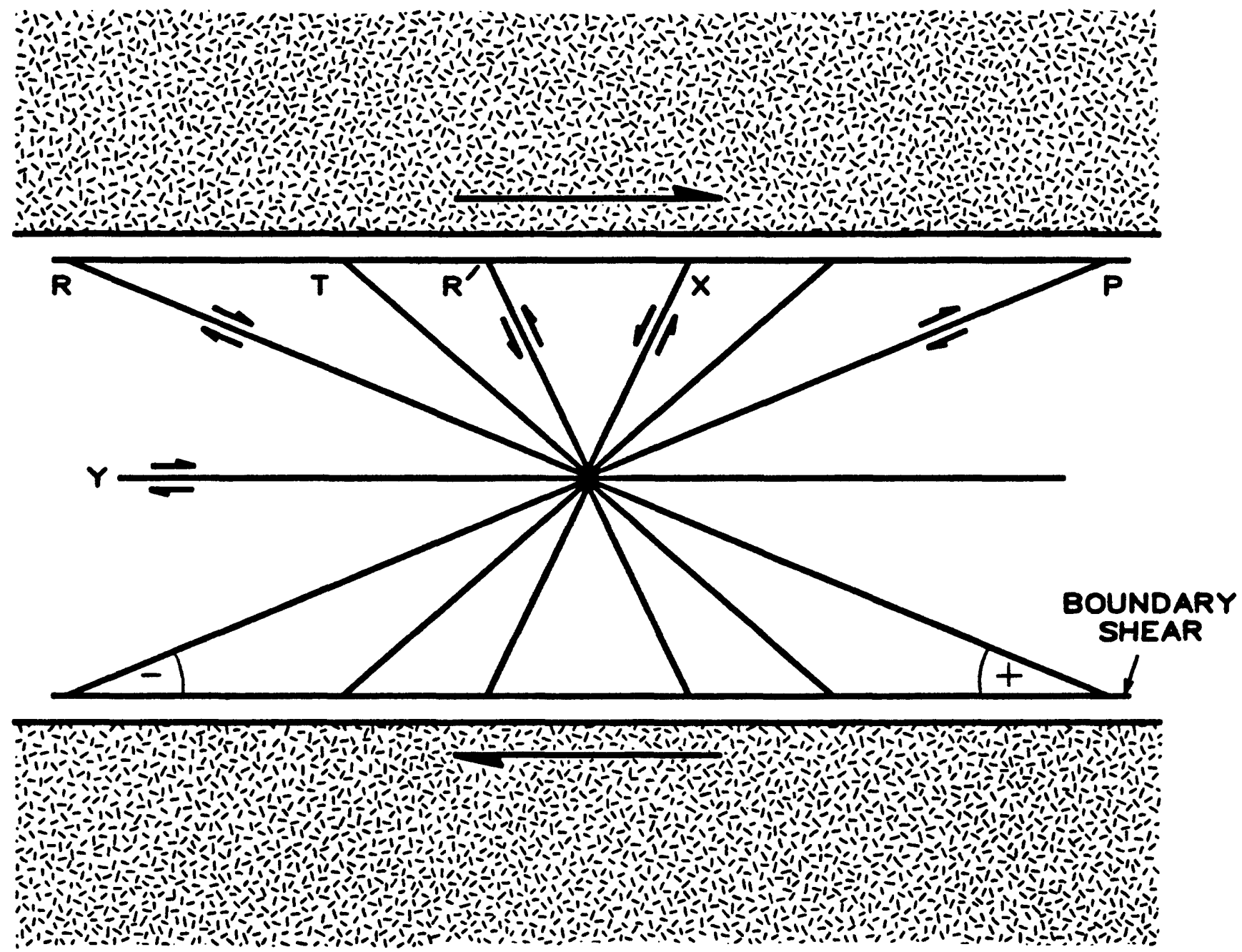

Figure 1. Labeling scheme of Logan et al. (1979) for fracture and shear arrays developed in gouge layers deformed in triaxial friction experiments. The offset directions of planes showing shear are indicated by arrows. The term 'boundary shears' was added by Moore et al. (1989) to describe $Y$ shears that form along the gouge-rock cylinder boundary. The designation $S$ (schistosité) was added from Vialon (1979). Angular orientations of fractures and shears in the experimental samples are made relative to the boundary of the gouge layer (parallel to the overall shearing direction), using the sign convention shown in the Figure. The orientations of fault traces of the San Andreas are determined relative to the average strike of the fault zone, using the same sign convention. 

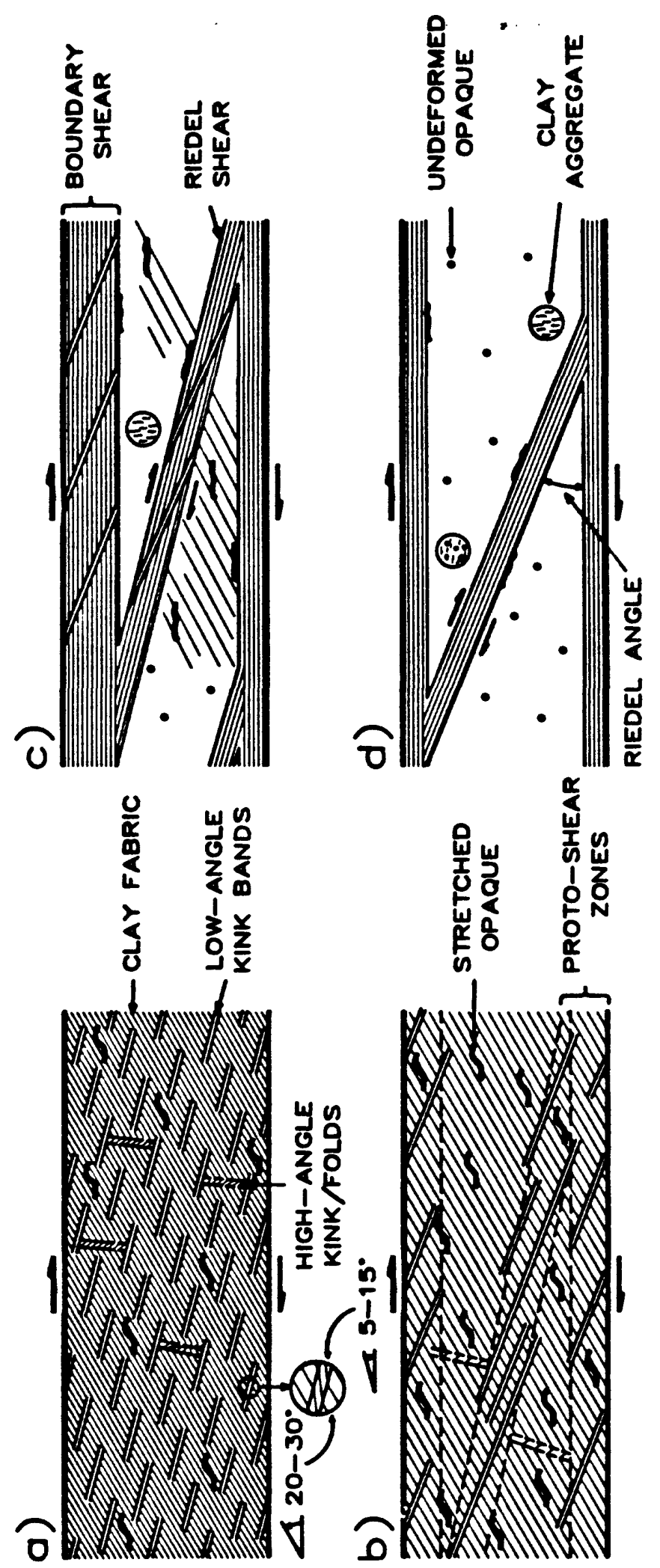

Figure 2. Diagrammatic sketches of textural gradations in illite gouge run products. a) Deformation distributed throughout gouge. b) Deformation still pervasive in gouge, but some proto-shears present. c) Good development of wide boundary and numerous cross-cutting shears; rest of gouge at least somewhat deformed. d) All deformation concentrated along narrow boundary and a few Riedel shears; rest of gouge undeformed. 
boundary of the gouge layer (Riedel angles) were measured. It was found that the sliding behavior of the illite gouge could be correlated with its textural classification and maximum measured Riedel angle, as summarized in Table 1. All of the texture a samples slide stably, and the texture $b$ samples, with their poorly developed shears and relatively low Riedel angles, show at most short periods of stick-slip motion. The samples with localized deformation (textures $\mathrm{c}$ and d) display stick-slip motion if the maximum Riedel angle is greater than $14^{\circ}$ and stable slip if the angles are all less than $10^{\circ}$. If the largest Riedel angle is between 10 and $14^{\circ}$, the texture $c$ samples have variable sliding behavior, whereas the texture $\mathrm{d}$ samples, with their more highly localized shear, show stick-slip. The samples with the highest Riedel angles also have the largest stress drops. These results led Moore et al. $(1988,1989)$ to conclude that localization of shear is a necessary but not a sufficient requirement for stick-slip motion and that high Riedel angles are also somehow involved, although the actual role of the Riedel shear orientations as a cause or alternatively a result of stick-slip motion is not yet known.

The other examined gouges show correlations among their overall textures, Riedel shear orientations, and sliding behavior that are similar to those summarized for illite in Table 1. The montmorillonite-rich and serpentine gouges are essentially identical to the illite gouge in their textures and angular relations, whereas the quartzofeldspathic gouges show some textural differences that are caused by their different mineral contents and grain sizes and shapes. For example, the granite and quartz sand gouges do not contain kink bands, which depend on the presence of a clay (or other sheet-silicate mineral) fabric to form. Instead, fracturing and crushing of the quartz and feldspar grains are important processes. In the pervasively deformed samples of quartzofeldspathic gouge, grain size reduction occurs throughout the gouge layer, whereas in the samples showing localized shear, the fracturing and crushing are concentrated in the subsidiary shears. The measured Riedel angles in the granite gouge and their relationships to sliding behavior are the same as those in Table 1. For the gouge composed of quartz sand, however, samples with Riedel angles as large as $24^{\circ}$ slide stably and the stick-slip samples have Riedel angles of up to $35^{\circ}$.

\section{PRESENT STUDY}

Scope. This work uses the six maps of recently active breaks along the San Andreas fault between Point Delgada and Cajon Pass, prepared by geologists of the U.S. Geological Survey (Brown, 1970, 1972; Brown and Wolfe, 1972; Ross, 1969; Sarna-Wojcicki et al., 1975; and Vedder and Wallace, 1970). A general view of this part of the San Andreas, showing important locality names and the area covered by each of the six maps, is presented in Figure 3. The studied sections north of San Francisco (Brown and Wolfe, 1972) were restricted to the on-land portions between Point Arena and Bolinas Bay. South of Cajon Pass, the San Andreas system splits up into several major splays. Three maps of recently active fault traces have been compiled for parts of this area (Hope, 1969; Sharp, 1971; Clark, 1984). These maps have been excluded from the present study, however, because of the complicated nature of faulting in this part of southern California. They will be examined in the future, along with maps of the Calaveras and Hayward faults. 
Table 1. Relationships Among Textural Classification, Sliding Behavior, and Maximum Riedel Angle for Experimentally Deformed Illite Gouge

\begin{tabular}{|c|c|c|c|}
\hline & \multicolumn{3}{|c|}{ Maximum Riedel Angle } \\
\hline & $<10^{\circ}$ & $10-14^{\circ}$ & $>14^{\circ}$ \\
\hline$\underline{\mathbf{a}}$ & - & - & - \\
\hline b & Stable & $\begin{array}{c}\text { Stable or Part Stable/ } \\
\text { Part Stick-Slip }\end{array}$ & - \\
\hline c & Stable & $\begin{array}{l}\text { Stable, Part Stable/Part } \\
\text { Stick-Slip, or Stick-Slip }\end{array}$ & Stick-Slip \\
\hline d & Stable & Stick-Slip & Stick-Slip \\
\hline
\end{tabular}


PT. DELGADA

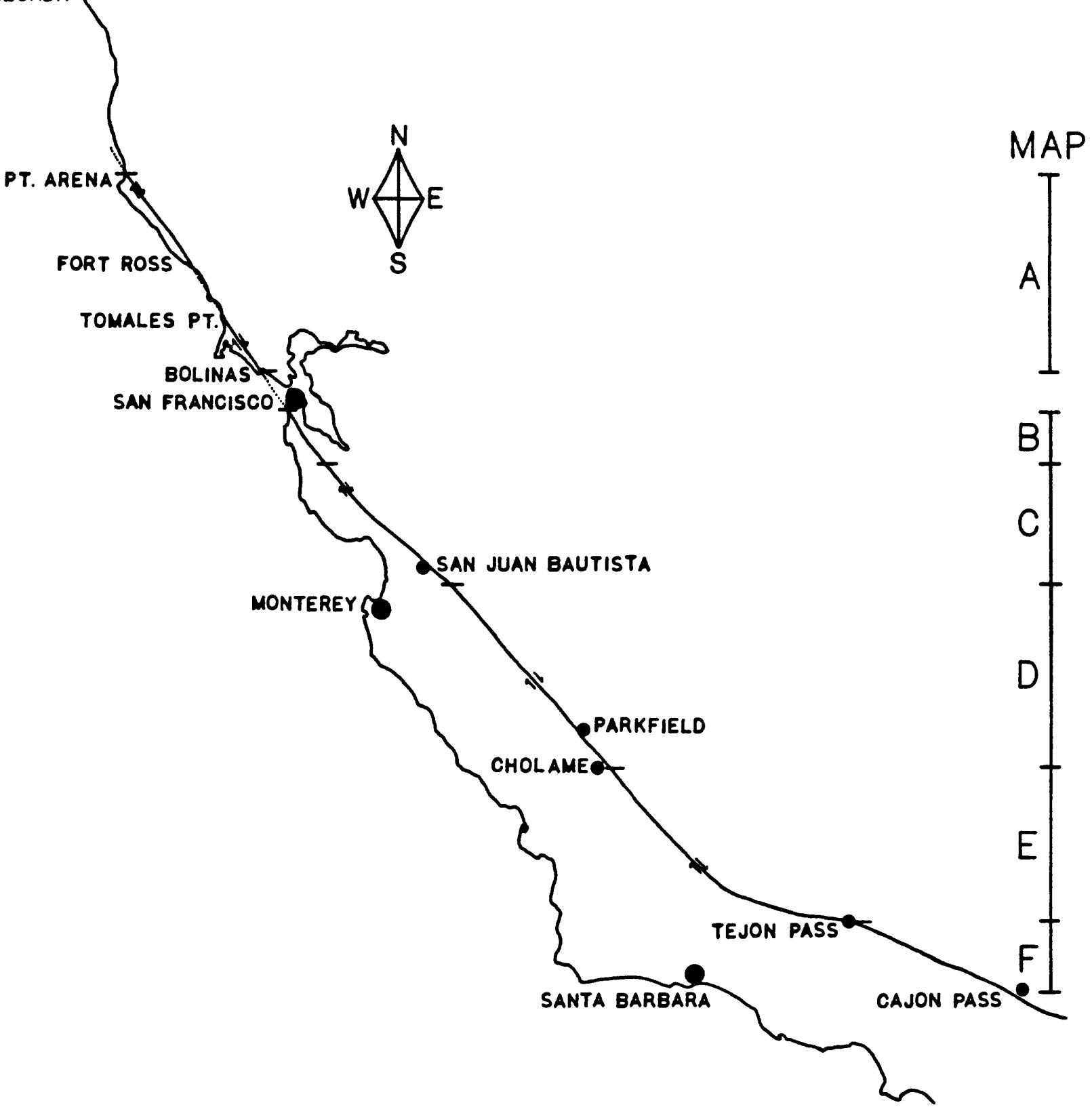

Figure 3. Map of the San Andreas fault between Point Delgada and Cajon Pass, with locality names that are mentioned in the text. U.S.G.S. strip maps of recently active breaks along the San Andreas between Point Arena and Cajon Pass are the focus of this study. The extent of each strip map is shown in the figure: Map A - Point Delgada to Bolinas Bay (Brown and Wolfe, 1972); Map B - San Mateo County (Brown, 1972); Map C - Santa Cruz Mountains to northern Gabilan Range (Sarna-Wojcicki et al., 1975); Map D - northern Gabilan Range to Cholame Valley (Brown, 1970); Map E - Cholame Valley to Tejon Pass (Vedder and Wallace, 1970); Map F - Tejon Pass to Cajon Pass (Ross, 1969). That portion of the fault from just south of San Juan Bautista to the Cholame Valley comprises the creeping section of the San Andreas; the rest of the fault is locked. 
Procedures and Data. The purpose of this study was to compare the types, orientations, and degree of development of secondary structures in the natural and experimental fault zones. In order to achieve an exact correspondence with Figure 1, all of the mapped San Andreas fault traces should be vertical and show pure strike-slip motion. The maps of recently active breaks do not yield information on fault plane orientations or absolute motion for each trace. Nevertheless, these two requirements are probably more or less met by most of the fault traces, because most structural and seismological studies have indicated the presence of high-angle fault planes, and the overall motion on the fault is almost pure strike-slip. The presence of small scarps along some fault traces can generally be attributed to the lateral offset of irregular topography rather than vertical motion ( $R$. Brown, written communication, 1989). For this first treatment of the data, therefore, all of the mapped faults are assumed to fit these criteria. Nevertheless, it should be remembered that the main fault traces are not everywhere vertical or near-vertical. In addition, major stepovers in the fault trace may be accompanied by normal or thrust faults, which accommodate the extensional or compressional stresses that develop in the stepover regions. Future studies will include an attempt to separate out those faults with largely normal- or thrust-type offsets.

Data collection for this study consisted of the measurement of orientation (strike) and length of every San Andreas fault trace included in the six maps. A small number of traces that appear to be landslide scars rather than fault ruptures were not considered; these omitted traces are indicated on the maps. The fault traces are typically curved, and where necessary they were divided into smaller sections of relatively uniform trend before the measurements were made. Some very short, highly curved traces were not subdivided; instead, an average strike was obtained for such faults. The San Andreas as a whole is also curved (Figure 3). It was therefore necessary to divide the fault zone itself into segments of uniform trend, in order to compare the orientation of individual traces with the average fault strike at a given locality. In this study, a fault 'segment' is defined solely on the basis of fault geometry, such that a given segment is a relatively straight stretch of the fault zone that is separated from adjoining segments by geometric discontinuities such as bends or stepovers (see also Barka and Kadinsky-Cade, 1988). This usage differs from the seismogenic or earthquake rupture segments that are defined on the basis of characteristic earthquakes that repeatedly rupture the same length of fault. The geometric subdivision of the San Andreas fault was kept as simple as possible; that is, both the number of segments and the amount of separation between adjoining segments (stepover size) were minimized. The average trend of a given segment follows as closely as possible the main trace of the fault. In all, 52 segments were defined along the examined 700-km length of the San Andreas. The segmentation of the fault is shown schematically in Figure 4, along with measurements of fault width; the average trends and lengths of the segments are listed at the top of Table 2. Fault zone width is defined in this study as the width of the zone of mapped recently active breaks, measured perpendicular to the average trend of the fault.

The maps from which the basic data for this report were derived are available for inspection only at the following repositories: 


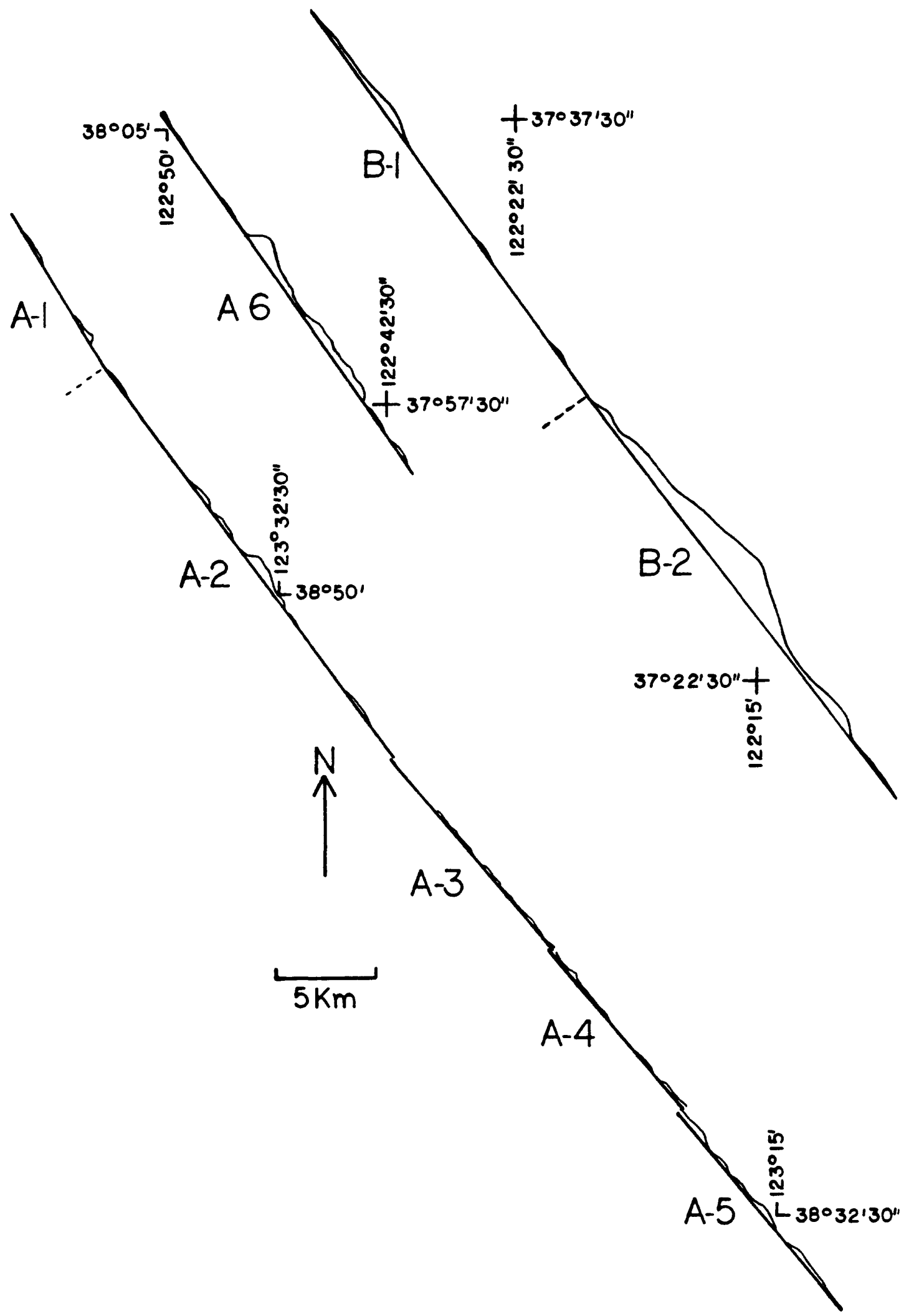

Figure 4. Schematic drawings of San Andreas fault segments and their inferred boundary relations. Added to the upper side of each segment line are measurements of fault zone width, which for this study was defined as the maximum distance between the mapped fault traces measured perpendicular to the average trend of the fault. The fault zone width and segment length measurements are plotted at the same scale. Gaps in the fault trace caused by alluvial deposits, road construction, etc., are not shown on the diagrams. See Figure 3 for location of segments. 


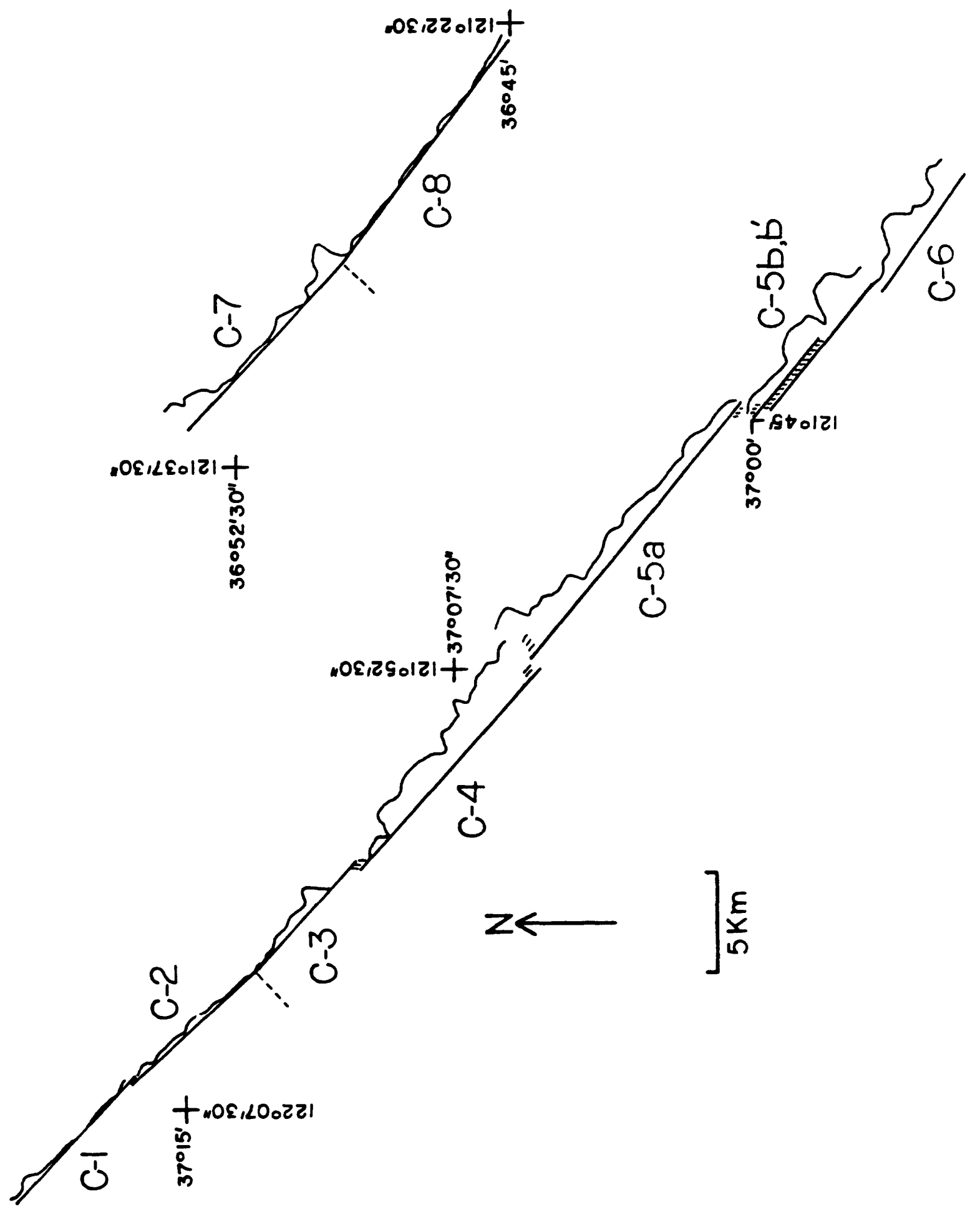

Figure 4, continued. 


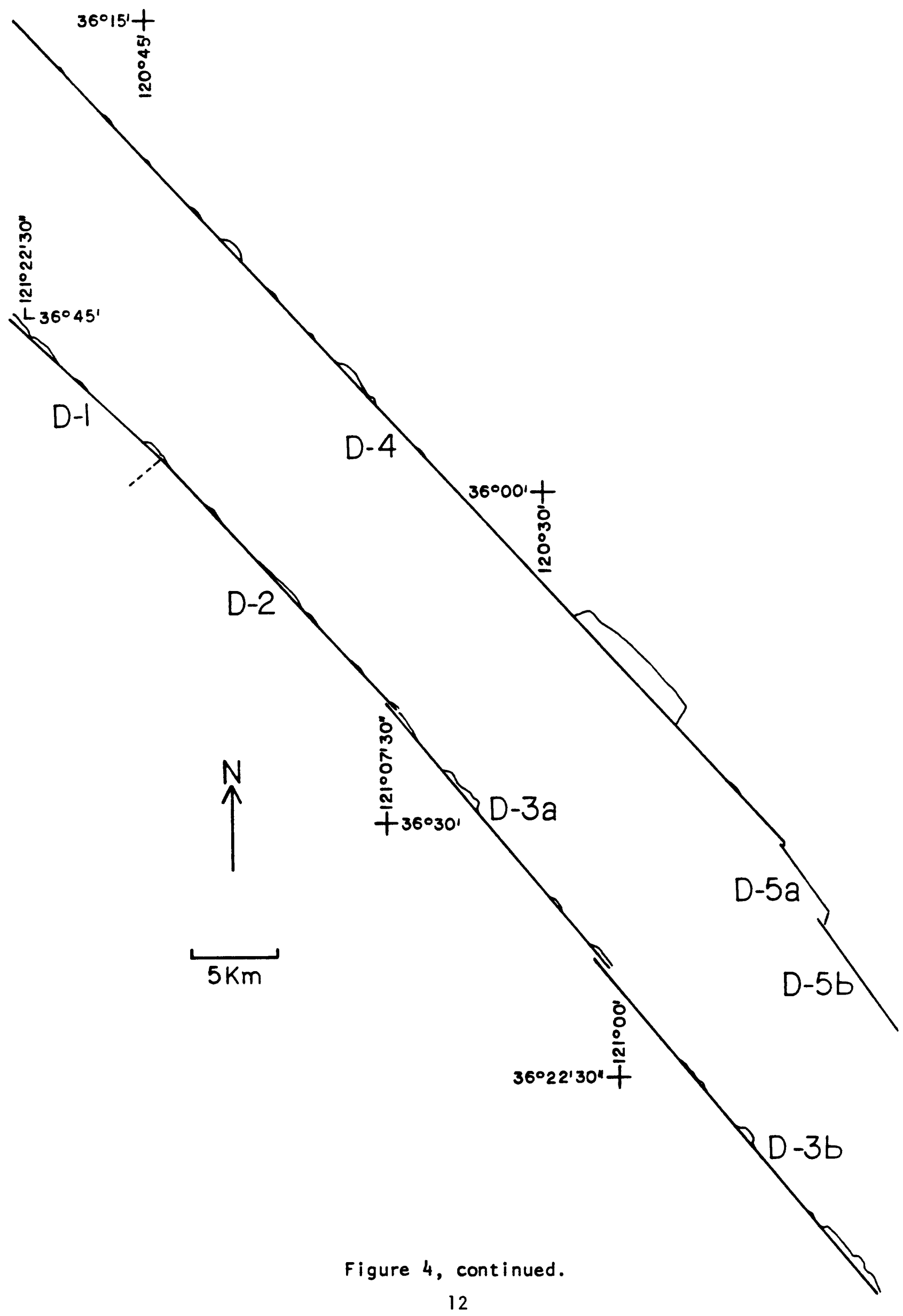




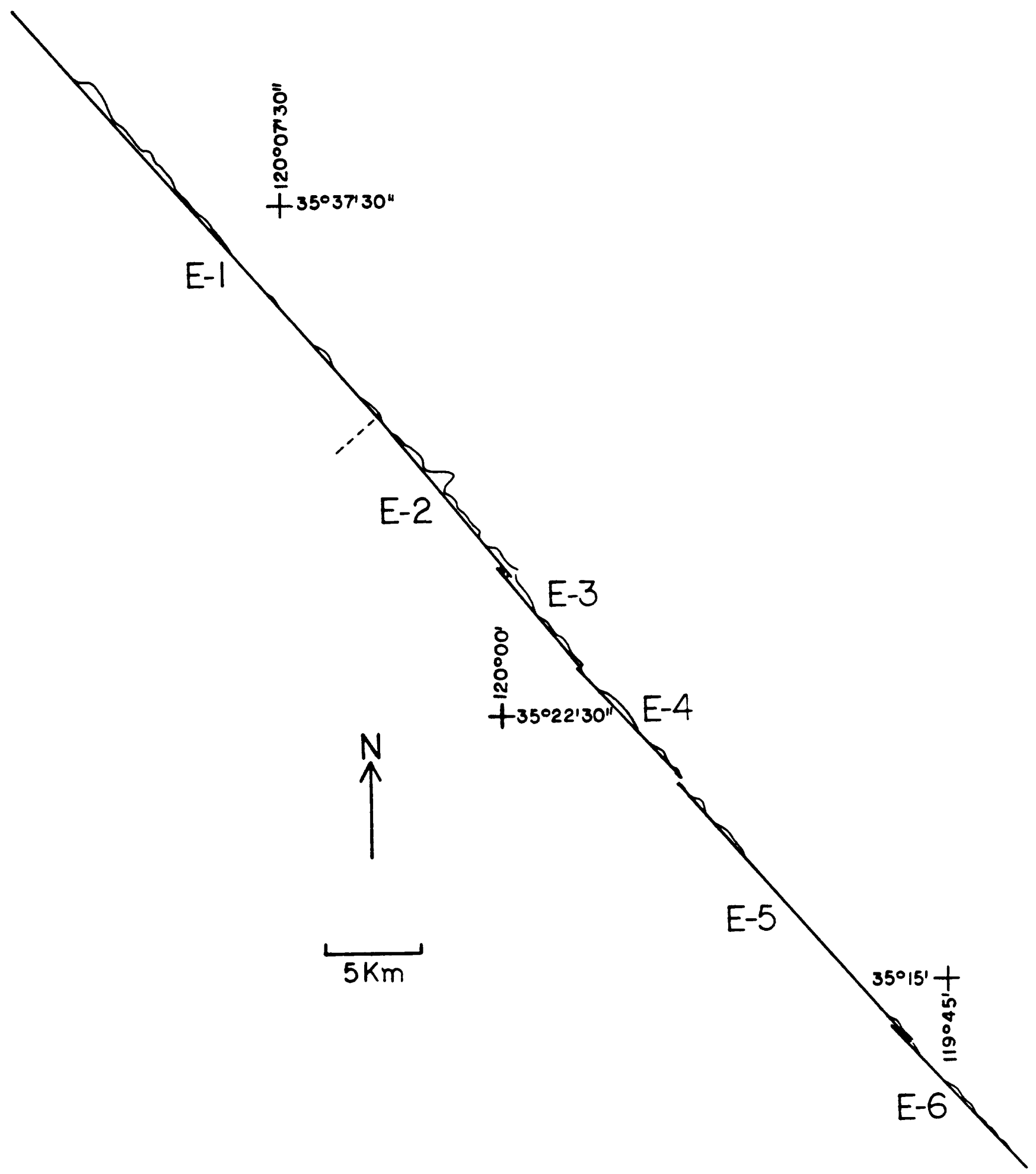

Figure 4, continued. 


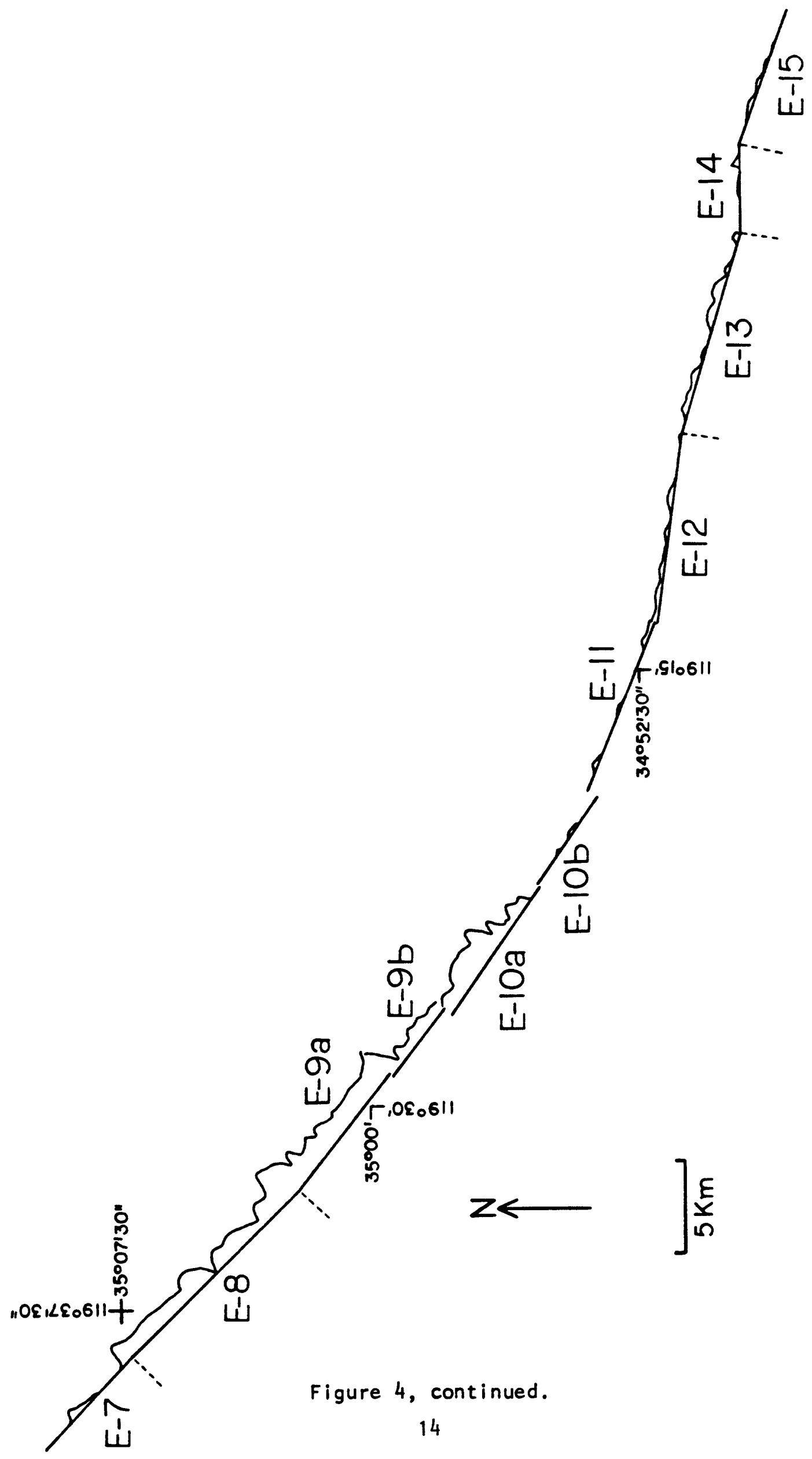




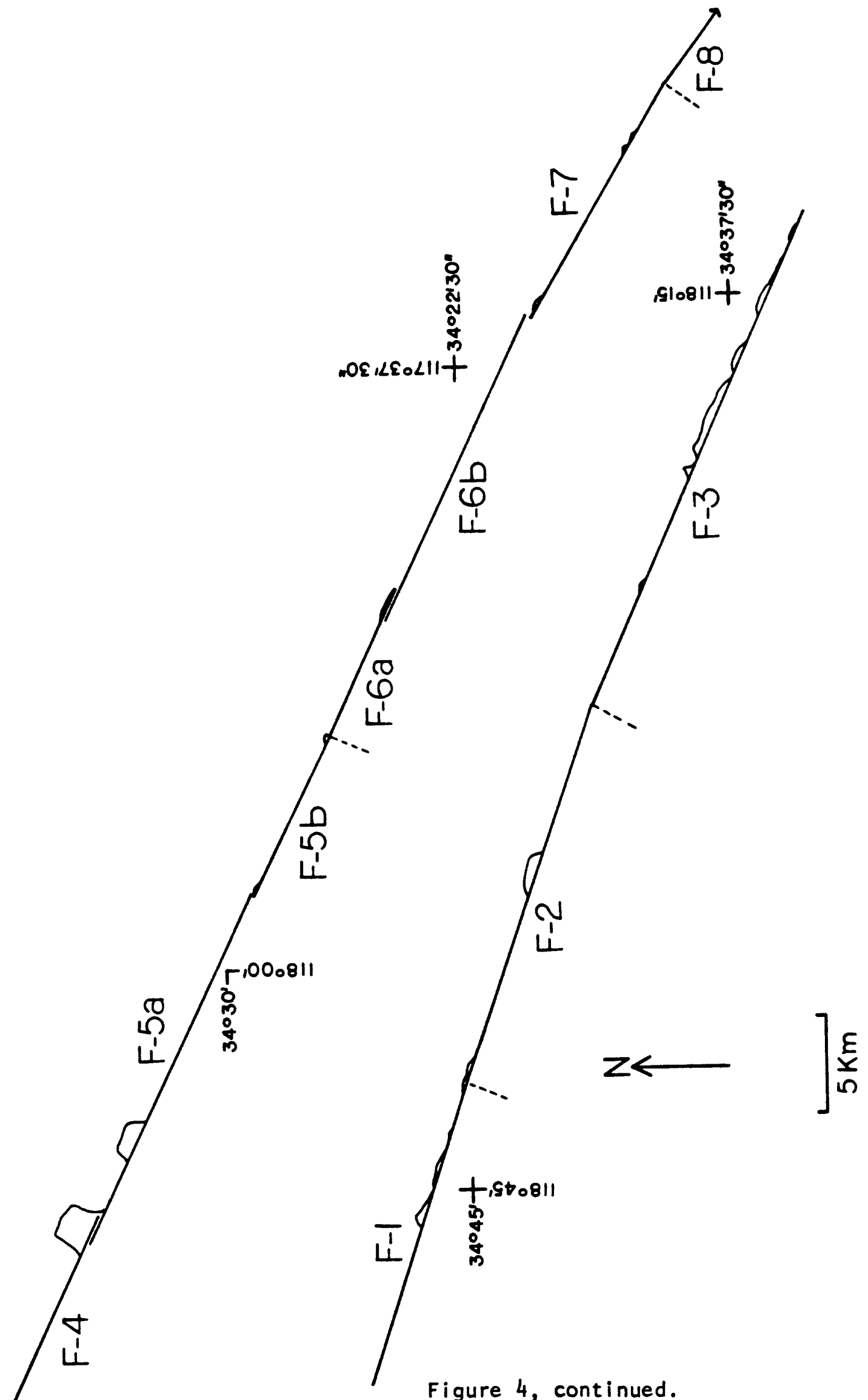

Figure 4 , continued. 
Table 2. Summary of Map Data for Segments of Uniform Average Trend.

\begin{tabular}{|c|c|c|c|c|c|c|c|c|}
\hline & A-1 & A-2 & A-3 & $A-4$ & A-5 & $A-6$ & B-1 & B-2 \\
\hline No. Segments & 1 & 1 & 1 & 1 & 1 & 1 & 1 & 1 \\
\hline Average Trend & $\mathrm{N} 31^{\circ} \mathrm{W}$ & $\mathrm{N} 36^{\circ} \mathrm{W}$ & $\mathrm{N} 38^{\circ} \mathrm{W}$ & $\mathrm{N} 40^{\circ} \mathrm{W}$ & $\mathrm{N} 39^{\circ} \mathrm{W}$ & $\mathrm{N} 35^{\circ} \mathrm{W}$ & $\mathrm{N} 35^{\circ} \mathrm{W}$ & $\mathrm{N} 37^{\circ} \mathrm{W}$ \\
\hline Seg. Length (km) & $9.2(t)$ & 24.3 & 14.0 & 10.3 & $12.9(+)$ & $22.0(+)$ & $23.9(+)$ & 25.4 \\
\hline Max. $R$ angle & $13^{\circ}$ & $21^{\circ}$ & $14^{\circ}$ & $19^{\circ}$ & $17^{\circ}$ & $26^{\circ}$ & $10^{\circ}$ & $17^{\circ}$ \\
\hline$T(\mathrm{~m})$ & - & - & - & - & - & - & - & - \\
\hline$S(\mathrm{~m})$ & - & - & - & - & - & - & - & 580 \\
\hline$R^{\prime}(\mathrm{m})$ & - & - & - & - & - & - & - & - \\
\hline$X(\mathrm{~m})$ & - & - & - & - & - & - & - & 130 \\
\hline$Y_{1}(1,-1)(m)$ & 3970 & 3815 & 4185 & 6360 & 3900 & 9420 & 2310 & 8880 \\
\hline$R_{1}(2,35)(\mathrm{m})$ & 3895 & 13890 & 9770 & 7930 & 13305 & 19435 & 11385 & 24975 \\
\hline$P_{1}(-2,-35)(\mathrm{m})$ & 850 & 12310 & 4575 & 2880 & 8740 & 11720 & 12880 & 20590 \\
\hline$P_{1} / R_{1}$ & 0.22 & 0.89 & 0.47 & 0.36 & 0.66 & 0.60 & 1.13 & 0.82 \\
\hline$Y_{1} / L$ & 0.46 & 0.13 & 0.23 & 0.37 & 0.14 & 0.23 & 0.09 & 0.16 \\
\hline$Y_{2}(4,-4)(m)$ & 6710 & 15180. & 9350 & 10865 & 12430 & 25045 & 12245 & 29245 \\
\hline$R_{2}(5,35)(\mathrm{m})$ & 1700 & 8785 & 6375 & 6305 & 6860 & 7905 & 4550 & 10285 \\
\hline$P_{2}(-5,-35)(\mathrm{m})$ & 305 & 6050 & 2805 & - & 6655 & 7625 & 9780 & 14915 \\
\hline$P_{2} / R_{2}$ & 0.18 & 0.69 & 0.44 & - & 0.97 & 0.96 & 2.15 & 1.45 \\
\hline \multirow[t]{2}{*}{$Y_{.2} / L$} & 0.77 & 0.51 & 0.50 & 0.63 & 0.48 & 0.62 & 0.46 & 0.53 \\
\hline & $\mathrm{C}-1$ & $\mathrm{C}-2$ & $\mathrm{C}-3$ & $\mathrm{C}-4$ & C- $-5 a$ & $C-5 b$ & $\mathrm{C}-6$ & $\mathrm{C}-7$ \\
\hline No. Segments & 1 & 1 & 1 & 1 & 1 & 2 & 1 & 1 \\
\hline Average Trend & $\mathrm{N} 48^{\circ} \mathrm{W}$ & $\mathrm{N} 42^{\circ} \mathrm{W}$ & $\mathrm{N} 47^{\circ} \mathrm{W}$ & $\mathrm{N} 48^{\circ} \mathrm{W}$ & $\mathrm{N} 50^{\circ} \mathrm{W}$ & $\mathrm{N} 50^{\circ} \mathrm{W}$ & $\mathrm{N} 54^{\circ} \mathrm{W}$ & $\mathrm{N} 47^{\circ} \mathrm{W}$ \\
\hline Seg. Length $(\mathrm{km})$ & 8.8 & 8.2 & 7.5 & 13.3 & 16.6 & 9.2 & 7.2 & 11.4 \\
\hline Max. $R$ angle & $23^{\circ}$ & $21^{\circ}$ & $23^{\circ}$ & $32^{\circ}$ & $30^{\circ}$ & $35^{\circ}$ & $31^{\circ}$ & $18^{\circ}$ \\
\hline$T(\mathrm{~m})$ & 495 & - & - & 1545 & 670 & 2850 & 930 & - \\
\hline[]$(\mathrm{m})$ & - & - & - & 1130 & - & 385 & 935 & - \\
\hline$R^{\prime}(\mathrm{m})$ & - & - & - & 440 & - & - & - & - \\
\hline$X(\mathrm{~m})$ & - & - & - & - & - & - & - & - \\
\hline$Y_{1}(1,-1)(m)$ & 2990 & 3680 & 5560 & 7260 & 11450 & 2690 & 4820 & 16050 \\
\hline$R_{1}(2,35)(\mathrm{m})$ & 9835 & 9735 & 7560 & 56090 & 38745 & 34000 & 20760 & 7295 \\
\hline$P_{1}(-2,-35)(\mathrm{m})$ & 6130 & 8870 & 4520 & 22010 & 32620 & 7880 & 19395 & 14165 \\
\hline$P_{1} / R_{1}$ & 0.62 & 0.91 & 0.60 & 0.39 & 0.84 & 0.23 & 0.93 & 1.94 \\
\hline$Y_{1} / L$ & 0.15 & 0.17 & 0.32 & 0.08 & 0.14 & 0.06 & 0.10 & 0.43 \\
\hline$Y_{2}(4,-4)(m)$ & 8960 & 13590 & 12000 & 25510 & 32250 & 12715 & 14915 & 23645 \\
\hline$R_{2}(5,35)(\mathrm{m})$ & 6555 & 6255 & 4435 & 45000 & 26730 & 28480 & 15575 & 4955 \\
\hline$P_{2}(-5,-35)(\mathrm{m})$ & 3440 & 2440 & 1205 & 14850 & 23835 & 3375 & 14485 & 8910 \\
\hline$P_{2} / R_{2}$ & 0.52 & 0.39 & 0.27 & 0.33 & 0.89 & 0.12 & 0.93 & 1.80 \\
\hline$Y_{2} / L$ & 0.46 & 0.61 & 0.68 & 0.29 & 0.39 & 0.27 & 0.32 & 0.63 \\
\hline
\end{tabular}


Table 2. (continued)

\begin{tabular}{|c|c|c|c|c|c|c|c|c|}
\hline & $\mathrm{C}-8$ & D-1 & D-2 & $\mathrm{D}-3$ & $\mathrm{D}-4$ & $\mathrm{D}-5$ & $\mathrm{E}-1$ & E-2 \\
\hline $\begin{array}{l}\text { No. Segments } \\
\text { Average Trend }\end{array}$ & $\begin{array}{c}1 \\
\mathrm{~N} 53^{\circ} \mathrm{W}\end{array}$ & $\begin{array}{c}1 \\
\mathrm{~N} 47^{\circ} \mathrm{W}\end{array}$ & $\begin{array}{c}1 \\
\mathrm{~N} 43^{\circ} \mathrm{W}\end{array}$ & $\begin{array}{c}2 \\
\mathrm{~N} 40^{\circ} \mathrm{W}\end{array}$ & $\begin{array}{c}1 \\
\mathrm{~N} 42^{\circ} \mathrm{W}\end{array}$ & $\begin{array}{c}2 \\
\mathrm{~N} 35^{\circ} \mathrm{W}\end{array}$ & $\begin{array}{c}1 \\
\mathrm{~N} 41^{\circ} \mathrm{W}\end{array}$ & $\begin{array}{c}1 \\
\mathrm{~N} 38^{\circ} \mathrm{W}\end{array}$ \\
\hline $\begin{array}{l}\text { Seg. Length }(\mathrm{km}) \\
(\mathrm{km})\end{array}$ & 13.8 & 12.1 & 20.9 & 45.8 & 66 & 12.9 & 29 & 10.9 \\
\hline Max. $R$ angle & $13^{\circ}$ & $8^{\circ}$ & $6^{\circ}$ & $13^{\circ}$ & $14^{\circ}$ & $23^{\circ}$ & $25^{\circ}$ & $15^{\circ}$ \\
\hline$T(\mathrm{~m})$ & - & - & - & - & - & - & - & 565 \\
\hline$S(\mathrm{~m})$ & - & - & - & - & - & - & - & - \\
\hline$R^{\prime}(\mathrm{m})$ & - & - & - & - & - & - & - & - \\
\hline$X(\mathrm{~m})$ & - & - & - & - & - & - & - & - \\
\hline$Y_{1}(1,-1)(m)$ & 5420 & 5005 & 8440 & 13985 & 16840 & 5255 & 13620 & 2540 \\
\hline$R_{1}(2,35)(\mathrm{m})$ & 9620 & 4225 & 7310 & 19640 & 26170 & 5460 & 20545 & 11470 \\
\hline$P_{1}(-2,-35)(\mathrm{m})$ & 14815 & 4310 & 8750 & 27160 & 34410 & 2045 & 16760 & $\mathbf{5 7 3 0}$ \\
\hline$P_{1} / R_{1}$ & 1.54 & 1.02 & 1.20 & 1.38 & 1.32 & 0.37 & 0.82 & 0.50 \\
\hline$Y_{1} / L$ & 0.18 & 0.37 & 0.34 & 0.23 & 0.22 & 0.41 & 0.27 & 0.13 \\
\hline$Y_{2}(4,-4)(m)$ & 19080 & 7750 & 18145 & 28875 & 38710 & 7400 & 27540 & 6615 \\
\hline$R_{2}(5,35)(\mathrm{m})$ & 5390 & 1885 & 2380 & 14840 & 15120 & 3750 & 13745 & 8795 \\
\hline$P_{2}(-5,-35)(\mathrm{m})$ & 5385 & 3905 & 3975 & 17070 & 23590 & 1610 & 9640 & 4330 \\
\hline$P_{2} / R_{2}$ & 1.00 & 2.07 & 1.67 & 1.15 & 1.56 & 0.43 & 0.70 & 0.49 \\
\hline \multirow[t]{2}{*}{$Y_{2} / L$} & 0.64 & 0.57 & 0.74 & 0.48 & 0.50 & 0.58 & 0.54 & 0.33 \\
\hline & E-3 & $\mathrm{E}-4$ & $\mathrm{E}-5$ & E-6 & E-7 & $\mathrm{E}-8$ & E-9 & $\mathrm{E}-10$ \\
\hline No. Segments & 1 & 1 & 1 & 1 & 1 & 1 & 2 & 2 \\
\hline Average Trend & $\mathrm{N} 39^{\circ} \mathrm{W}$ & $\mathrm{N} 42^{\circ} \mathrm{W}$ & $\mathrm{N} 41^{\circ} \mathrm{W}$ & $\mathrm{N}^{4} 3^{\circ} \mathrm{W}$ & $\mathrm{N} 48^{\circ} \mathrm{W}$ & $\mathrm{N} 45^{\circ} \mathrm{W}$ & $\mathrm{N} 52^{\circ} \mathrm{W}$ & $\mathrm{N} 56^{\circ} \mathrm{W}$ \\
\hline Seg. Length $(\mathrm{km})$ & 6.8 & 7.9 & 18.3 & 10.4 & 6.9 & 12.9 & 12.5 & 14.0 \\
\hline Max. $R$ angle & $18^{\circ}$ & $30^{\circ}$ & $12^{\circ}$ & $22^{\circ}$ & $11^{\circ}$ & $32^{\circ}$ & $24^{\circ}$ & $30^{\circ}$ \\
\hline$T(\mathrm{~m})$ & 115 & 310 & - & - & - & 825 & 475 & 815 \\
\hline$S(\mathrm{~m})$ & 75 & - & - & 200 & - & 655 & 620 & 1655 \\
\hline$R^{\prime}(\mathrm{m})$ & - & - & - & - & - & - & 65 & - \\
\hline$X(\mathrm{~m})$ & - & - & - & - & - & - & - & 240 \\
\hline$Y_{1}(1,-1)(m)$ & 4090 & 1990 & 11770 & 9820 & 5035 & 8405 & 12120 & 5165 \\
\hline$R_{1}(2,35)(\mathrm{m})$ & 6370 & 7260 & 5280 & 4735 & 2725 & 28950 & 20090 & 16580 \\
\hline$P_{1}(-2,-35)(\mathrm{m})$ & 5325 & 7910 & 1915 & 2410 & 2080 & 11140 & 15435 & 16270 \\
\hline$P_{1} / R_{1}$ & 0.84 & 1.09 & 0.36 & 0.51 & 0.76 & 0.38 & 0.77 & 0.98 \\
\hline$Y_{1} / L$ & 0.26 & 0.11 & 0.62 & 0.57 & 0.51 & 0.17 & 0.25 & 0.13 \\
\hline$Y_{2}(4,-4)(m)$ & 9100 & 6355 & 16665 & 15015 & 8050 & 15630 & 20700 & 14595 \\
\hline$R_{2}(5,35)(\mathrm{m})$ & 3615 & 6030 & 1550 & 890 & 790 & 25060 & 17240 & 9810 \\
\hline$P_{2}(-5,-35)(\mathrm{m})$ & 3070 & 4775 & 750 & 1060 & 1000 & 7805 & 9705 & 13610 \\
\hline$P_{2} / R_{2}$ & 0.85 & 0.79 & 0.48 & 1.19 & 1.26 & 0.31 & 0.56 & 1.39 \\
\hline$Y_{2} / L$ & 0.57 & 0.36 & 0.88 & 0.87 & 0.82 & 0.31 & 0.42 & 0.36 \\
\hline
\end{tabular}


Table 2. (continued)

\begin{tabular}{|c|c|c|c|c|c|c|c|c|}
\hline & E-11 & E-12 & E-13 & E-14 & E-15 & $F-1$ & F-2 & F-3 \\
\hline $\begin{array}{l}\text { No. Segments } \\
\text { Average Trend } \\
\text { Seg. Length }(\mathrm{km}) \\
\text { Max. } R \text { angle }\end{array}$ & $\begin{array}{c}1 \\
\mathrm{~N} 68^{\circ} \mathrm{W} \\
9.6 \\
15^{\circ}\end{array}$ & $\begin{array}{c}1 \\
\mathrm{~N} 82^{\circ} \mathrm{W} \\
10.6 \\
29^{\circ}\end{array}$ & $\begin{array}{c}1 \\
{\mathrm{~N} 73^{\circ} \mathrm{W}}^{11.3} \\
28^{\circ}\end{array}$ & $\begin{array}{c}1 \\
\text { EW } \\
4.8 \\
16^{\circ}\end{array}$ & $\begin{array}{c}1 \\
\mathrm{~N} 70^{\circ} \mathrm{W} \\
7.9^{\circ} \\
28^{\circ}\end{array}$ & $\begin{array}{c}1 \\
N 72^{\circ} \mathrm{W} \\
16.4 \\
14^{\circ}\end{array}$ & $\begin{array}{c}1 \\
{\mathrm{~N} 71^{\circ} \mathrm{W}} \\
20.6 \\
7^{\circ}\end{array}$ & $\begin{array}{c}1 \\
\mathrm{~N} 66^{\circ} \mathrm{W} \\
27.8 \\
11^{\circ}\end{array}$ \\
\hline $\begin{array}{l}T(\mathrm{~m}) \\
S(\mathrm{~m}) \\
R^{\prime}(\mathrm{m}) \\
X(\mathrm{~m})\end{array}$ & $\begin{array}{l}- \\
- \\
- \\
-\end{array}$ & $\begin{array}{l}- \\
- \\
-\end{array}$ & $\begin{array}{l}- \\
520 \\
- \\
-\end{array}$ & $\begin{array}{l}340 \\
- \\
- \\
-\end{array}$ & $\begin{array}{l}120 \\
390 \\
- \\
-\end{array}$ & $\begin{array}{l}- \\
- \\
- \\
-\end{array}$ & $\begin{array}{l}- \\
- \\
-\end{array}$ & $\begin{array}{l}- \\
- \\
-\end{array}$ \\
\hline $\begin{array}{l}Y_{1}(1,-1)(\mathrm{m}) \\
R_{1}(2,35)(\mathrm{m}) \\
P_{1}(-2,-35)(\mathrm{m}) \\
\quad P_{1} / R_{1} \\
\quad Y_{1} / L\end{array}$ & $\begin{array}{l}1110 \\
5940 \\
4775 \\
0.80 \\
0.09\end{array}$ & $\begin{array}{r}2040 \\
14365 \\
5865 \\
0.41 \\
0.09\end{array}$ & $\begin{array}{r}5260 \\
13055 \\
9790 \\
0.75 \\
0.18\end{array}$ & $\begin{array}{l}1295 \\
2905 \\
1895 \\
0.65 \\
0.20\end{array}$ & $\begin{array}{l}1445 \\
6065 \\
5175 \\
0.85 \\
0.11\end{array}$ & $\begin{array}{r}6280 \\
11355 \\
2815 \\
0.25 \\
0.31\end{array}$ & $\begin{array}{l}6910 \\
7495 \\
5065 \\
0.68 \\
0.36\end{array}$ & $\begin{array}{r}10725 \\
9920 \\
9400 \\
0.95 \\
0.36\end{array}$ \\
\hline $\begin{array}{l}Y_{2}(4,-4)(\mathrm{m}) \\
R_{2}(5,35)(\mathrm{m}) \\
P_{2}(-5,-35)(\mathrm{m}) \\
\quad P_{2} / R_{2} \\
\quad Y_{2} / L\end{array}$ & $\begin{array}{l}3535 \\
4735 \\
3555 \\
0.75 \\
0.30\end{array}$ & $\begin{array}{r}8105 \\
10450 \\
3715 \\
0.36 \\
0.37\end{array}$ & $\begin{array}{r}11655 \\
9980 \\
6470 \\
0.65 \\
0.41\end{array}$ & $\begin{array}{l}2505 \\
2170 \\
1420 \\
0.65 \\
0.39\end{array}$ & $\begin{array}{l}3305 \\
4520 \\
4860 \\
1.08 \\
0.25\end{array}$ & $\begin{array}{r}10180 \\
9210 \\
1060 \\
0.12 \\
0.50\end{array}$ & $\begin{array}{r}12480 \\
2385 \\
4605 \\
1.93 \\
0.64\end{array}$ & $\begin{array}{r}25630 \\
2420 \\
1995 \\
0.82 \\
0.85\end{array}$ \\
\hline & $F-4$ & $F-5$ & $F-6$ & F-7 & F-8 & & & \\
\hline $\begin{array}{l}\text { No. Segments } \\
\text { Average Trend } \\
\text { Seg. Length }(\mathrm{km}) \\
\text { Max. } R \text { angle }\end{array}$ & $\begin{array}{c}1 \\
\mathrm{~N} 65^{\circ} \mathrm{W} \\
10.6 \\
14^{\circ}\end{array}$ & $\begin{array}{c}2 \\
\mathrm{~N} 64^{\circ} \mathrm{W} \\
29.1 \\
15^{\circ}\end{array}$ & $\begin{array}{c}2 \\
\mathrm{~N} 65^{\circ} \mathrm{W} \\
24.1 \\
12^{\circ}\end{array}$ & $\begin{array}{c}1 \\
\mathrm{~N} 60^{\circ} \mathrm{W} \\
14.0 \\
12^{\circ}\end{array}$ & $\begin{array}{c}1 \\
\mathrm{~N} 54^{\circ} \mathrm{W} \\
4.8(+) \\
3^{\circ}\end{array}$ & & & \\
\hline $\begin{array}{l}T(\mathrm{~m}) \\
S(\mathrm{~m}) \\
R^{\prime}(\mathrm{m}) \\
X(\mathrm{~m})\end{array}$ & $\begin{array}{l}- \\
- \\
-\end{array}$ & $\begin{array}{l}- \\
- \\
-\end{array}$ & $\begin{array}{l}- \\
- \\
-\end{array}$ & $\begin{array}{l}- \\
- \\
-\end{array}$ & $\begin{array}{l}- \\
- \\
-\end{array}$ & & & \\
\hline $\begin{array}{l}Y_{1}(1,-1)(\mathrm{m}) \\
R_{1}(2,35)(\mathrm{m}) \\
P_{1}(-2,-35)(\mathrm{m}) \\
\quad P_{1} / R_{1} \\
\quad Y_{1} / L\end{array}$ & $\begin{array}{l}3820 \\
4780 \\
3095 \\
0.65 \\
0.33\end{array}$ & $\begin{array}{r}14580 \\
10345 \\
4630 \\
0.45 \\
0.49\end{array}$ & $\begin{array}{l}3440 \\
8365 \\
7260 \\
0.87 \\
0.18\end{array}$ & $\begin{array}{l}1705 \\
6700 \\
3980 \\
0.59 \\
0.14\end{array}$ & $\begin{array}{l}1000 \\
2180 \\
1360 \\
0.62 \\
0.22\end{array}$ & & & \\
\hline $\begin{array}{l}Y_{2}(4,-4)(\mathrm{m}) \\
R_{2}(5,35)(\mathrm{m}) \\
P_{2}(-5,-35)(\mathrm{m}) \\
\quad P_{2} / R_{2} \\
\quad Y_{2} / L\end{array}$ & $\begin{array}{r}9.35 \\
2110 \\
450 \\
0.21 \\
0.78\end{array}$ & $\begin{array}{r}24275 \\
4455 \\
825 \\
0.18 \\
0.82\end{array}$ & $\begin{array}{r}12565 \\
4950 \\
1550 \\
0.31 \\
0.66\end{array}$ & $\begin{array}{l}5160 \\
5130 \\
2095 \\
0.41 \\
0.42\end{array}$ & $\begin{array}{c}4160 \\
- \\
380 \\
- \\
0.92\end{array}$ & & & \\
\hline
\end{tabular}


1) U.S.G.S. Menlo Park Library, 345 Middlefield Road, Menlo Park, CA.

2) U.S.G.S. Reston Library, Room 4A100, 12201 Sunrise Valley Drive, Reston, VA.

3) U.S.G.S. Denver Library, 1526 Cole Blvd., at West Colfax Avenue, Golden, CO.

4) California Division of Mines and Geology, Room 1341, Resources Bldg. 1416 9th Street, Sacramento, CA

5) California Division of Mines and Geology, State Office Building, 107 South Broadway, Los Angeles, CA.

The data were compiled on paper copies of previously published maps (see reference list) and cannot be duplicated.

For each segment, the total length of fault with a given orientation was determined and plotted (1) on a rose diagram, to show the orientations of the fault traces relative to the compass directions (Figure 5) and (2) on a histogram normalized to the average trend to show the distribution of fault orientations about the average trend (Figure 6). Adjoining segments with the same average trend have been grouped together in these diagrams and eleswhere in the text (e.g., Table 2). The one exception involves segments C-5a and C$5 \mathrm{~b}$, both of which are oriented $\mathrm{N}^{\circ} 0^{\circ} \mathrm{W}$ but which have been kept separate because of the complexity of faulting in each one. Figure 7 illustrates the relationship between the rose diagrams and the segment configurations for two representative segments, one each from the locked and creeping parts of the fault. The segments are tracings of the appropriate fault maps, and the average trend is drawn directly beneath each one.

The recently active fault traces in each segment were classified according to the fracture sets shown in Figure 1. To illustrate the superposition of the experimental fracture pattern on the San Andreas, Figure 8 depicts the orientation of $R$ and $P$ fractures relative to an average northwesterly strike of the fault zone. $R$-type fractures would have a more northerly trend than the average and $P$-type fractures a more westerly trend. No formal limits have been defined in the literature for the angular range of a given fracture type; therefore limits were assigned specifically for this study, as described below. Two different cut-off values were applied to the $Y, R$, and $P$ faults. In one case, the range of $Y$ orientations was restricted to $\pm 1^{\circ}$ of the average trend, because laboratory shears that made angles of $2^{\circ}$ or more with the boundary of the gouge layer in our experimental samples could be traced all the way across the layer and were therefore considered to be $R$ or $P$ shears. This narrow range of $Y$ orientations seemed rather restrictive, however, so for comparison a wider range of $Y$ orientations was also selected, extending to $\pm 4^{\circ}$ of the average trend. The limits in this second case accord with the $5^{\circ}$ minimum angle of en echelon faults along the San Andreas that are figured in Wallace (1973). A $35^{\circ}$ maximum for the $R$ shears was chosen to correspond to the largest Riedel angle measured in the samples of quartz gouge. The angles for the other fracture types were then determined by symmetry requirements (Figure 1) (Logan et al., 1979); the upper boundaries of $R^{\prime}$ and $X$ fractures were not varied in common with the $R$ and $P$ limits, because no fault traces were oriented in the positive or negative $86-88^{\circ}$ range. The range of angles for each fracture set is listed below, where $0^{\circ}$ refers to the average trend of the segment under consideration. 

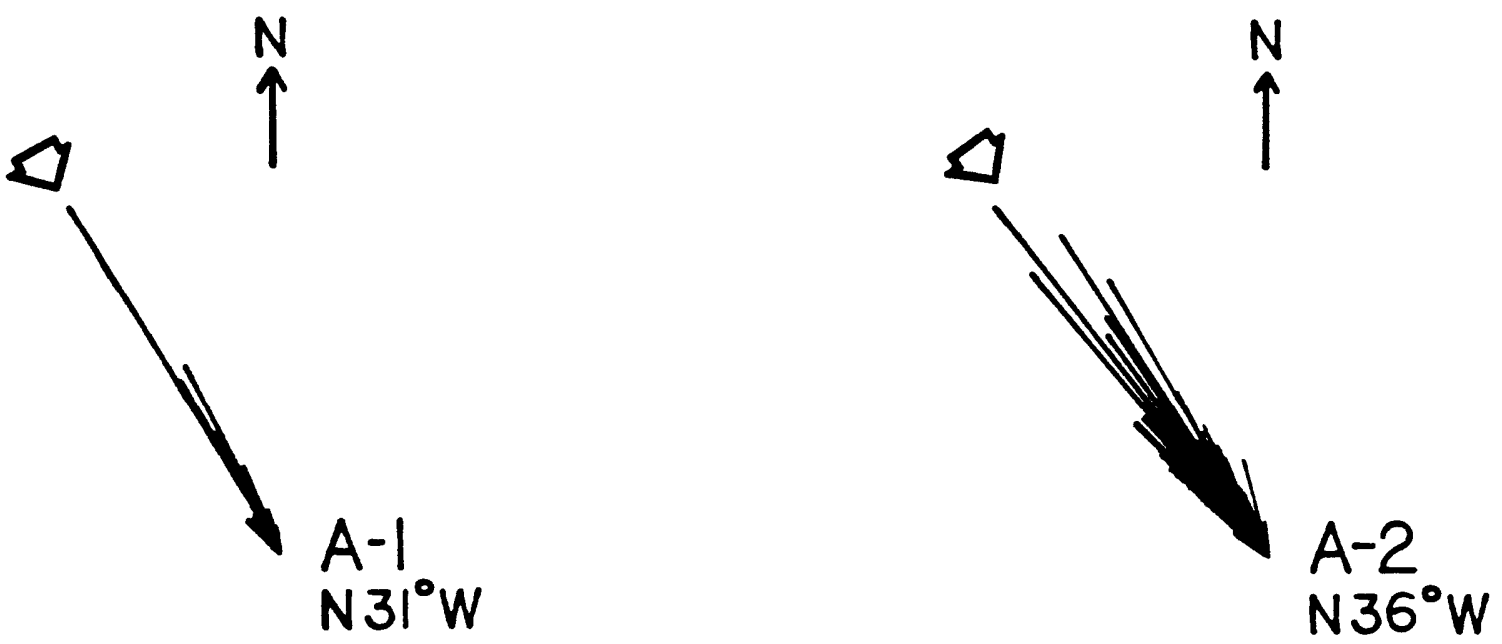

\section{$2000 \mathrm{~m}$}

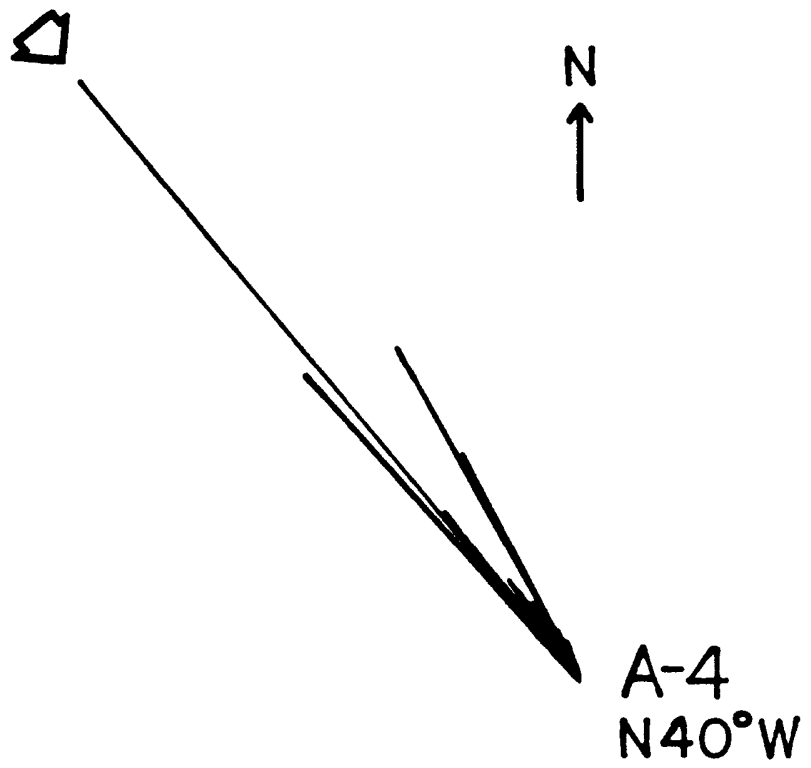

Figure 5. Rose diagrams of fault length relative to azimuthal position for the San Andreas fault segments. All of the mapped recently active breaks in a given segment are included in each diagram. The average trend of the segment considered is indicated by an arrow on the appropriate rose diagram. Adjoining segments with the same average trend have been grouped together in these plots, with the exception of the very complex fault segments C-5a and $\mathrm{C}-\mathbf{5 b}$. 

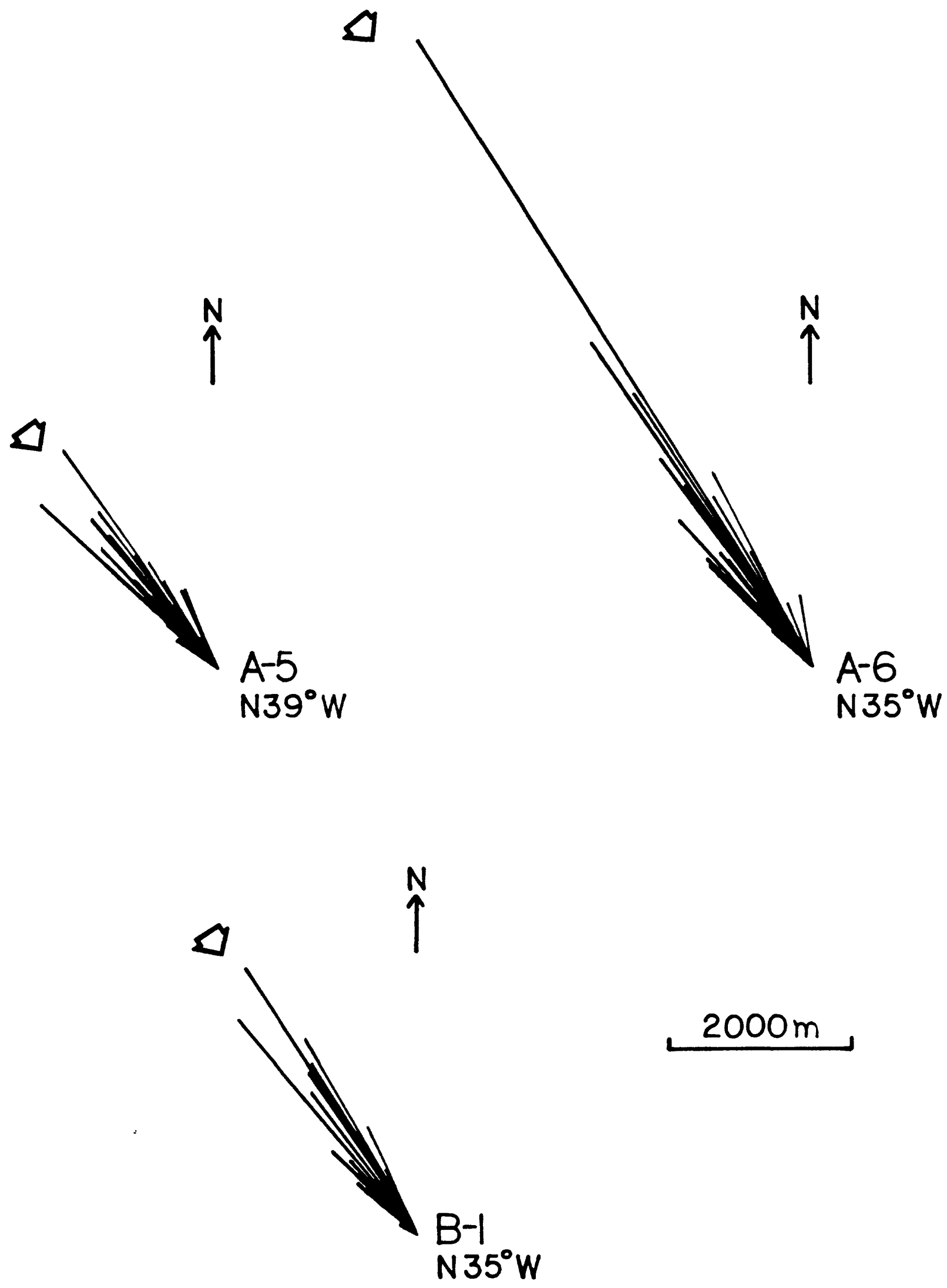

Figure 5, continued. 


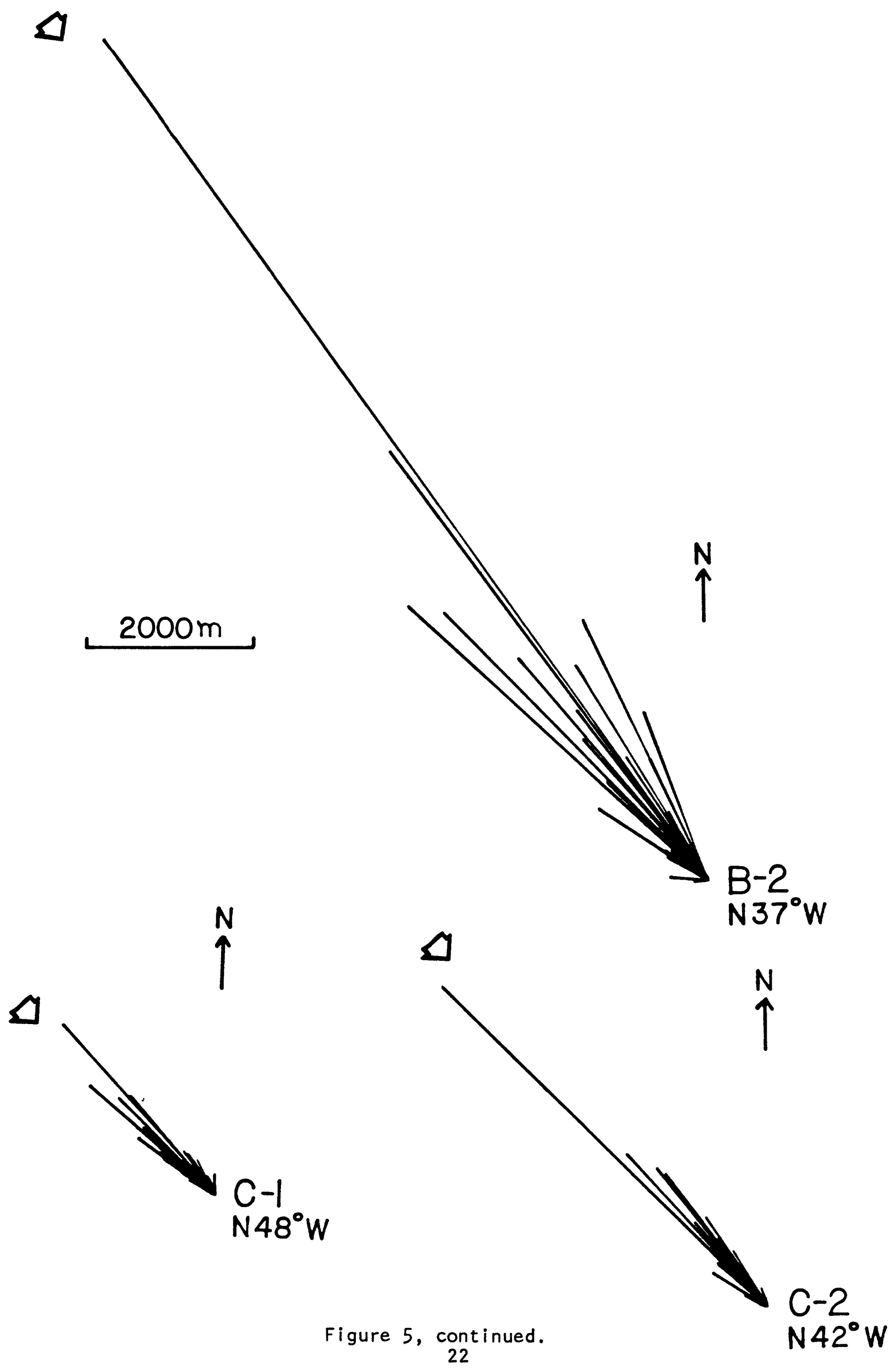



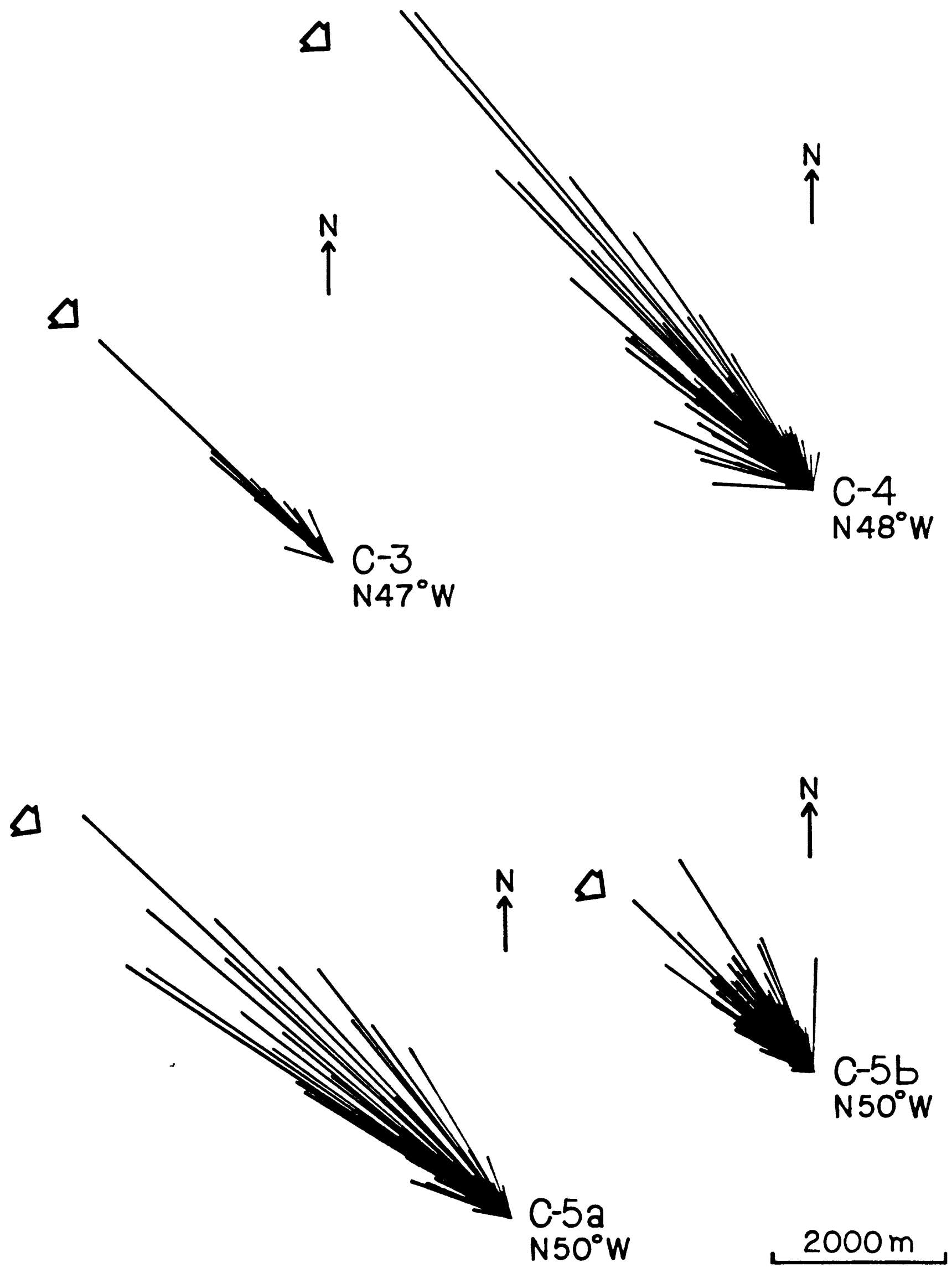

Figure 5, continued. 

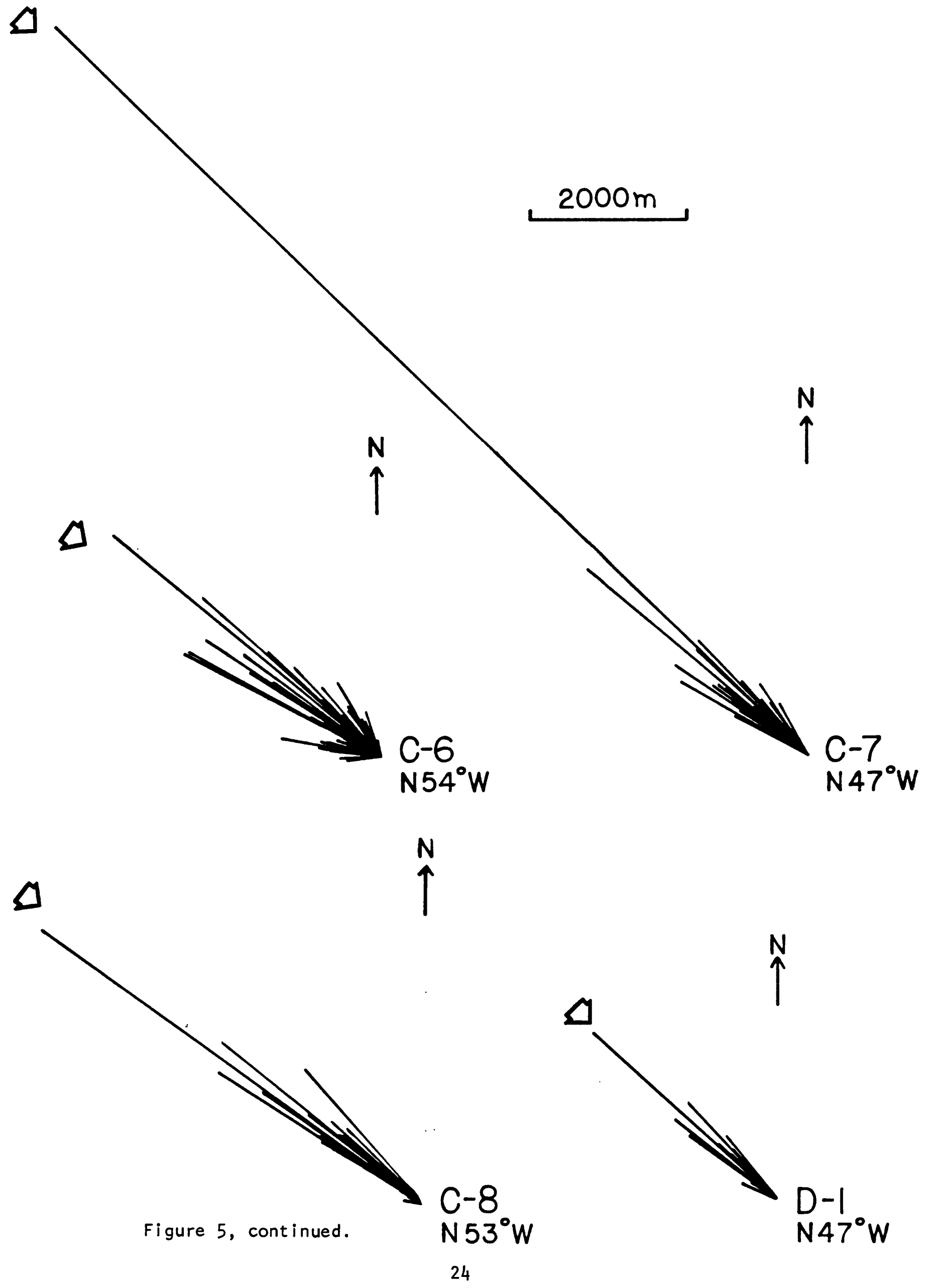


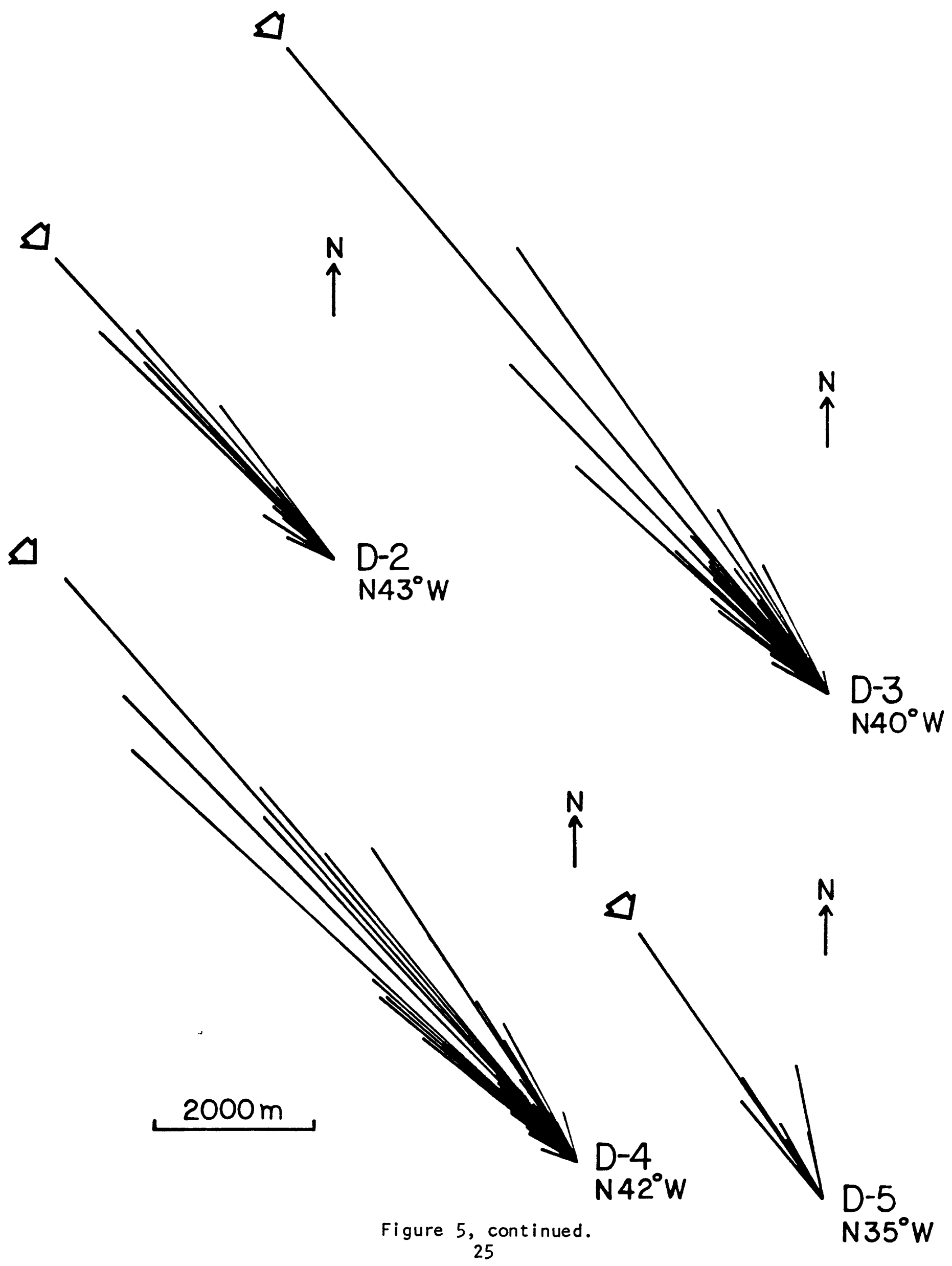



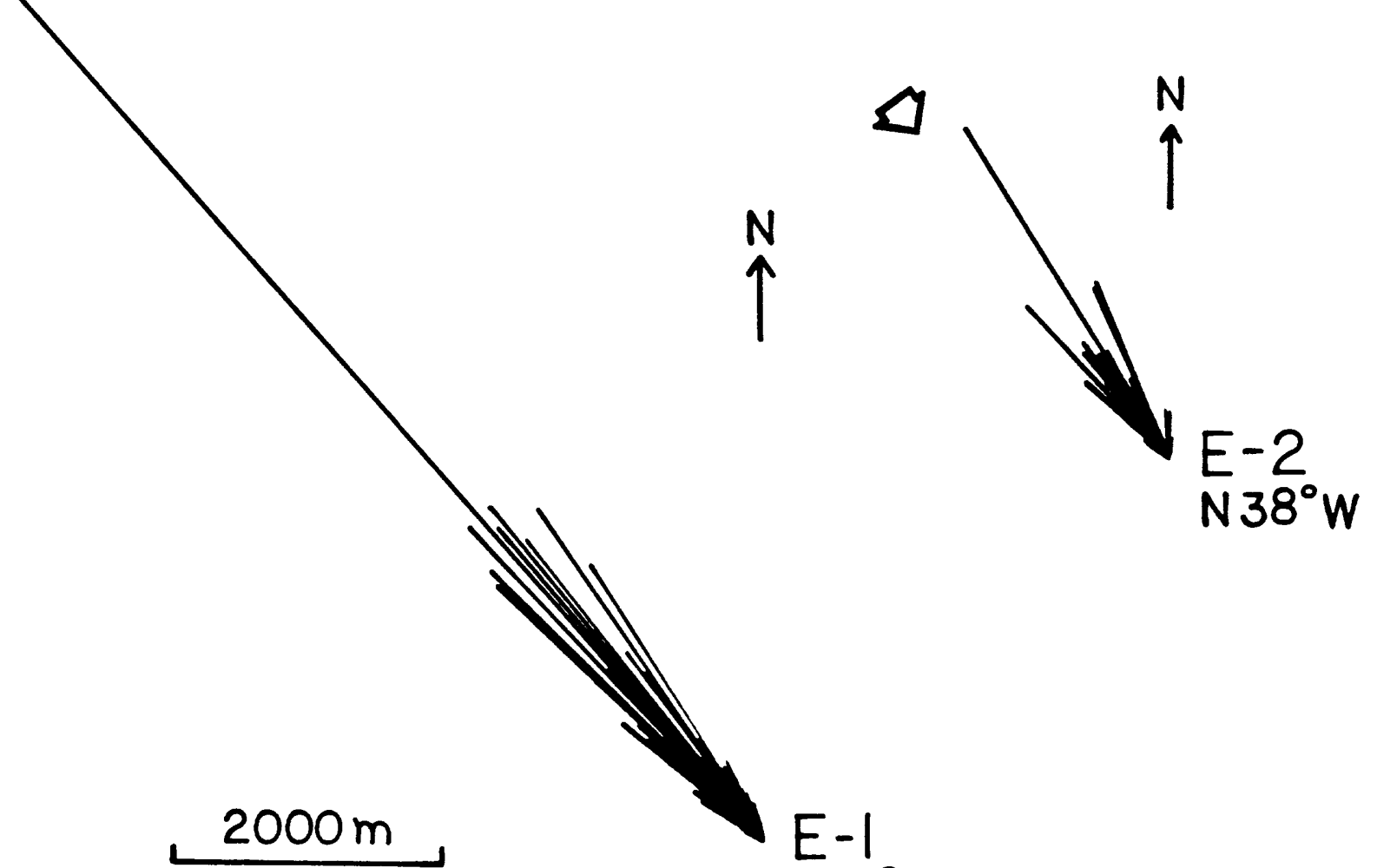

E-1

$\mathrm{N} 41^{\circ} \mathrm{W}$
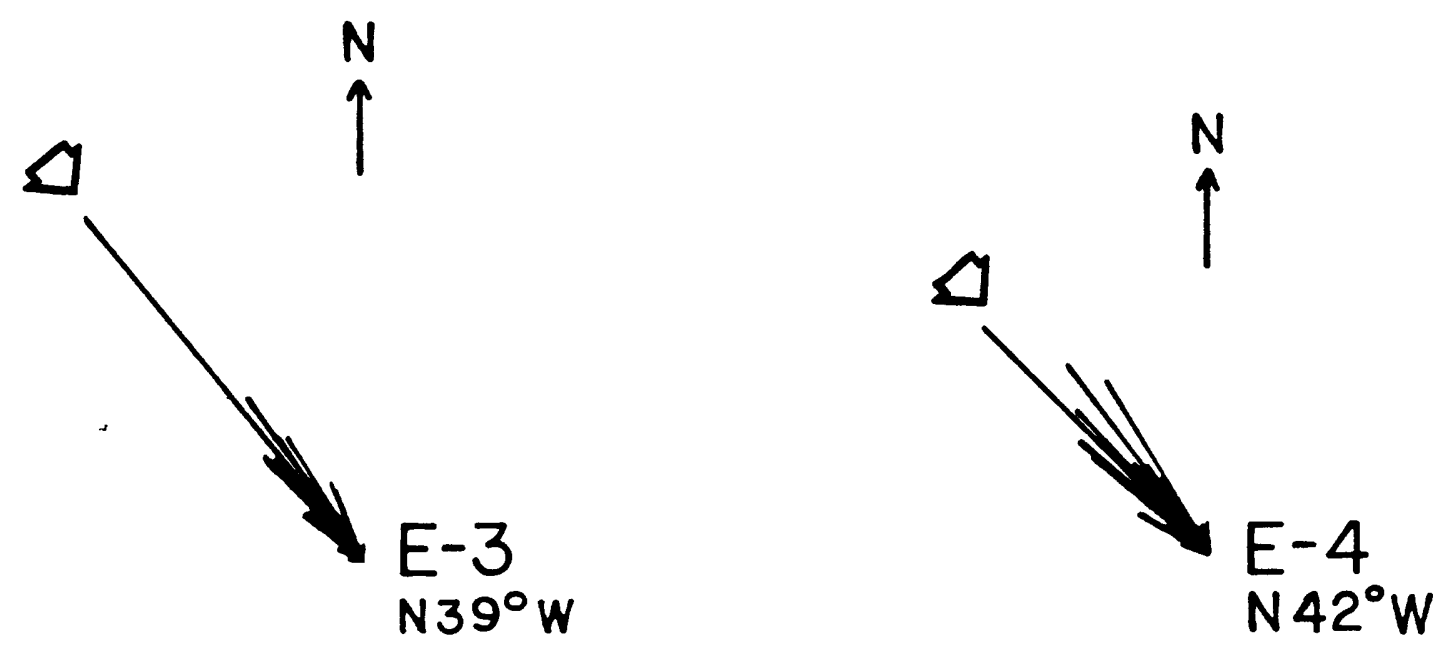

Figure 5, continued. 

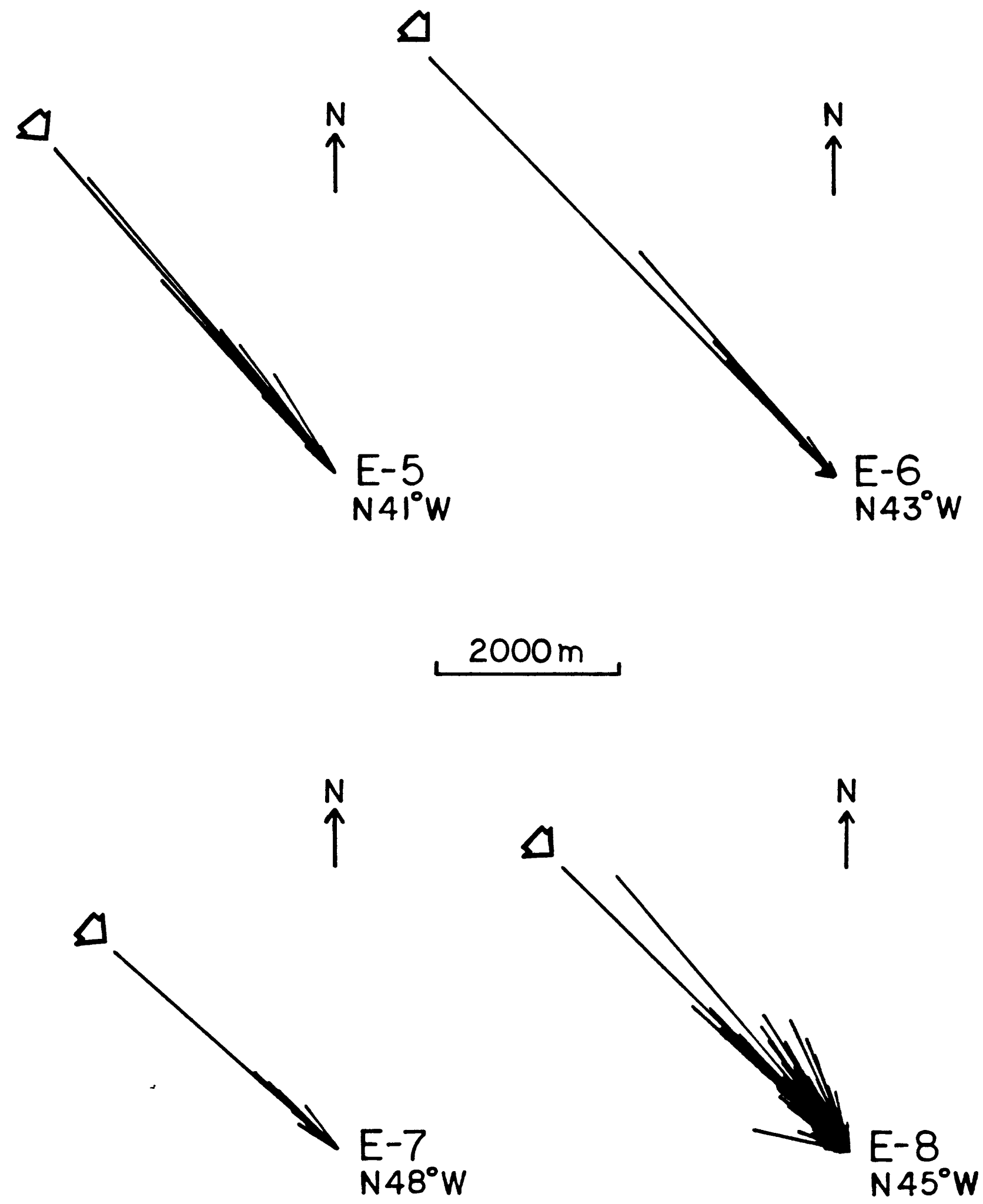

Figure 5, continued. 

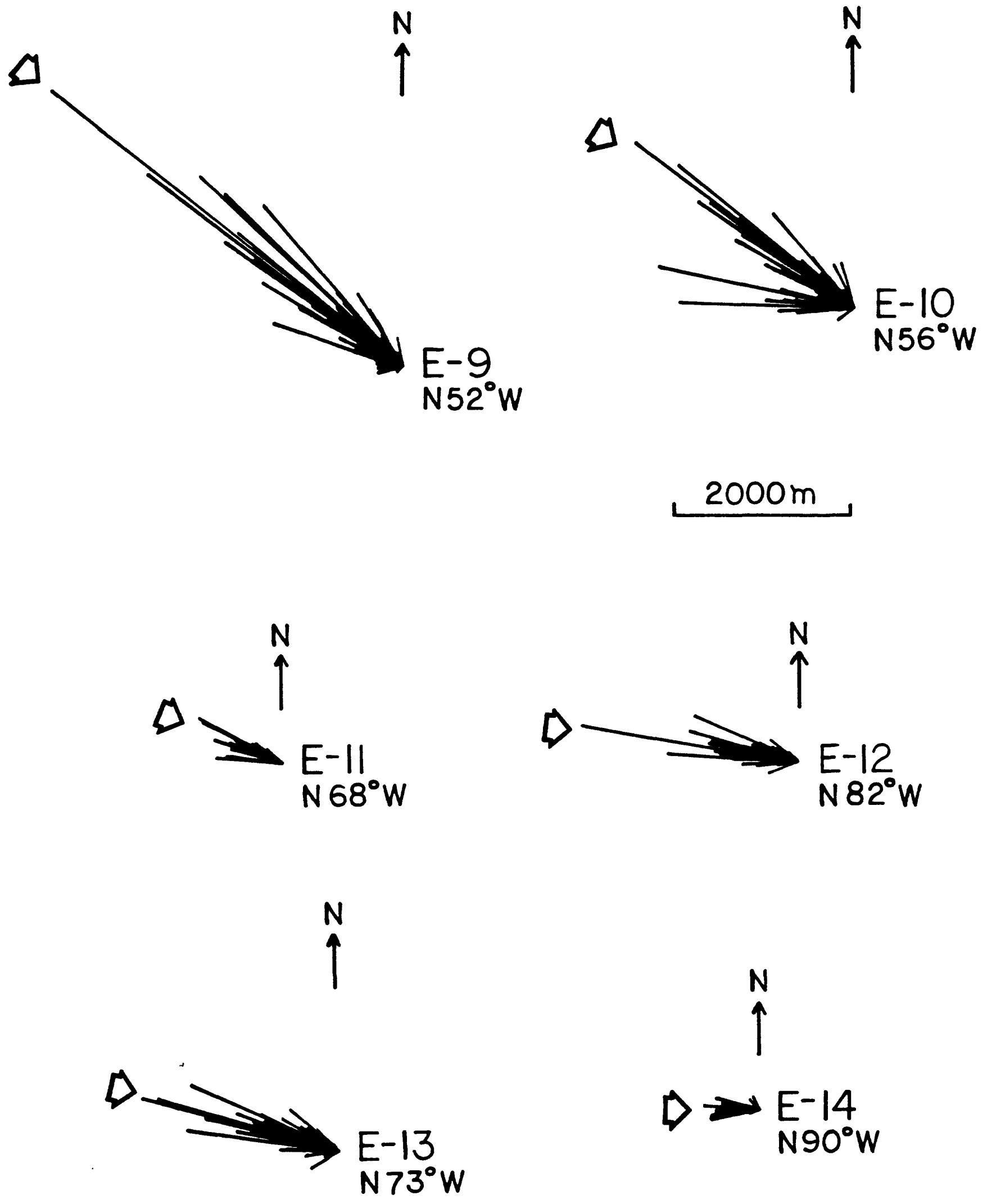

Figure 5 , continued. 


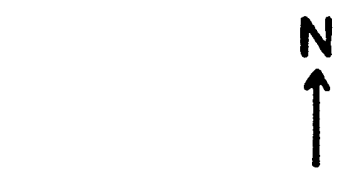

$\Delta$

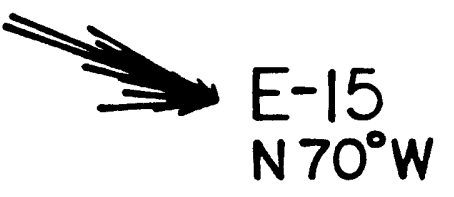

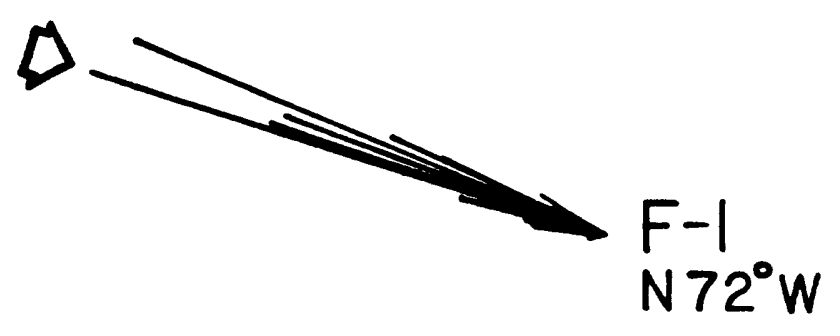

$N$

$\Delta$

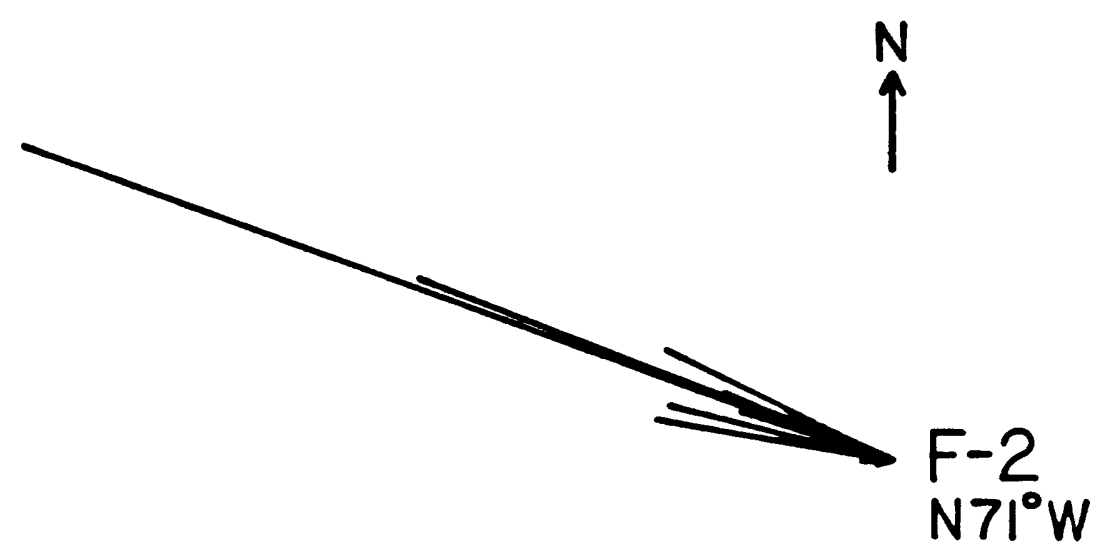

$2000 \mathrm{~m}$

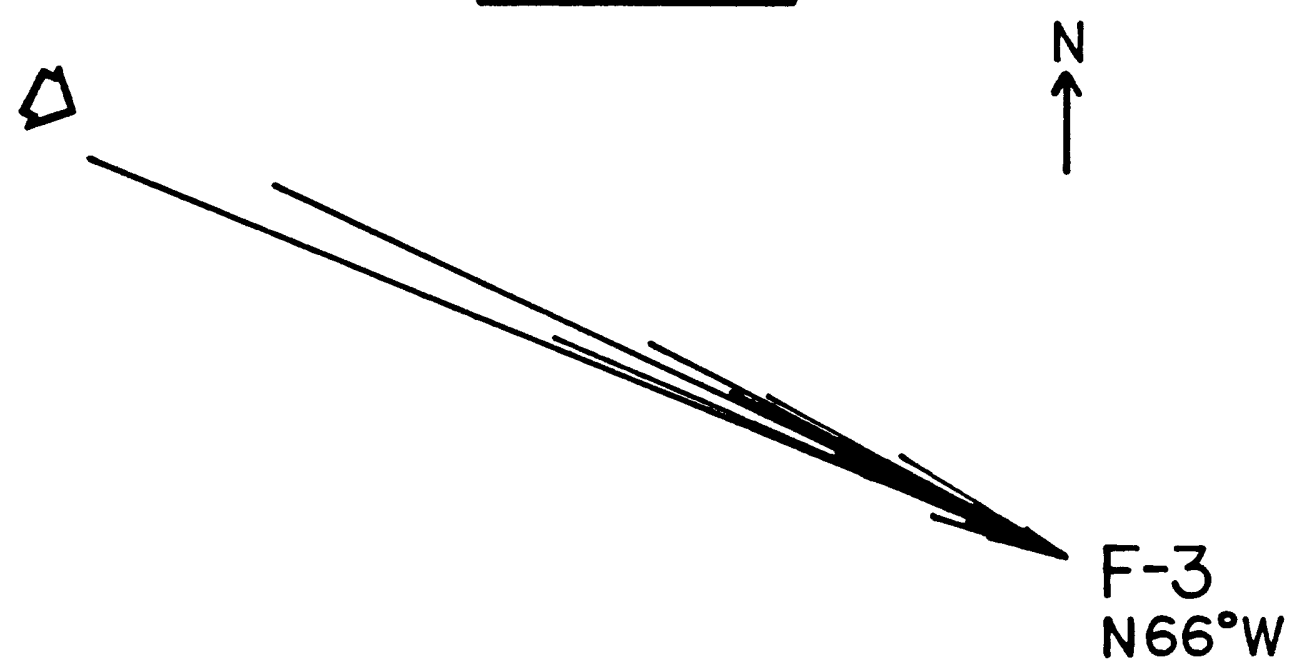

Figure 5, continued. 

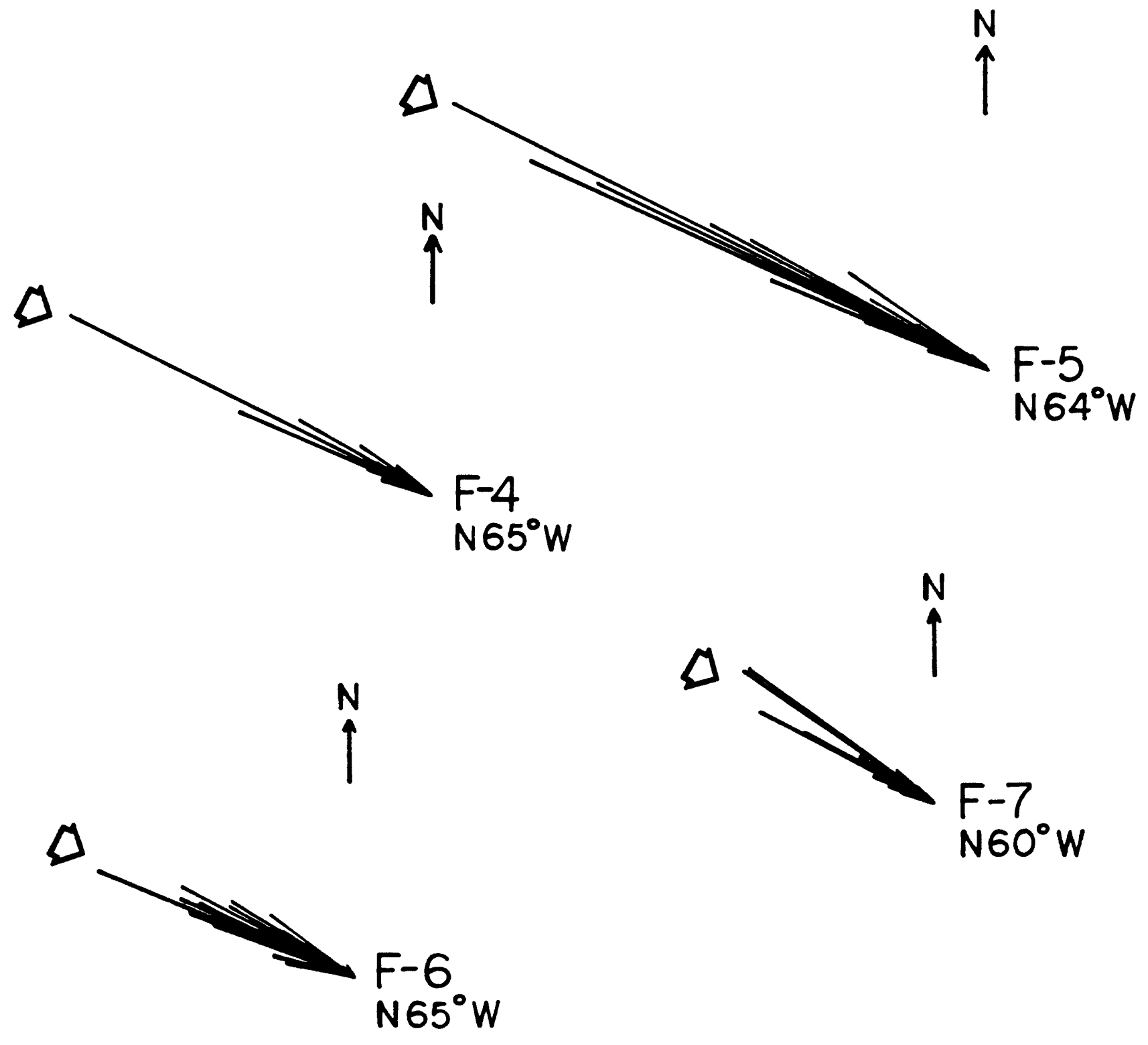

$2000 \mathrm{~m}$

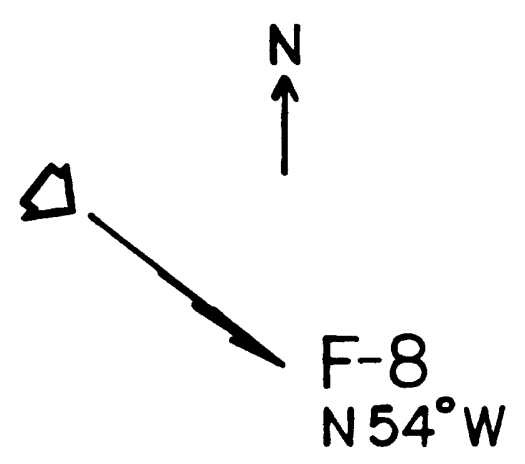

Figure 5, continued. 

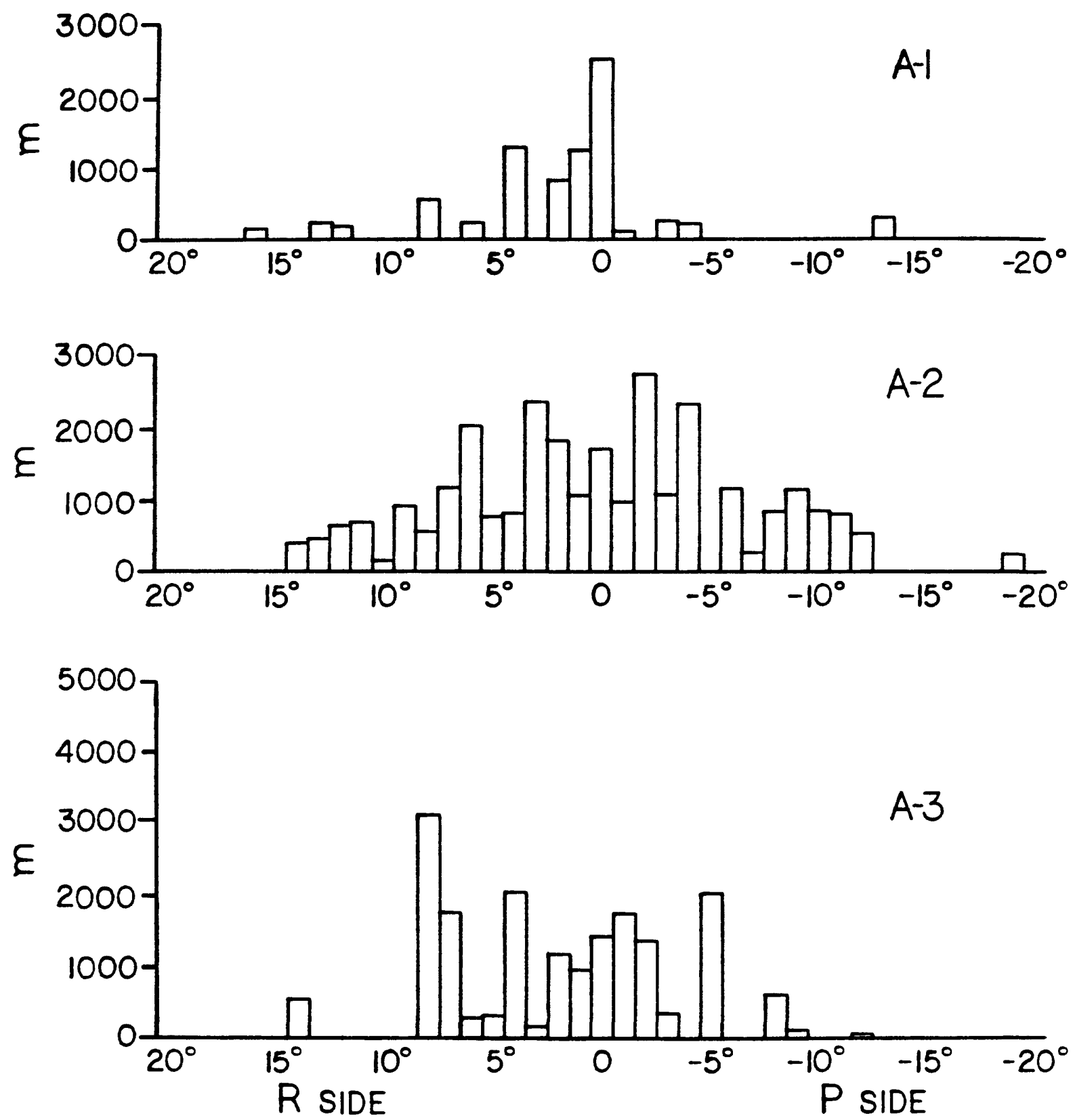

Figure 6. Histograms of fault length normalized to the average trend $\left(0^{\circ}\right)$ for the San Andreas fault segments. Fault traces with progressively more northerly orientations compared to the average trend of the segment ( $R$ side; see Figure 8) are indicated by increasingly positive numbers of degrees. Fault traces with progressively more westerly (or southerly) orientations compared to the average trend ( $P$ side; see Figure 8 ) are indicated by increasingly negative numbers of degrees. Because of space limitations, the histograms only contain those fault traces that are oriented within $20^{\circ}$ of the average trend. For more than half of the segments, however, this angular range covers all of the fault traces contained in them. Segment groupings are the same as in Figure 5. 

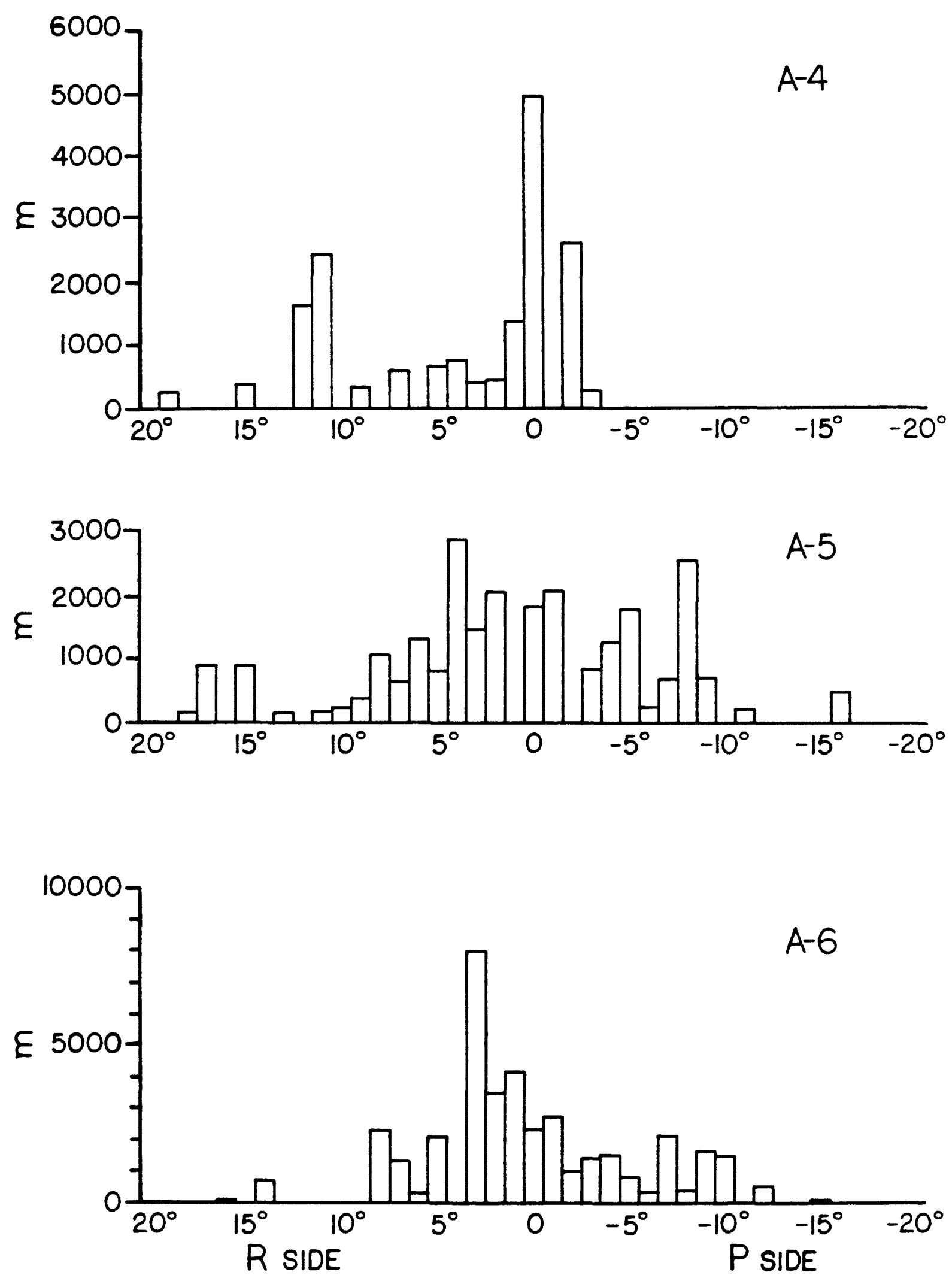

Figure 6 , continued. 

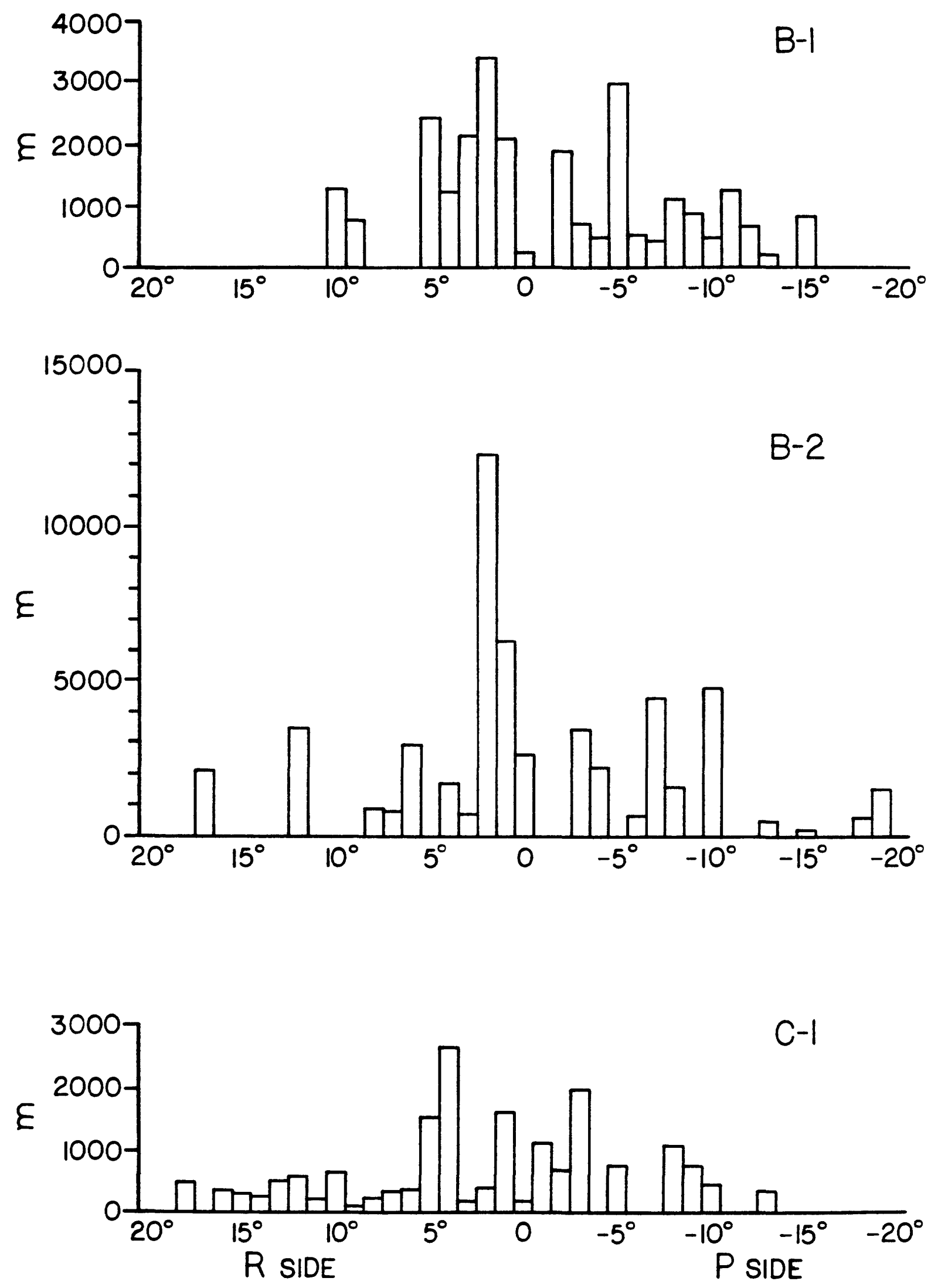

Figure 6 , continued. 

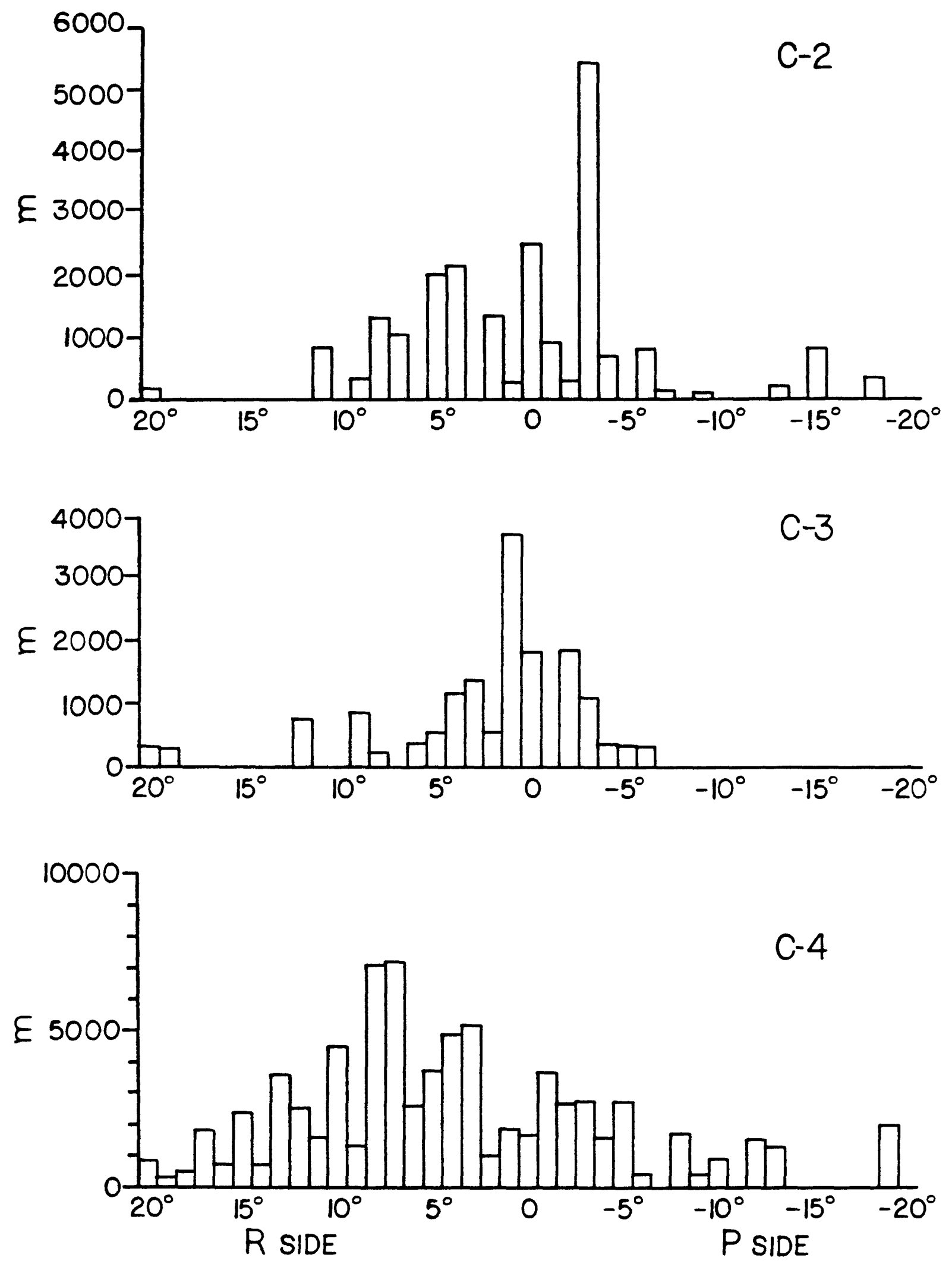

Figure 6 , continued. 

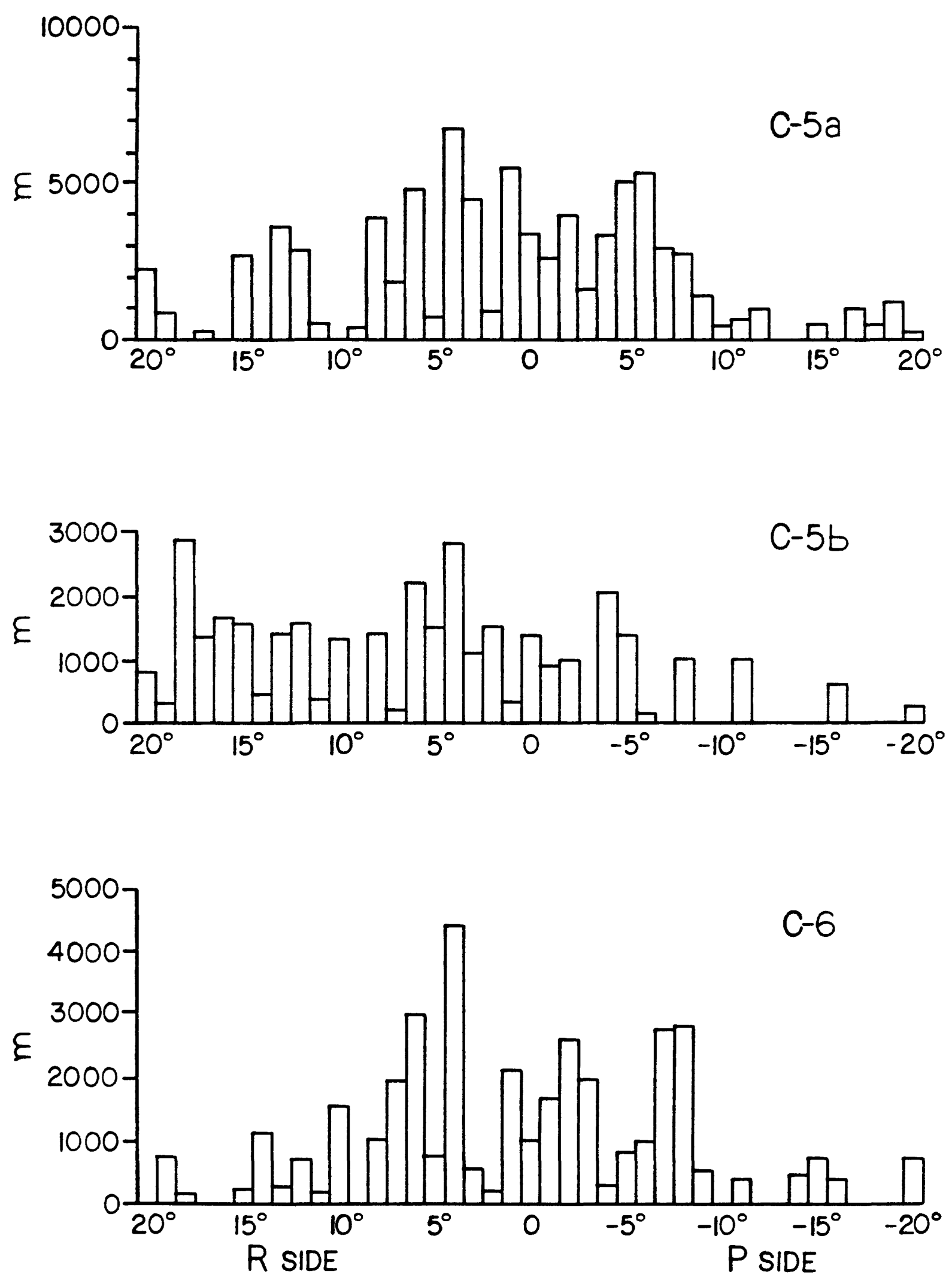

Figure 6 , continued. 

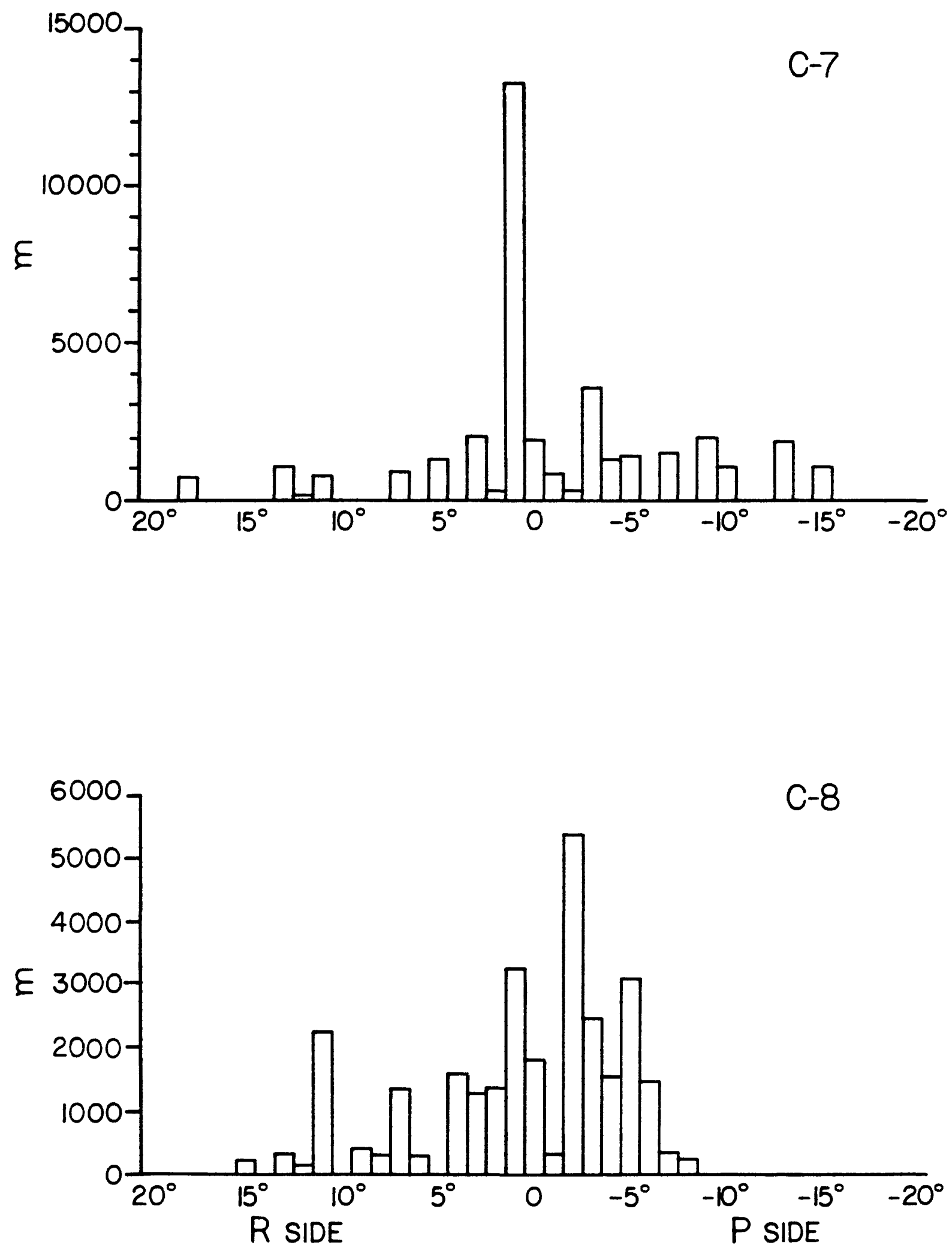

Figure 6 , continued. 

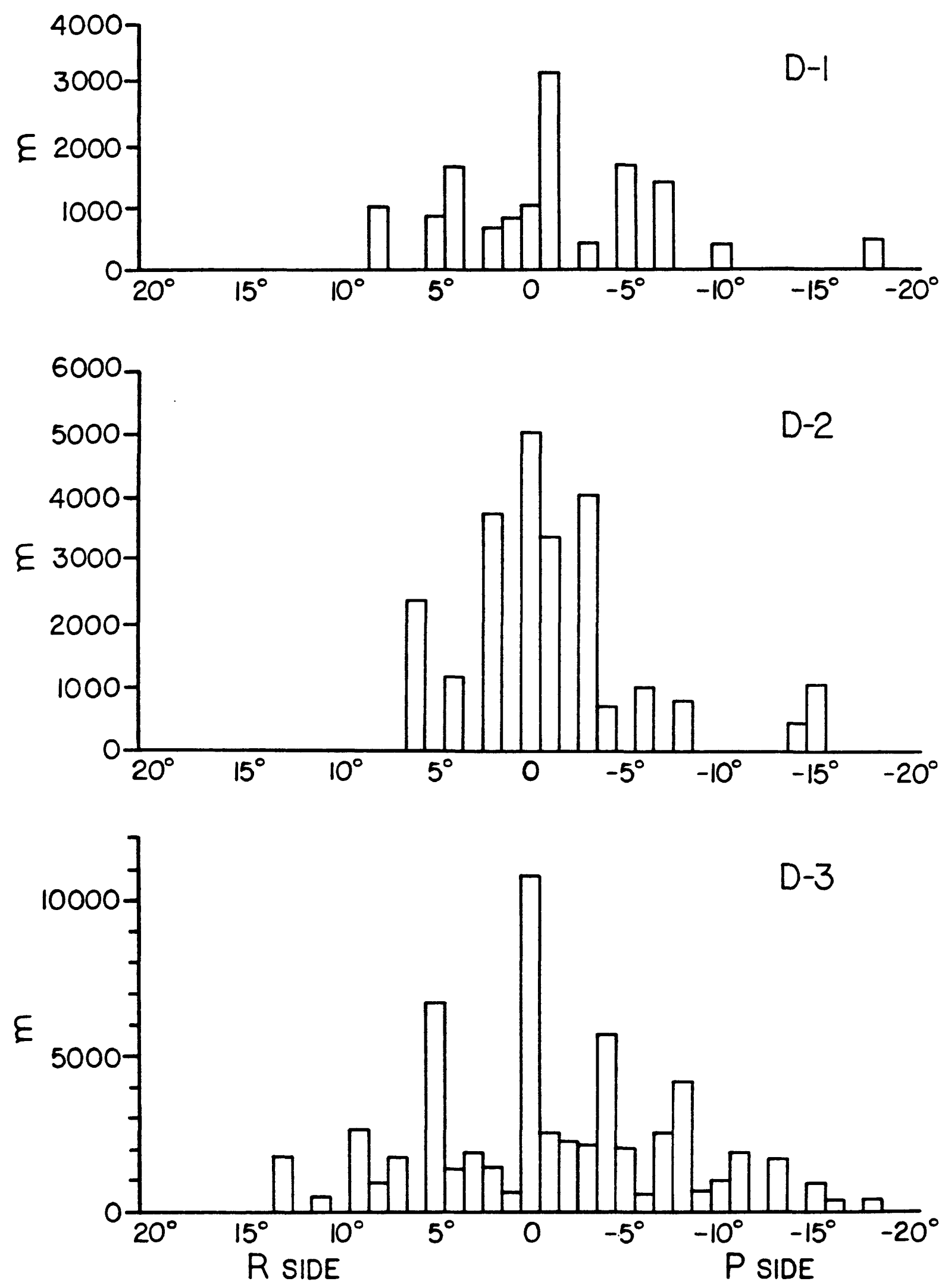

Figure 6 , continued. 

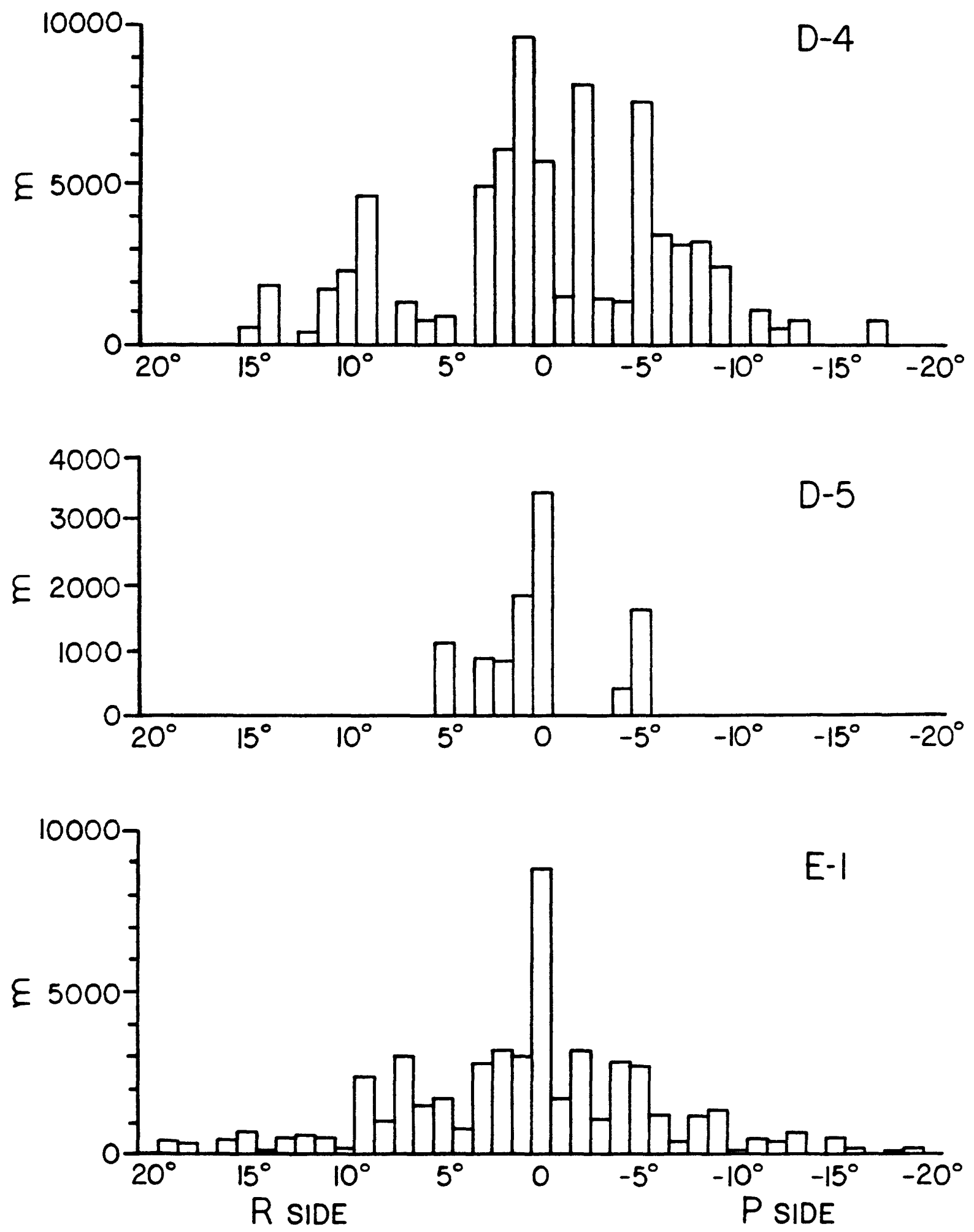

Figure 6 , continued. 

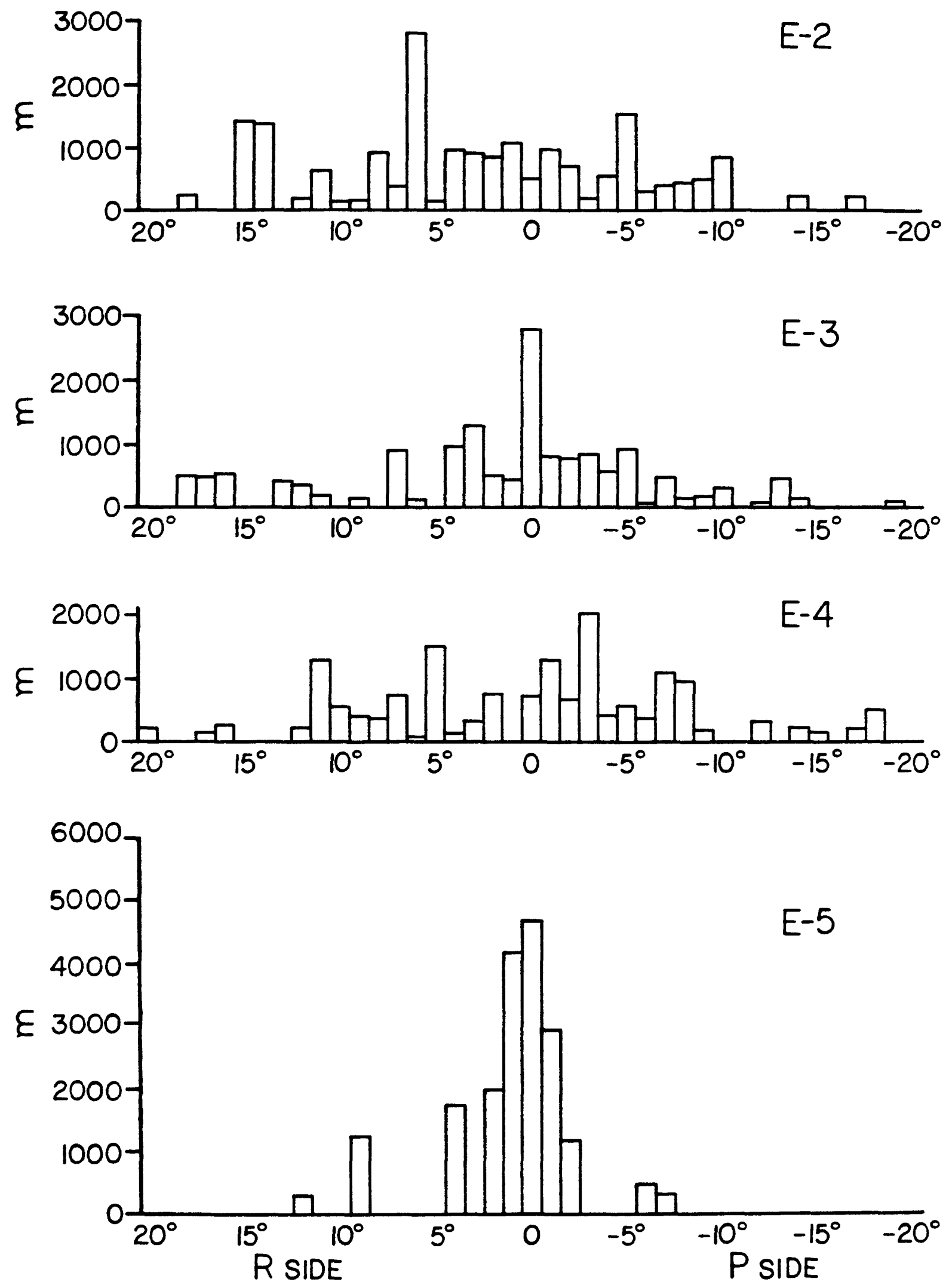

Figure 6 , continued. 

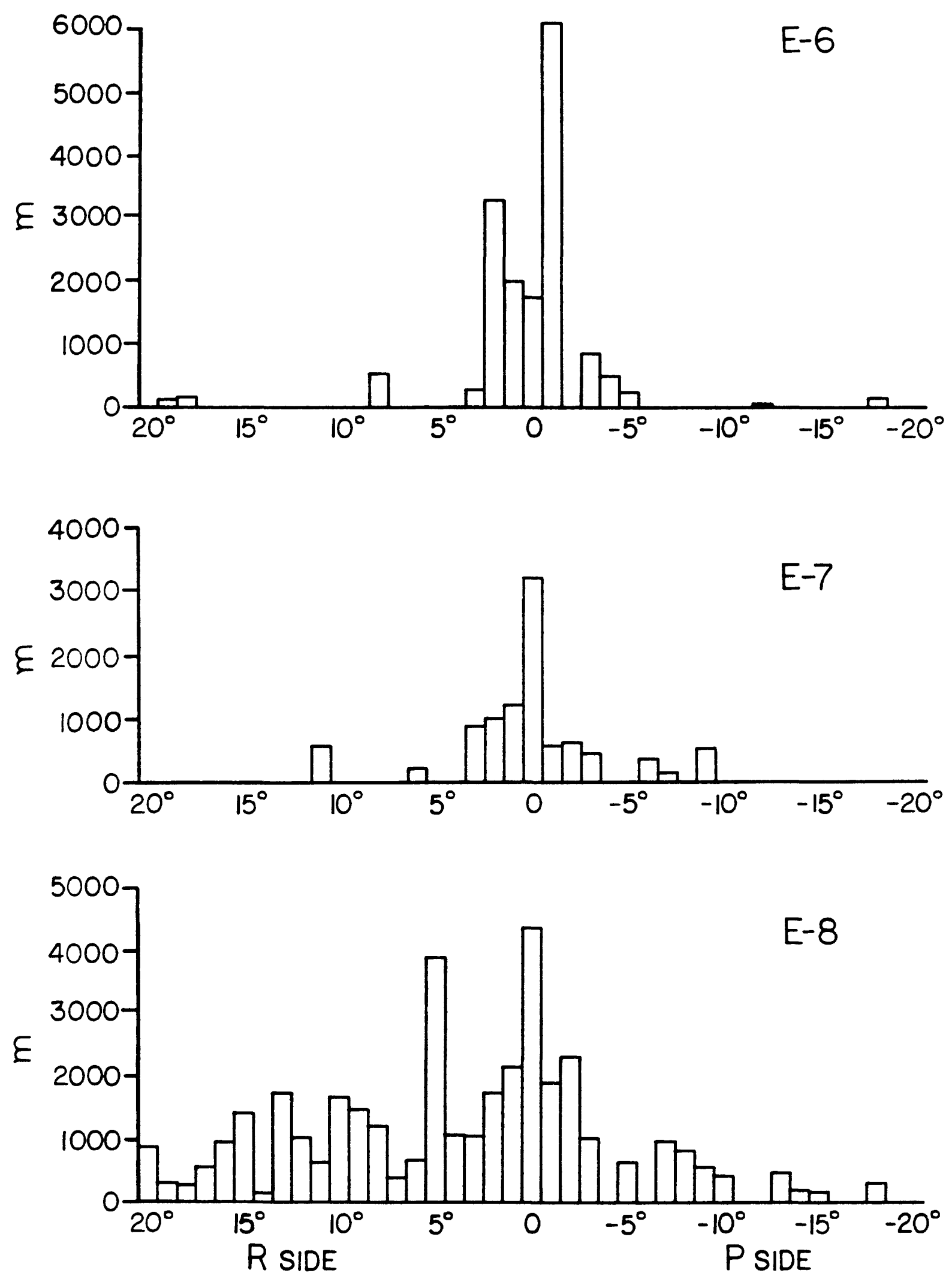

Figure 6 , continued. 

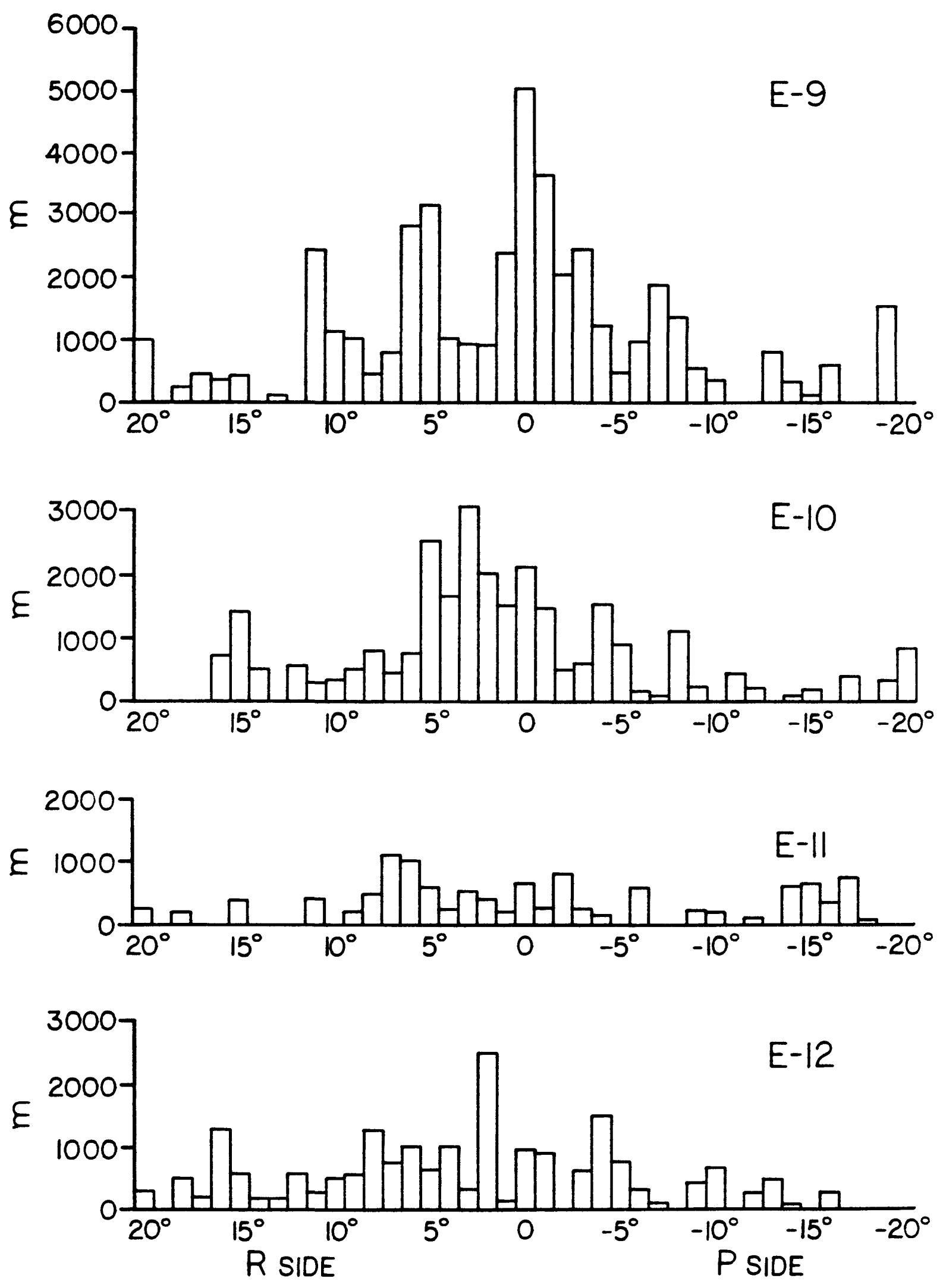

Figure 6 , continued. 

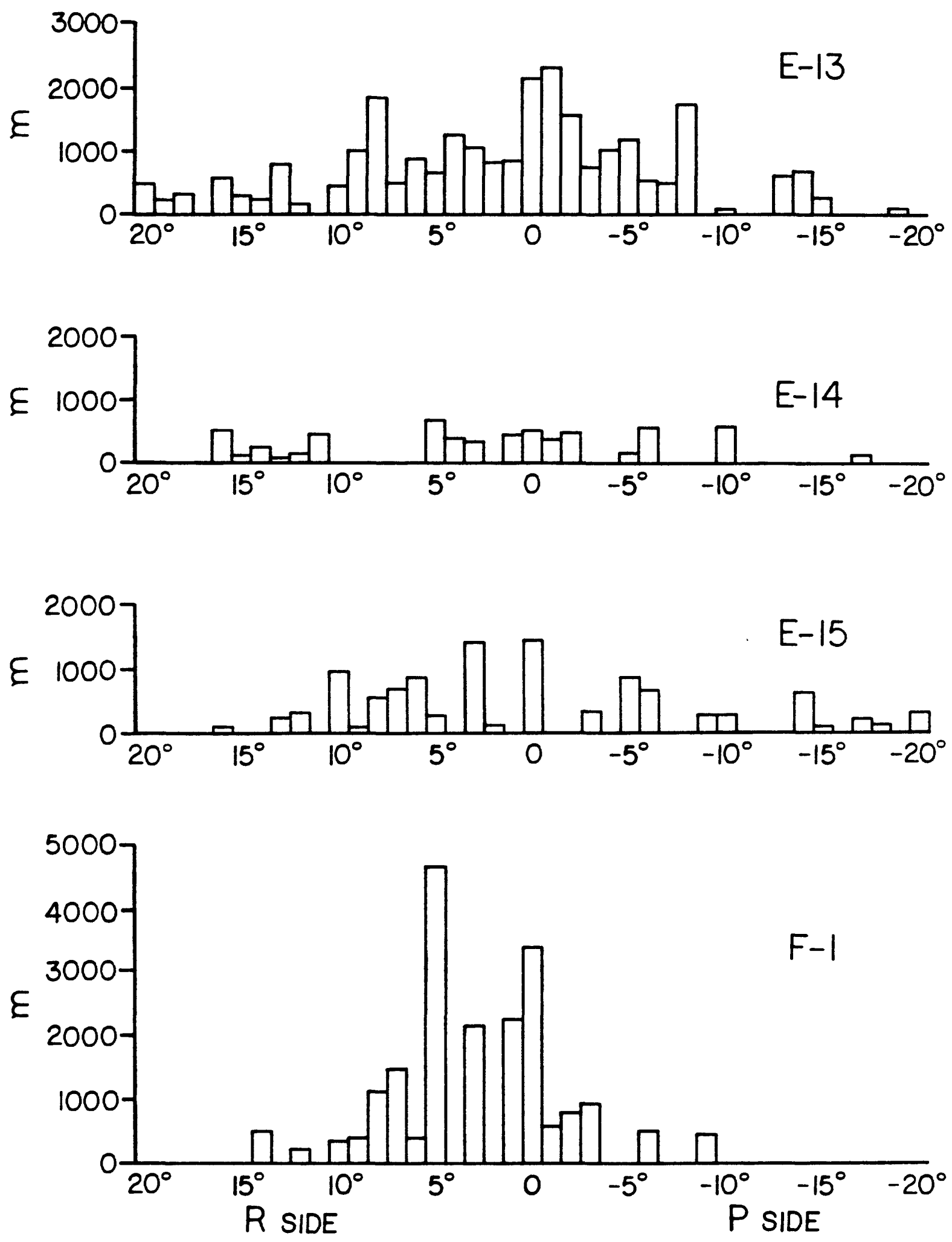

Figure 6 , continued. 

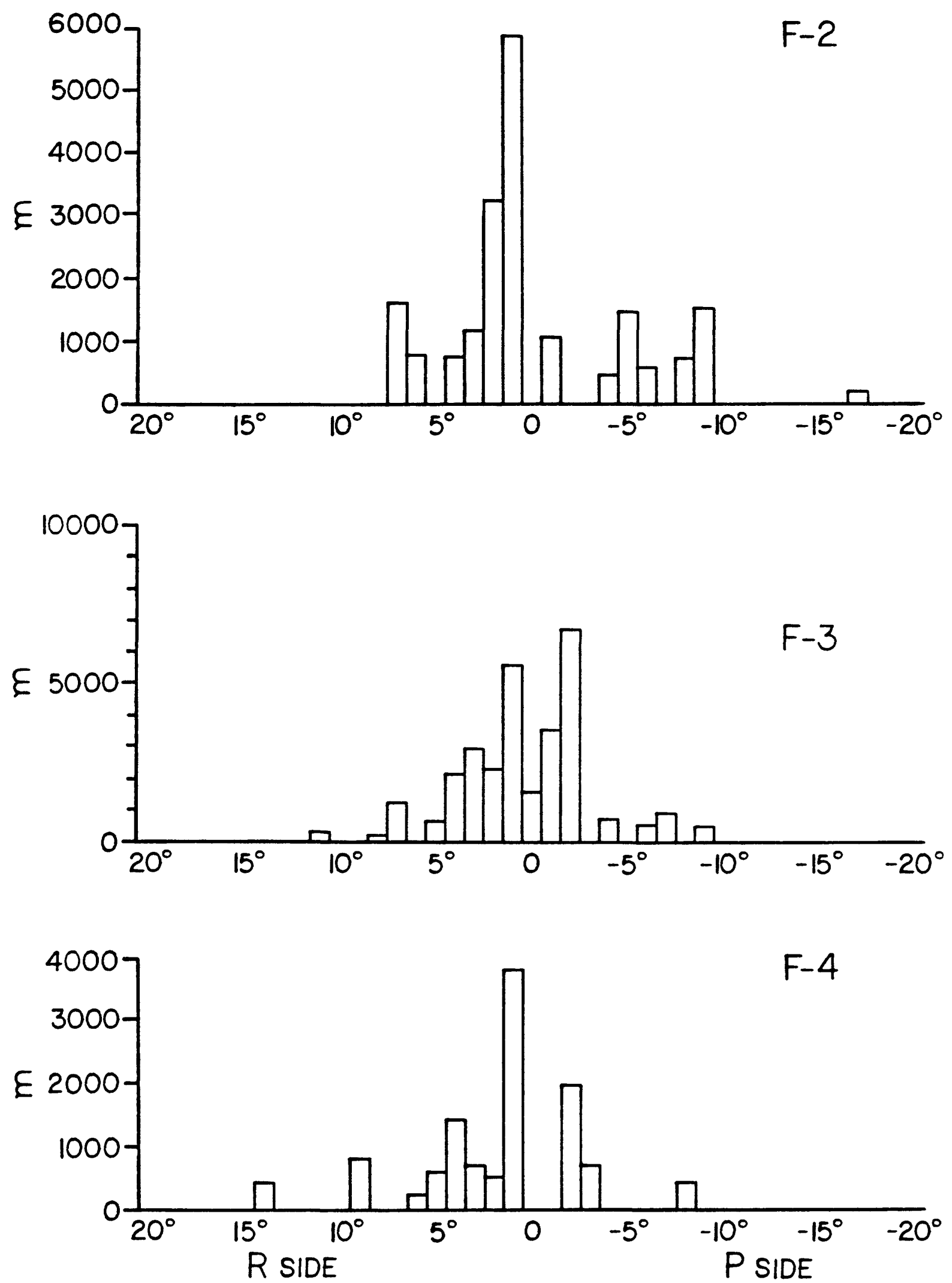

Figure 6 , continued. 

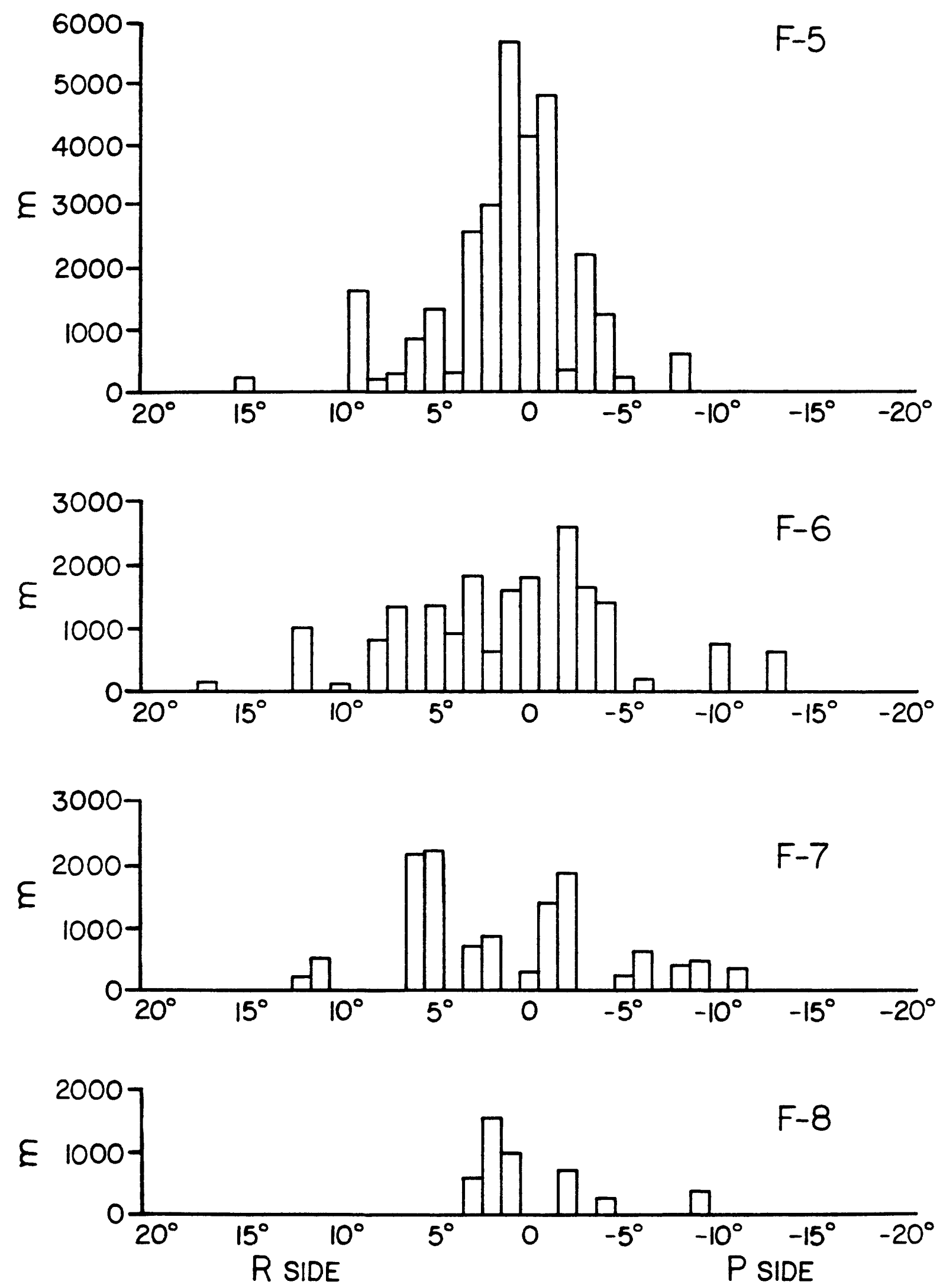

Figure 6 , continued. 

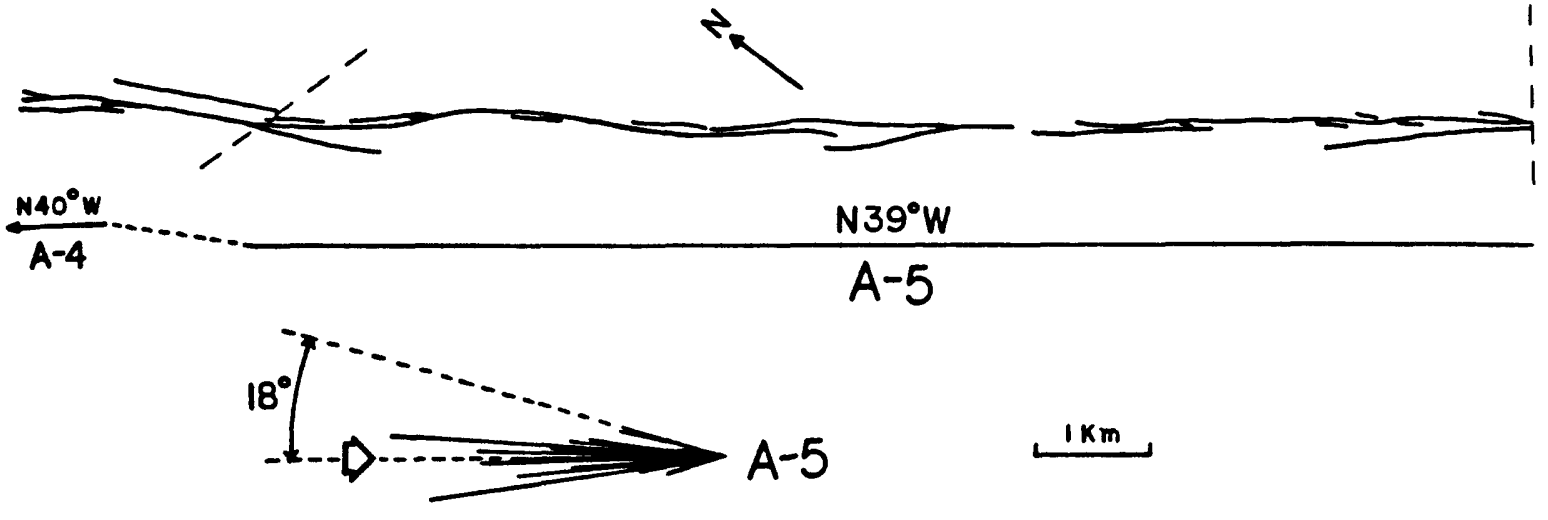

a)

LOCKED SECTION

(PLANTATION TO FORT ROSS)

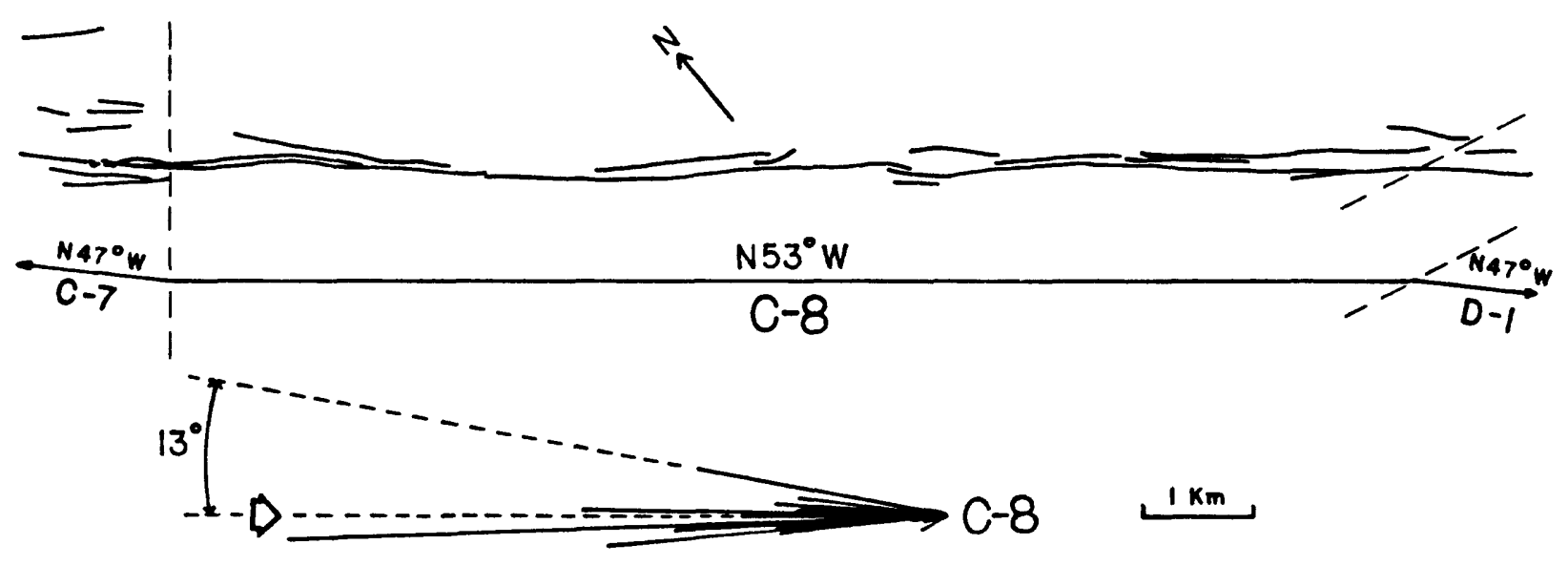

CREEPING SECTION

b) (SAN JUAN BAUTISTA TO ALMADEN WINERY)

Figure 7. Tracings of representative segments from the a) locked (A-5) and b) creeping (C-8) parts of the San Andreas fault. Segment boundaries are indicated by long-dashed lines in the sketches, and the average-trend lines are drawn directly beneath the segments. The accompanying rose diagram for each segment (Figure 5) is oriented so that its average trend (indicated by an arrow) is parallel to that of the segment. The angles added to the rose diagrams are the maximum Riedel angles (Table 2); the significance of these angles is discussed later in the text. 

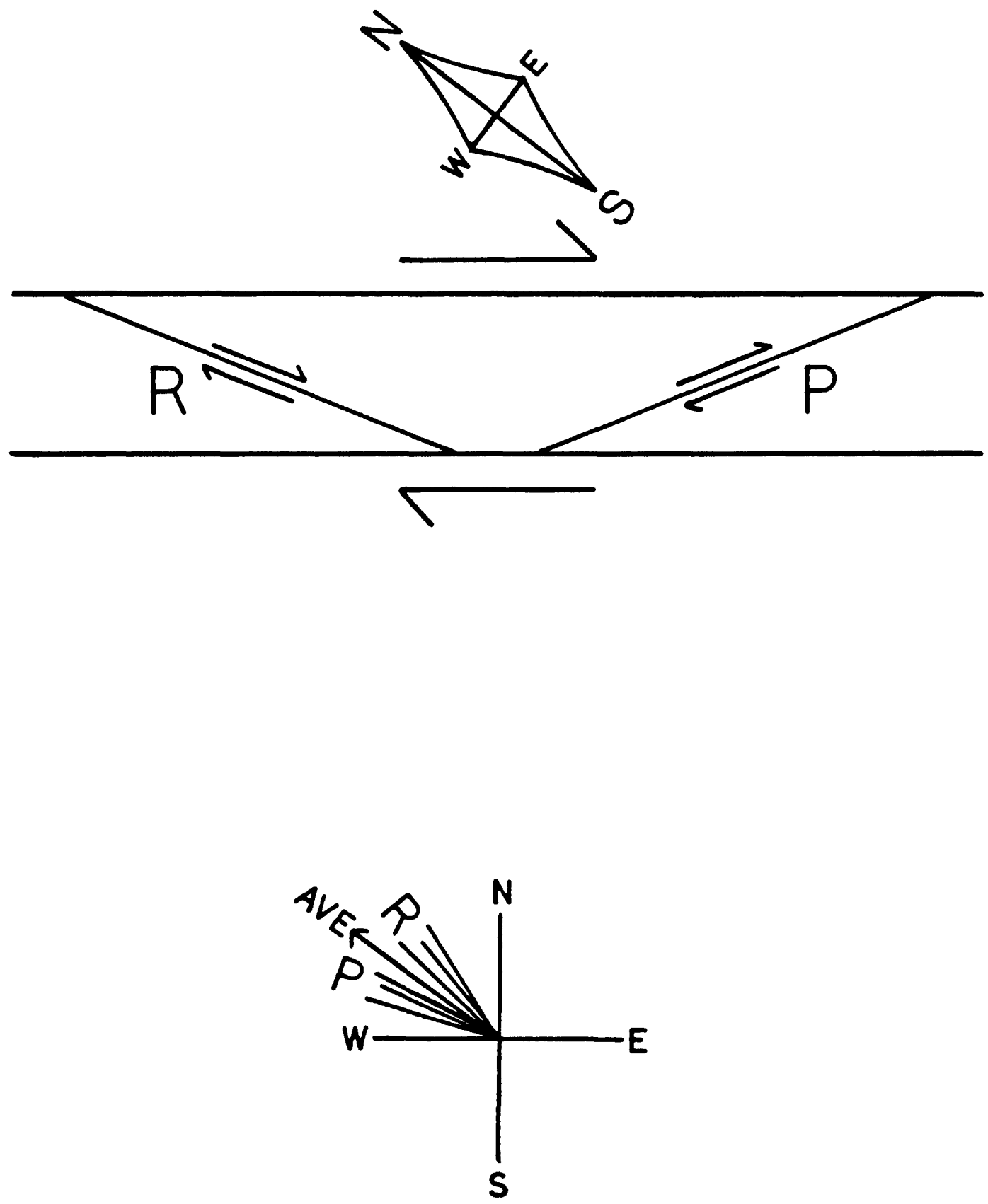

Figure 8. Schematic view of part of the San Andreas fault trace, showing the orientation of $R$ and $P$ fractures relative to the overall strike of the fault, assuming an average northwesterly trend. The relative positions of $R$ and $P$ fractures on the rose diagrams is also depicted. 
Case $1 \quad$ Case 2

$$
\begin{array}{cc}
Y-\left(-1^{\circ}\right) \text { to }\left(+1^{\circ}\right) & \left(-4^{\circ}\right) \text { to }\left(+4^{\circ}\right) \\
R-\left(+2^{\circ}\right) \text { to }\left(+35^{\circ}\right) & \left(+5^{\circ}\right) \text { to }\left(+35^{\circ}\right) \\
P-\left(-2^{\circ}\right) \text { to }\left(-35^{\circ}\right) & \left(-5^{\circ}\right) \text { to }\left(-35^{\circ}\right) \\
T-\left(+36^{\circ}\right) \text { to }\left(+54^{\circ}\right) \\
S-\left(-36^{\circ}\right) \text { to }\left(-54^{\circ}\right) \\
R^{\prime}-\left(+55^{\circ}\right) \text { to }\left(+88^{\circ}\right) \\
X-\left(-55^{\circ}\right) \text { to }\left(-88^{\circ}\right)
\end{array}
$$

The distribution of fault lengths among the different fracture sets for both cases is summarized for each segment in Table 2. The higher-angle fault traces are listed first, followed by the two definitions of $Y, R$, and $P$ traces. The angular range used for each of the latter three classes of faults is indicated in parentheses following the letter. Two calculations were made from the fault length data for each segment or segment pair (Table $2)$ : the ratio $P / R$ was calculated for each case, along with the proportion of $Y$ faults relative to the total length of active breaks in that segment or segment pair $(Y / L$, where $\left.L=Y+R+P+T+S+R^{\prime}+X\right)$.

For comparison to the experimental results in Table 1, the maximum Riedel angle in each segment is also listed in Table 2. The reported value represents the largest angle that is associated with a reasonable amount of fault length, which is considered here to be roughly $300 \mathrm{~m}$. This restriction was imposed to ensure that the maximum reported Riedel angle is associated with fault traces that are significant to the pattern of faulting in a segment. This is consistent with the experimental results, because angular measurements were made only on shears that cross-cut the entire gouge layer and that were considered to have contributed to the overall slip of the sample. As a result, several short, high-angle breaks in the gouge layers were not measured. For the San Andreas measurements, this requirement principally removes the curved tips of some fault traces from consideration as a maximum value for the Riedel angle.

\section{RESULTS}

Fault Segments and Their Boundaries. Subdivision of the fault into segments was begun as a geometric convenience for the analysis of fault trace orientations. Nevertheless, because the results are critically dependent on the choice of average trends, an effort was made to obtain segment configurations that are an accurate reflection of actual physical discontinuities along the fault. The fault segments defined for this work might also have applications to other studies. The analysis of fault geometry, and in particular fault segmentation, is becoming increasingly important, because of the many recent demonstrations of correlations between the location of bends and stepovers along a fault and earthquake rupture patterns (e.g., Weaver and Hill, 1978; Bakun et al., 1980; Lindh and Boore, 1981; Sibson, 1985, 1986; and Barka and Kadinsky-Cade, 1988). Therefore, although the comparison of experimental and natural fault zones focusses on fault geometry within segments, the segment boundaries are also described in some detail in this section. 
The 52 segments defined in this study range from 4.6 to $66 \mathrm{~km}$ in length (Table 2). For the most part, the segment boundaries could be readily positioned within several tens of meters. Problems were encountered principally in the more complexly faulted areas, where the zone of rupturing is wide and the main fault trend hard to locate (e.g., , C-4, C-6, E-9, E-10). The relatively straight stretch of fault northwest of Cajon Pass (F-4, F-5, and F-6) also provided considerable difficulties because, although the fault trend is obviously not quite straight, the bends are slight and the fault shows no obvious discontinuities. Alternative subdivisions were examined for some of the problematic parts of the fault; use of these alternative boundaries would not affect the conclusions reached concerning the relationships between the experimental results and San Andreas fault geometry.

The nature of each of the segment boundaries is summarized in Table 3 using the terminology for stepovers, (offset, overlap, separation) of Barka and Kadinsky-Cade (1988). Several of the segment boundaries are located in gaps in the fault trace that are caused by alluvial deposits or construction. In such cases the segment boundaries must be inferred; where possible, they have been designated as simple bends (e.g., B-1/B-2 and E-14/ $\mathrm{E}-15$ boundaries). If the inferred boundaries of the gaps are considered, then there are approximately equal numbers of simple bends and combined bend/stepovers and a much smaller number of stepovers without bends (Figure 4).

All but three of the stepovers (with or without accompanying bends) are right steps (Table 3, Figure 4) that commonly contain sets of $R$ faults. A right step on a right-lateral fault should be associated with extension (e.g., Segall and Pollard, 1980; Sibson, 1985, 1986), and the boundary between segments A-4 and A-5 provides a good illustration of this (Figure 7a). The boundary consists of a slight bend combined with a right separation that is outlined by $R$ faults. The presence of a lake and a swamp between the $R$ faults is suggestive of depressional features associated with extension.

The strike of the San Andreas fault varies markedly along its length, and those variations combined with the sliding behavior of the fault were used to separate the fault into straight sections and bend areas, as shown in Figure 9 and described in Table 4. A straight section is roughly defined as a group of segments in which the maximum bend between adjoining segments is less than $5^{\circ}$. The northern end of the central creeping section, however, has been extended one segment to the north of a $6^{\circ}$ bend, in order to coincide with the approximate northern limit of measured fault creep and the southern limit of rupturing accompanying the 1906 San Francisco earthquake. The two segments of D-5 comprise the smallest section, which does not correspond to either a straight section or a bend. Nevertheless, it is the site of a pronounced discontinuity in the trend of the fault zone, and it is important in separating the central creeping and central locked sections. Segments A-1, F-7, and F-8 are not included in Table 4; they may mark the beginnings of bends at the northern and southern ends of the study area.

The bend areas and straight sections have a number of distinguishing features. For example, the width of the zone of surface rupturing is generally narrower in the straight sections than in the bend areas (Figure 4). For the most part, the fault zone is less than $300 \mathrm{~m}$ wide in the straight sections, and the maximum width is approximately $1630 \mathrm{~m}$. 
Table 3 Boundary Relations Between Segments of San Andreas

Fault from Point Arena to Cajon Pass

\begin{tabular}{|c|c|}
\hline $\begin{array}{l}\text { Segment } \\
\text { Boundary }\end{array}$ & Nature of Boundary \\
\hline $\mathbf{A}-\mathbf{1} / \mathbf{A}-\mathbf{2}$ & gap (landslide and creek), modeled as simple bend \\
\hline $\mathbf{A}-\mathbf{2} / \mathbf{A}-\mathbf{3}$ & bend and offset; $75 \mathrm{~m}$ right step \\
\hline $\mathbf{A}-\mathbf{3} / \mathbf{A}-4$ & bend and overlap; $150 \mathrm{~m}$ right step \\
\hline $\mathbf{A}-4 / \mathbf{A}-5$ & bend and separation; $270 \mathrm{~m}$ right step \\
\hline $\mathrm{B}-1 / \mathrm{B}-2$ & gap (reservoir); modeled as simple bend \\
\hline $\mathrm{B}-2 / \mathrm{C}-1$ & simple bend \\
\hline $\mathrm{C}-1 / \mathrm{C}-2$ & bend and overlap; $75 \mathrm{~m}$ right step \\
\hline $\mathrm{C}-2 / \mathrm{C}-3$ & $\begin{array}{l}\text { gap (creek and road), modeled as bend and offset; } \\
135 \text { m right step }\end{array}$ \\
\hline $\mathrm{C}-3 / \mathrm{C}-4$ & bend and separation; $440 \mathrm{~m}$ right step \\
\hline$C-4 / C-5 a$ & bend and offset; $750 \mathrm{~m}$ left step \\
\hline$C-5 a / C-5 b$ & separation; $940 \mathrm{~m}$ right step \\
\hline$C-5 b / C-5 b^{\prime}$ & overlap; $365 \mathrm{~m}$ right step \\
\hline$C-5 b^{\prime} / C-6$ & bend and separation (or offset ?); $480 \mathrm{~m}$ right step \\
\hline$C-6 / C-7$ & simple bend \\
\hline $\mathrm{C}-7 / \mathrm{C}-8$ & simple bend \\
\hline$C-8 / D-1$ & simple bend \\
\hline $\mathrm{D}-1 / \mathrm{D}-2$ & simple bend \\
\hline$D-2 / D-3 a$ & bend and separation (or offset ?); $150 \mathrm{~m}$ right step \\
\hline$D-3 a / D-3 b$ & separation (or offset ?); $250 \mathrm{~m}$ right step \\
\hline $\mathrm{D}-3 \mathrm{~b} / \mathrm{D}-4$ & bend and separation; $150 \mathrm{~m}$ right step \\
\hline$D-4 / D-5 a$ & bend and separation; $250 \mathrm{~m}$ right step \\
\hline$D-5 a / D-5 b$ & separation; $750 \mathrm{~m}$ right step \\
\hline$D-5 b / E-1$ & simple bend \\
\hline$E-1 / E-2$ & simple bend \\
\hline$E-2 / E-3$ & bend and overlap; $325 \mathrm{~m}$ right step \\
\hline
\end{tabular}


Table 3

(continued)

\begin{tabular}{|c|c|}
\hline $\begin{array}{l}\text { Segment } \\
\text { Boundary }\end{array}$ & Nature of Boundary \\
\hline$E-3 / E-4$ & bend and overlap; $150 \mathrm{~m}$ right step \\
\hline$E-4 / E-5$ & $\begin{array}{l}\text { gap (creek and road), modeled as bend and offset; } \\
285 \text { m right step }\end{array}$ \\
\hline$E-5 / E-6$ & bend and overlap; $115 \mathrm{~m}$ right step \\
\hline$E-6 / E-7$ & simple bend (smooth) \\
\hline $\mathrm{E}-7 / \mathrm{E}-8$ & simple bend \\
\hline E-8/E-9a & simple bend \\
\hline$E-9 a / E-9 b$ & separation; $150 \mathrm{~m}$ right step \\
\hline E-9b/E-10a & bend and separation; $420 \mathrm{~m}$ right step \\
\hline$E-10 a / E-10 b$ & $\begin{array}{l}\text { gap (hilly terrain), modeled as separation; } \\
170 \mathrm{~m} \text { left step }\end{array}$ \\
\hline$E-10 b / E-11$ & bend and separation; $575 \mathrm{~m}$ left step \\
\hline $\mathrm{E}-11 / \mathrm{E}-12$ & bend and offset; $95 \mathrm{~m}$ right step \\
\hline$E-12 / E-13$ & gap (road) modeled as simple bend \\
\hline$E-13 / E-14$ & gap (alluvium and road), modeled as simple bend \\
\hline $\mathrm{E}-14 / \mathrm{E}-15$ & gap (road, alluvium, buildings), modeled as simple bend \\
\hline$E-15 / F-1$ & gap (road), modeled as simple bend \\
\hline$F-1 / F-2$ & simple bend \\
\hline $\mathrm{F}-2 / \mathrm{F}-3$ & gap (alluvium and road), modeled as simple bend \\
\hline$F-3 / F-4$ & gap (creeks and roads), modeled as simple bend \\
\hline$F-4 / F-5 a$ & bend and overlap; $95 \mathrm{~m}$ right step \\
\hline$F-5 a / F-5 b$ & stepover; $90 \mathrm{~m}$ right step \\
\hline$F-5 b / F-6 a$ & gap (creek and roads), modeled as simple bend \\
\hline$F-6 a / F-6 b$ & overlap; $100 \mathrm{~m}$ right step \\
\hline$F-6 b / F-7$ & $\begin{array}{l}\text { gap (creek and roads), modeled as bend and separation; } \\
290 \mathrm{~m} \text { right step }\end{array}$ \\
\hline$F-7 / F-8$ & simple bend \\
\hline
\end{tabular}




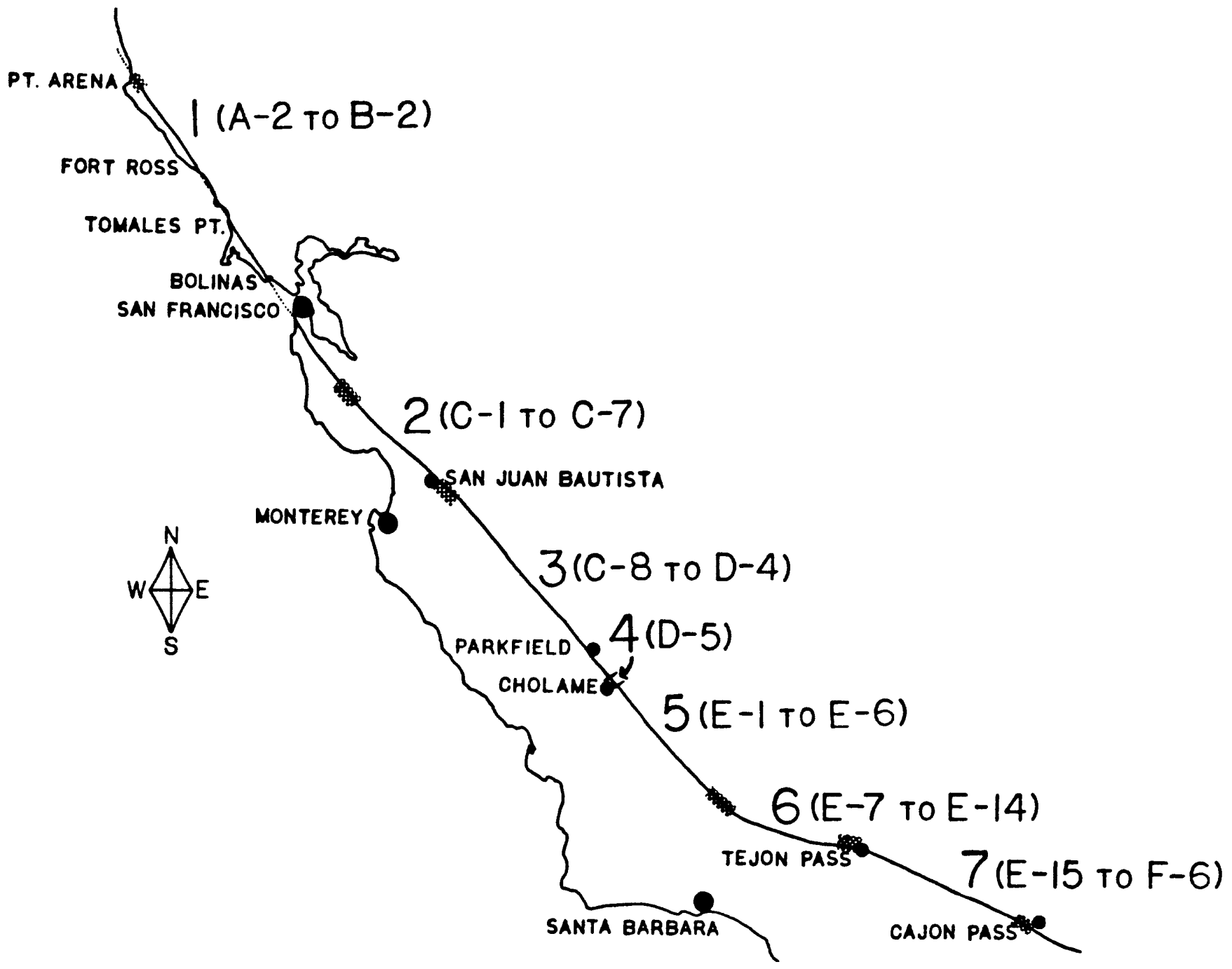

Figure 9. Grouping of segments along San Andreas fault: 1-Northern locked segment; 2-Northern bend; 3-Central creeping section; 4-Cholame Valley; 5-Central locked section; 6-Southern bend; 7-Southern locked section. With the exception of Cholame Valley, the group boundaries are not precisely located and are indicated generally by stippled areas. 
Table 4. Grouping of San Andreas Fault Segments into Straight Sections and Bend Areas (Point Arena to Cajon Pass)

\begin{tabular}{|c|c|c|c|}
\hline Designation & $\begin{array}{l}\text { Approx. } \\
\text { Trend } \\
\end{array}$ & Segments & $\begin{array}{c}\text { Ave. Seg. } \\
\text { Length }\end{array}$ \\
\hline $\begin{array}{l}\text { (1) Northern } \\
\text { Locked } \\
\text { Section }\end{array}$ & $\mathrm{N} 35-40^{\circ} \mathrm{W}$ & $\begin{array}{c}\text { A-2 } \\
\text { to } \\
\text { B-2 }\end{array}$ & 14.7 \\
\hline $\begin{array}{l}\text { (2) Northern } \\
\text { Bend } \\
\text { Area }\end{array}$ & $\mathrm{N} 42-54^{\circ} \mathrm{W}$ & $\begin{array}{l}\mathrm{C}-1 \\
\text { to } \\
\mathrm{C}-7\end{array}$ & 9.1 \\
\hline $\begin{array}{l}\text { (3) Central } \\
\text { Creeping } \\
\text { Section }\end{array}$ & $\mathrm{N} 40-53^{\circ} \mathrm{W}$ & $\begin{array}{c}C-8 \\
\text { to } \\
D-4\end{array}$ & 26.3 \\
\hline $\begin{array}{l}\text { (4) Cholame } \\
\text { Valley }\end{array}$ & $\mathrm{N} 35^{\circ} \mathrm{W}$ & D-5 & 6.4 \\
\hline $\begin{array}{l}\text { (5) Central } \\
\text { Locked } \\
\text { Section }\end{array}$ & $\mathrm{N} 38-43^{\circ} \mathrm{W}$ & $\begin{array}{c}E-1 \\
\text { to } \\
E-6\end{array}$ & 13.9 \\
\hline $\begin{array}{l}\text { (6) Southern } \\
\text { Bend } \\
\text { Area }\end{array}$ & $\mathrm{N} 45-90^{\circ} \mathrm{W}$ & $\begin{array}{c}E-7 \\
\text { to } \\
E-14\end{array}$ & 8.3 \\
\hline $\begin{array}{l}\text { (7) Southern } \\
\text { Locked } \\
\text { Section }\end{array}$ & $\mathrm{N} 64-72^{\circ} \mathrm{W}$ & $\begin{array}{c}E-15 \\
\text { to } \\
F-6\end{array}$ & 15.2 \\
\hline
\end{tabular}


The two parallel traces near Parkfield are about $1400 \mathrm{~m}$ apart. The maximum fault width is about $2500 \mathrm{~m}$ in the northern bend area and about $2300 \mathrm{~m}$ in the southern bend area.

The segments of the bends show a large range of orientations, and the strike of adjacent segments shifts in a zig-zag (or sawtooth, Bilham and Williams, 1985) pattern between more northerly and more westerly trends; e.g., from segments $\mathrm{E}-11$ to $\mathrm{E}-15$ in the southern bend area the fault strike varies as follows: $N 68^{\circ} \mathrm{W}-\mathrm{N} 82^{\circ} \mathrm{W}-\mathrm{N} 73^{\circ} \mathrm{W}-\mathrm{EW}-\mathrm{N} 70^{\circ} \mathrm{W}$ (Figure 4). The southern bend area separates the southern and central locked sections that differ by $20-30^{\circ}$ in their average trends (Table 4). There is only a $0-15^{\circ}$ difference between the average orientations of segments in the northern locked section and the central creeping section, and the range of segment orientations in the northern bend area is also less. Overall, the segments of the two bend areas have more westerly trends than the straight sections that they separate.

The two bend areas contain the only observed left (compressional) stepovers, which occur at the boundaries between segments $\mathrm{C}-4$ and $\mathrm{C}-5 \mathrm{a}, \mathrm{E}-10 \mathrm{a}$ and $\mathrm{E}-10 \mathrm{~b}$, and E-10b and E-11. The segments within the bend areas also have the shortest average lengths (Table 4). Among the straight sections, the average segment length is greatest in the central creeping section.

Distribution of Fault Traces in Segments. More than half of the segments contain only $Y, R$, and $P$-type structures (Table 2, Figure 1); segments of this type are concentrated in the straight sections of the fault (Figure 9). The segments with a wide range of fault orientations are principally found in the two bend areas (Figure 9), where the $R^{\prime}, X, T$ and $S$ traces contribute to the complex appearance of the fault zone in the bends. Even so, such high-angle traces comprise at most 7.6 percent $(E-10)$ and generally less than 4 percent of the total length of recently active breaks in any given segment.

The average trend of a segment only rarely coincides with the orientation having the greatest length of fault (Figures 5 and 6); instead, the mode of fault length can occur up to about $5^{\circ}$ on either side of the average fault strike. The amount of fault length also does not decrease gradually with increasing angle from the mode. Rather, the individual rose diagrams and histograms have the appearance of a series of spikes separated by angular intervals of a few to several degrees that are represented by very little fault length.

One of the distinguishing features between the stably sliding and stick-slip experimental samples was the maximum angle measured between the Riedel and boundary shears (Figure 1; Table 1), and Table 2 contains the maximum Riedel angle for each segment (or segment pair). The range of maximum Riedel angles is 6 to $14^{\circ}$ for segments C-8 through D-4, which comprise the section of measured fault creep (central creeping section of Figure 9). With the exception of segments F-1 through F-8, the locked segments have maximum Riedel angles in the range 10 to $35^{\circ}$, with the great majority having angles of $15^{\circ}$ or more. The segments of the bend areas generally have the highest Riedel angles; these same segments are the ones that also contain the higher-angle $T, X$, and other traces.

The relative lengths of $R$ and $P$ traces in each segment were compared. For both definitions of $R$ and $P$ traces, it was found that $P$-type breaks predominate over $R$-type 
breaks $(P / R>1)$ in all segments of the creeping section (C-8 through $\mathrm{D}-4)$, whereas $R$ traces predominate over $P$ traces $(P / R<1)$ in most of the locked segments (Table 2). The differences between the creeping and locked sections are more pronounced with $P_{1} / R_{1}$, which was calculated using the larger ranges of $R$ and $P$ orientations. For the creeping segments, the ratio $P_{1} / R_{1}$ varies from 1.02 to 1.54 , whereas $P_{1} / R_{1}$ is less than 1.00 for all but 3 of the locked segments. One of the 3 locked segments with $P_{1} / R_{1}>1$ is $\mathrm{C}-7$, which adjoins the creeping section at its northern end. Use of $P_{2} / R_{2}$, with its narrower range of $R$ and $P$ orientations, yields a wider scatter of values for both the locked and creeping sections, and 8 of the locked segments now have $P_{2} / R_{2}>1$. Nevertheless, $P_{2} / R_{2}<1$ for 80 percent of the locked segments, and $P_{2} / R_{2} \geq 1(1.00-2.07)$ for all of the creeping segments.

The individual fault segments vary greatly in their size and character, as seen in the wide variety of fault length distributions among the rose diagrams and histograms of Figures 5 and 6, respectively. In order to more clearly identify any possible differences in the distribution of $R$ and $P$ faults between the creeping and locked segments, a histogram of fault length relative to the average trend for each segment was prepared for the creeping segments as a group (Figure 10a) and compared to one for all the locked segments as a group (Figure 10b). Figure $10 \mathrm{a}$ is clearly skewed towards the right $(P)$ side, whereas Figure 10b is skewed towards the left $(R)$ side. The ratio $P / R$ for the grouped data is essentially independent of the limits set for the $P$ and $R$ shears, so that both $P_{1} / R_{1}$ and $P_{2} / R_{2}$ are approximately 1.38 for the creeping section as a whole and 0.63 for the locked sections as a whole (Table 5 ). The $P / R$ ratios for the creeping and locked sections differ by slightly more than a factor of 2; thus, relative to some unit length of $R$ traces, the creeping section on the average contains more than twice the length of $P$ traces than does the locked section. In contrast, the proportion of $Y$ faults relative to the total measured length of recently active breaks (L) is roughly the same for the creeping and locked sections, at approximately 0.23 for $Y_{1} / L$ and 0.52 for $Y_{2} / L$.

In Figure 11, the locked segments have been separated into the 3 straight sections (Figure 11a) and the 2 bend areas (Figure 11b) defined in Table 3 , and $P / R$ and $Y / L$ ratios for each are presented in Table 5 . Both the $P / R$ and $Y / L$ ratios are slightly lower for the bend areas than for the straight sections. The lower values of $Y / L$ are consistent with the greater abundance of higher-angle faults in the bend areas (Table 2). Removing the segments of the bend areas makes $Y / L$ for the remaining locked sections even closer to the $Y / L$ values for the creeping section.

\section{DISCUSSION}

Comparison of San Andreas and Experimental Results. With respect to the maximum Riedel angles, the creeping and locked sections of the San Andreas fault are consistent for the most part with the experimental results summarized in Table 1. The maximum Riedel angle for the segments of the creeping section ranges from $6^{\circ}$ to $14^{\circ}$, whereas it is commonly more than $20^{\circ}$ or even $30^{\circ}$ in the locked segments (Table 2). The southern locked section (Figure 9) between Tejon Pass and Cajon Pass is an exception in that the 

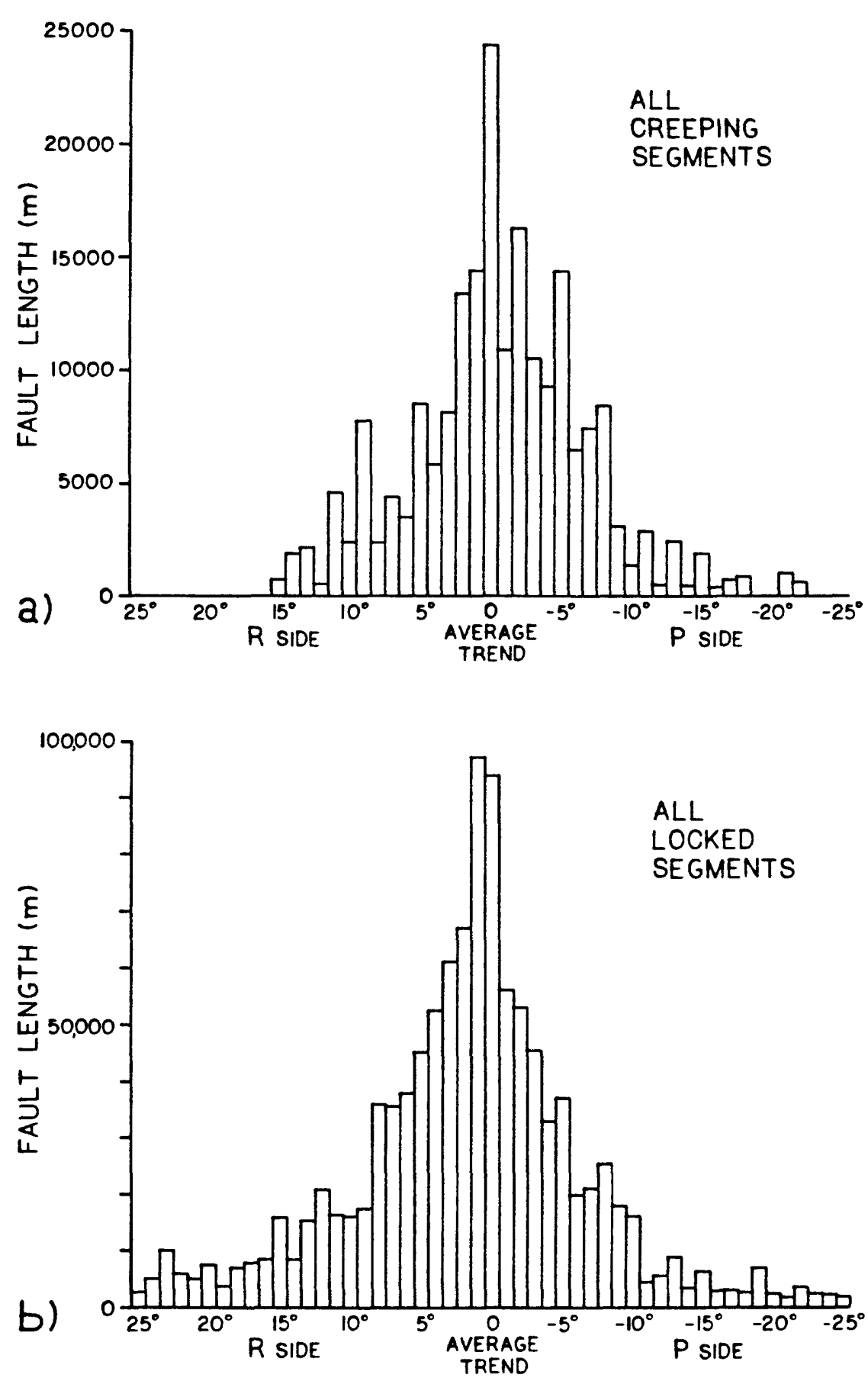

Figure 10. Histograms of fault length relative to the average trend $\left(0^{\circ}\right)$ for a) all of the creeping segments grouped together and b) all of the locked segments grouped together. Fault traces with a more northerly strike than the average trend in both diagrams are assigned positive angles ( $R$ side), and traces with a more westerly or southerly strike than the average trend are assigned negative angles ( $P$ side). 

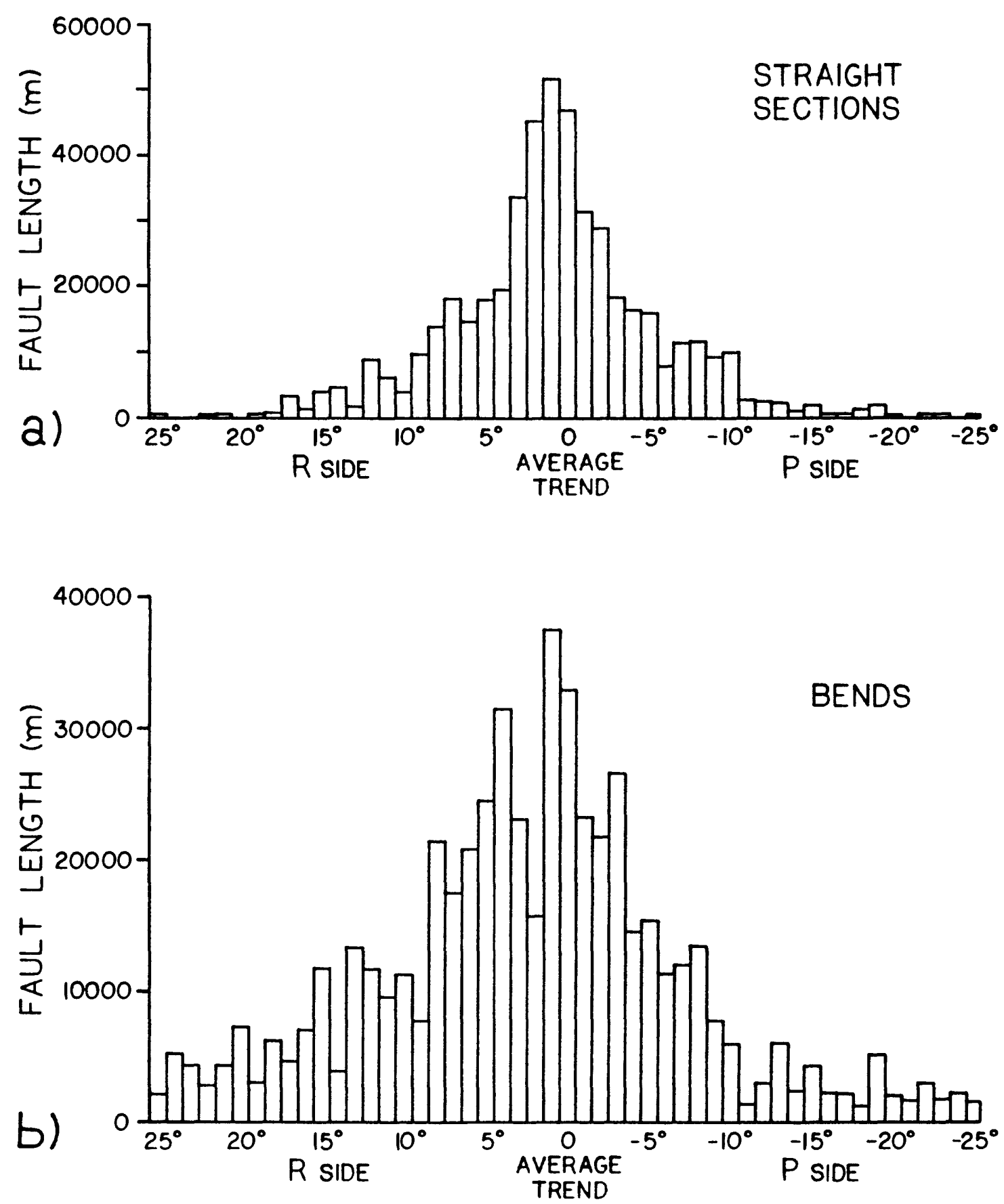

Figure 11. Histograms of fault length relative to the average trend $\left(0^{\circ}\right)$ for a) the three locked straight sections $(1,5$, and 7$)$ and b) the two locked bend areas (2 and 6) defined in Figure 9 and Table 4. Histogram construction is the same as in Figures 6 and 10. 
Table 5. Summary of Map Data Relative to $Y, R$, and $P$ Faults for Different Groupings of Fault Segments

\begin{tabular}{ccccc}
\hline & $\begin{array}{c}\text { All Creeping } \\
\text { Segments }\end{array}$ & $\begin{array}{c}\text { All Locked } \\
\text { Segments }\end{array}$ & $\begin{array}{c}\text { Locked Straight } \\
\text { Sections }(1,5,7)\end{array}$ & $\begin{array}{c}\text { Locked Bend } \\
\text { Areas }(2,6)\end{array}$ \\
\hline \hline$Y_{1}(1,-1)(\mathrm{km})$ & 49.7 & 247.6 & 129.9 & 93.8 \\
$R_{1}(2,35)(\mathrm{km})$ & 66.0 & 528.9 & 212.9 & 288.6 \\
$P_{1}(-2,-35)(\mathrm{km})$ & 90.0 & 343.6 & 150.2 & 188.5 \\
$P_{1} / R_{1}$ & 1.36 & 0.65 & 0.71 & 0.65 \\
$Y_{1} / L$ & 0.24 & 0.22 & 0.26 & 0.16 \\
$Y_{2}(4,-4)(\mathrm{km})$ & 113.1 & 559.8 & 292.2 & 227.3 \\
$R_{2}(5,35)(\mathrm{km})$ & 38.7 & 348.3 & 114.3 & 218.1 \\
$P_{2}(-5,-35)(\mathrm{km})$ & 53.9 & 212.0 & 86.5 & 125.5 \\
$P_{2} / R_{2}$ & 1.39 & 0.61 & 0.76 & 0.58 \\
$Y_{2} / L$ & 0.55 & 0.49 & 0.59 & 0.39 \\
\end{tabular}


maximum Riedel angles in the segments of that area are comparable to those of the central creeping section.

Because our earlier textural studies of laboratory run products had been concentrated on the $R$ and boundary shears, the samples of illite gouge were reexamined during this study for $P$-shear development. All of the texture d and many of the texture c samples were found to contain considerably more $R$ than $P$ shears; however, a few texture c samples do contain well developed $P$ shears that in a few cases may equal if not surpass the $R$ shears in abundance. The texture c run products with abundant $P$ shears typically contain many, relatively wide shears and strongly developed fabric elements in the areas between the shears, which would place them closer to texture $b$ than texture $\mathrm{d}$ samples. Almost all of the samples that contain many $P$ shears have maximum Riedel angles of $14^{\circ}$ or less; and their sliding behavior ranges from stable slip to stick-slip with relatively small stress drops. The $P$ and $R$ shears tend to be segregated, such that $P$ shears predominate on one side of the gouge layer and $R$ shears on the other, as sketched in Figure 12. The $P$ and $R$ shears in the Figure form a sort of loop, and the samples may contain one to three such loops along the length of the gouge layer.

Based on $P$-shear development and on maximum Riedel angles, the San Andreas fault segments that show creep can be correlated with the texture $\mathrm{c}$ samples in Table 1 that have maximum Riedel angles of $14^{\circ}$ or less and whose sliding behavior ranges from stable motion to stick-slip with relatively small stress drops. This range of sliding behavior is consistent with the types of motion observed in the creeping section of the San Andreas fault, which vary from aseismic creep to moderate-sized earthquakes. Most of the locked segments would correspond to texture $\mathrm{c}$ or $\mathrm{d}$ samples that have maximum Riedel angles greater than $14^{\circ}$ and that also contain more $\bar{R}$ than $P$ shears. The locked section between Tejon Pass and Cajon Pass has maximum Riedel angles principally in the $10-14^{\circ}$ range, but the ratio $P / R$ is less than 1.0 in all of the segments of that section and in places is as low as $\mathbf{0 . 2 5}$. These segments can therefore be correlated with the texture $\mathrm{d}$ samples in the $10-14^{\circ}$ range of maximum Riedel angles, which show only stick-slip motion.

Quality of Correlations. This preliminary study of San Andreas fault structures has yielded significant differences in geometry of active breaks between the creeping and locked sections that appear to correspond to textural differences found between laboratory samples of fault gouge that slide stably and ones that show stick-slip motion. The quality of the correlation must be examined, however, to determine the relevance of the experimental results to natural faults.

The results of the San Andreas study are dependent upon the quality of the map base used. The six maps used in this study were prepared by several geologists, which can have advantages and disadvantages. Two geologists mapping the same part of the San Andreas could produce quite different maps, based on their interpretations of the geology and their criteria for identifying recently active breaks. The advantage for our study is that both the locked and creeping portions of the San Andreas are contained on more than one of the maps. Thus, segments of the creeping section have similar faulting patterns even though they appear on two different maps. The distinctive characteristics of the 


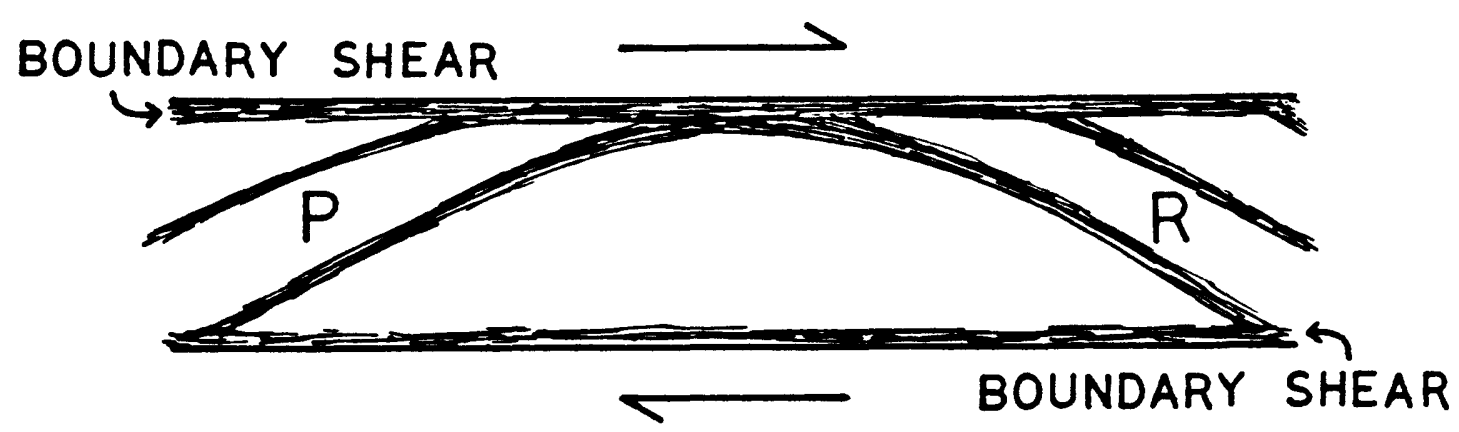

Figure 12. Sketch of texture $\mathrm{c}$ illite samples containing many $P$ shears. The $P$ shears tend to be concentrated on one side of the gouge layer and the $R$ shears on the other. The thickness of the gouge layer before shearing was $0.65 \mathrm{~mm}$; the gouge layer was placed along a $30^{\circ}$ sawcut in a granite cylinder that was $19 \mathrm{~mm}$ diameter. 
creeping section, therefore, are not an artifact of one geologist's mapping procedure. In contrast, the southern locked section of fault located between Tejon Pass and Cajon Pass is all found on one map (Map F-Ross, 1969), and the low Riedel angles of that section could be explained as a function of the mapping rather than the actual fault configuration. Other maps of this area need to be examined, to verify the absence of higher-angle fault traces. Two different map scales - 1:24000 and 1:62500 - were used for this series of strip maps. However, as noted by $R$. Brown (written communication, 1989), the recently active breaks all along the fault were initially mapped at the same scale on aerial photographs, following field examination. The identified traces were then transferred to the final maps. The differences in fault geometry are therefore a reflection of the original mapping and not of the final map scale used.

Another potential source of error is our choice of segment orientations and boundaries for analysis of the fault data. The average trend of a given segment is restricted to a very narrow range of orientations, and the determinations of maximum Riedel angle should not be affected by a slight change in the average trend. In contrast, a modest shift in the strike can greatly affect the total lengths of $Y, R$, and $P$ faults in a given segment. For example, if the average trend of each of the locked segments were shifted $1^{\circ}$ to the north and the average trend of each creeping segment were shifted $1^{\circ}$ to the south, most of the difference in $P / R$ ratio between the locked and creeping portions of the fault would be removed. Moving the segment boundaries will also affect the results.

Two separate definitions of $Y, R$, and $P$ traces were reported in this study, in order to show that the choice of angular limits did not affect the differences in $P$ and $R$ abundances between the locked and creeping sections. Two other definitions of $Y$ faults: $Y=0^{\circ}$ and $Y=-5$ to $+5^{\circ}$, were also examined but not included here; the results were the same as for the two cases that are reported in Tables 2 and 5 . The apparent variations in $P / R$ ratio warrant more rigorous statistical analysis.

Assuming that future improvements to the map base and segment definitions uphold the presently observed correlations between the experimental and San Andreas fault patterns, the next question is whether or not our experimental design and conditions are applicable to natural faults. At least some minor differences between the San Andreas and laboratory faults can be attributed to the sample configuration, which includes the presence of a well-developed gouge zone at the start of faulting and straight, smooth boundaries between the gouge and country rock (a granite cylinder in the experiments). Differences in the gouge-country rock boundary relations may explain the almost universal appearance of a pair of boundary shears in the experimental samples (Figures 1 and 2), contrasted with the rare occurrence of comparable fault pairs along the San Andreas. Segments A-6, $\mathrm{C}-1, \mathrm{D}-4$, and F-3 are the only ones containing pairs of $Y$ faults that appear to follow the outer edges of the fault zone. R. Summers, (U.S.G.S., personal communication, 1988) ran four experiments in which a layer of granite or quartz-sand gouge was placed along a tension fracture rather than a sawcut in the granite cylinder. After the experiments the samples did not contain any boundary shears, apparently due to the irregularities of the fracture surfaces. Indentations in the fracture surface were preferential locations for the initiation of $R$ shears; however, the Riedel angles measured in these samples were the 
same as in otherwise identical experiments run with a sawcut. The angular measurements made in this study should therefore be independent of the nature of the gouge-country rock interface.

The triaxial equipment also does not permit large amounts of slip, so that the ensuing experimental fault patterns might most appropriately be compared to young rather than mature fault zones. Shear box (Morgenstern and Tchalenko, 1967; Tchalenko, 1970), sand box (Naylor et al., 1986), and rotary shear (Mandl et al., 1977) experiments can be run to considerably larger displacements, however, and they have yielded some information about experimental fault zone evolution. In standard simple shear tests on unconsolidated materials such as sand and clays, relatively high-angle $R$ shears form first, as Coulomb shears. The establishment of these shears causes changes in the stress fields in the intervening areas, which in turn leads to the formation of lower-angle $R, Y$, and $P$ shears in those areas. The original high-angle $R$ shears are not well oriented to accommodate large amounts of slip, so that shearing gradually becomes more and more concentrated along the shears that are subparallel to the direction of motion ( $Y$ shears), and the 'mature' fault has an anastomosing pattern.

The Riedel shears of our short-run experimental samples would correspond to the early-formed, high-angle Riedel shears of the longer experiments. Successful comparison of fault orientations between youthful and mature fault zones would therefore depend on the degree to which the early-formed structures and their orientations are preserved. The higher-angle structures are still discernible in the mature experimental samples, but the earlier-formed fault traces may not be as well preserved in a natural fault zone, for which maturity is measured on a geological rather than a laboratory time scale. It is possible, then, that low Riedel angles measured in a San Andreas fault segment are a reflection of its age rather than its sliding behavior.

Because the laboratory experiments were conducted at high pressures, comparing the experimental textures with surficial fault patterns is only appropriate if the surface structures are representative of those found at deeper levels. This question cannot be answered at present, because we do not have a very good idea of what faults are like below the earth's surface. Many workers have assumed that faulting patterns become more simplified at depth, and in keeping with this idea, most shear box and sand box experiments, as well as the intact rock samples of Bartlett et al. (1981) have been conducted with a single, straight, narrow fault at the base of the samples. Sharp (1979) envisions a simple but possibly very wide fault zone at depth. In contrast, examination of faults exposed in deep mines has shown that the fault patterns remain complex to at least that level (Wallace and Morris, 1986). The ore-bearing faults that were studied by Wallace and Morris (1986) may originally have formed at depths to about $5 \mathrm{~km}$. At least some of the major surface irregularities in the San Andreas and Calaveras fault zones have been identified at depth by means of detailed microseismic studies (e.g., Eaton et al., 1970; Bakun et al., 1980; Reasenberg and Ellsworth, 1982). In their fractal analyses of the San Andreas fault, both Aviles et al. (1987) and Okubo and Aki (1987) also support the suggestion that the mapped surface irregularities extend to deeper levels within the seismogenic zone. 
Rogers (1973) proposed an evolutionary trend for transcurrent faults that is at odds with the experimental evolutionary pattern described above. If his model is correct, the San Andreas fault patterns could not be compared to the experimental ones. Rogers (1973) suggested that a given fault trace starts out straight, as a $Y$-type fault, that it gradually becomes more and more curved as a result of deformation accompanying increasing slip, and that it is eventually replaced by a new, straight one. In his model, the orientation of a given fault trace would be a function of the amount of distortion to which it had been subjected rather than simple shear mechanics. The merits of this model in relation to the experimental model cannot be evaluated at present. This possibility should be kept in mind, however, during the analysis of fault patterns.

One final possibility is that the presently observed variations in sliding behavior along the San Andreas may not be representative of its overall motion. The modern fault creep in central California may be a temporary phenomenon; this part of the fault may once have been and will again be locked. Similarly, other parts of the San Andreas may have had or will have episodes of fault creep. The present locked and creeping sections, therefore, might not reflect fundamental differences in fault behavior; if that is the case, then correlations of stick-slip experiments with the current locked sections and stable-slip experiments with the current creeping section are meaningless.

Alternative Interpretations of Fault Patterns. In the previous section we considered the quality of the data and the appropriateness of applying the experimentally derived textures to San Andreas fault patterns. The section between Tejon Pass and Cajon Pass warrants additional study, because although the fault patterns can be correlated with the experimental results in Table 1, they nevertheless are anomalous compared to the other locked sections. The quality of the segment designations should be tested by all possible geological and seismological means. Some questions were raised concerning the appropriateness of correlating the experimental and natural fault patterns, which must be answered where possible. At the present time, however, there is no reason to reject the experimental fault patterns as a viable model for the San Andreas, to be tested and examined further.

The next question then is-given that this is a possible model, is it the correct one to explain the San Andreas fault patterns? What alternative models can be found? Some possibilities are considered below.

(1) Total Offset/Age of Fault-As described previously, a given experimental simple shear zone shows a well-defined sequence of fault trace development during progressive slip. The earlier discussion was aimed at the appropriateness of comparing experimental and natural fault patterns; this same topic warrants repeating here, with regard to comparing San Andreas fault segments with each other. Two segments of the San Andreas can show contrasting fault patterns if they are not in the same stage of development. Differences in age between the two segments or differences in slip rate between two segments of the same age can both produce this effect. The active trace of the San Andreas does not remain indefinitely in one place; it may shift its position for a number of reasons, such as to cut off high-angle bends or stepovers (Wesnousky, 1988) that impede slip or in response 
to movements on nearby faults. For example, the exhumed Punchbowl Fault may have been the main trace of the San Andreas near Cajon Pass for much of the Quaternary (Sharp and Silver, 1971; Woodburne, 1975). The San Andreas takes up much of the plate boundary motion, so that slip rates should be largely comparable along the length of the fault. Along parts of the system, however, the plate motion is distributed among several fault strands, as in the San Francisco Bay region and south of Cajon Pass in southern California. Individual strands would account for only a portion of the plate motion, and their fault patterns might change more slowly than for segments with higher slip rates.

In this regard, it is interesting that the proportions of $Y$ shears were the same overall for the locked and creeping sections (Table 5). If the proportion of $Y$ shears can be taken as a rough indicator of maturity, then the locked and creeping sections on the whole may represent similar stages of fault zone development. Nevertheless, the age and total offset of a given segment should be kept in mind when evaluating its fault patterns.

(2) Control of Fault Orientations by Pre-Existing Structures-Studies of laboratory (Paterson and Weiss, 1966; Jackson and Dunn, 1974) and natural (Segall and Pollard, 1983) faults have shown that they will preferentially form along pre-existing planes of weakness such as joint systems or fold axes, if the older structures are favorably oriented relative to the principal stresses. As a result, individual fault traces may reflect the local geology or structure rather than the prevailing stress fields. This effect would vary from segment to segment as the geologic structures vary, and it would tend to randomize the fault patterns, obscuring any differences that might be related to the sliding behavior. The influence of the local geology may be the cause of some of the irregular fault distributions shown in the individual rose diagrams and histograms of Figures 5 and 6 . That the effect would vary randomly from segment to segment may explain why the differences between the locked and creeping sections are clearer on the combined histograms of Figure 10 than on the ones for individual segments (Figure 6).

(3) Control of Fault Orientations by Current or Pre-Existing Stress States-In most laboratory studies of faulting, including ours, the samples are not subjected to a pre-faulting differential stress. However, Sanderson and Marchini (1984) and Naylor et al. (1986) have demonstrated theoretically and experimentally, respectively, that the orientations of Riedel shears in a strike-slip fault can vary with the pre-faulting differential stress state. Naylor et al. (1986) tested two end-member pre-stress conditions experimentally. In the first test, the maximum compressional stress $\left(\sigma_{1}\right)$ was initially parallel to the fault zone (transtension). In the second test, $\sigma_{1}$ was initially perpendicular to the fault zone (transpression). For both cases, according to Naylor et al. (1986), $\sigma_{1}$ will rotate from its initial position to make a $45^{\circ}$ angle with the fault zone, in accordance with simple shear (Mandl et al., 1977); but the first-formed faults will reflect the initial position of $\sigma_{1}$. In transtension, the first en echelon faults will make only a small angle with the fault zone. Such faults are favorably oriented for slip, and no new faults need to form as $\sigma_{1}$ assumes a $45^{\circ}$ position. In transpression, the first $R$-type faults make a high angle to the fault zone. These faults will be unfavorably oriented for large amounts of slip, and they will be replaced by progressively lower-angle $R$ faults as $\sigma_{1}$ continues to rotate. 
The initial differential stress state provides perhaps the most important alternative model to explain the variations in Riedel angle along the San Andreas. The choice of stress state is a problem, though. Use of the current or a previous plate motion vector, which would be uniform along the length of the fault, does not explain why similarly oriented sections of the San Andreas, such as the central creeping and central locked sections (Figure 9), have different Riedel angles. Some recent studies (e.g., Mount and Suppe, 1987; Zoback et al., 1987) have suggested that $\sigma_{1}$ is perpendicular to the strike of the fault all along its length. This is a controversial finding and if it is true, modeling by Wesson (1988) suggests that $\sigma_{1}$ would be perpendicular to the fault to a depth of only a few kilometers. Below that depth, in the locked seismogenic zone, $\sigma_{1}$ would assume an approximately $45^{\circ}$ position consistent with geodetic data (Savage et al., 1986) and with a simple shear model. As argued previously with the plate motion vectors, a uniformly orthogonal relationship between $\sigma_{1}$ and fault strike will not explain the variations in maximum Riedel angle along the length of the San Andreas. The effects of more localized stress fields, such as the interaction of the San Andreas with other fault systems, could potentially explain the variation in fault patterns, however. This latter possibility requires further examination.

Significance of Correlations. If the experimentally derived textures summarized in Table 1 and Figure 2 are eventually shown to be a good model for the San Andreas fault patterns, then it will be necessary to understand the controls on textural development in the experiments. At the present time, however, neither the variations in Riedel angle nor the relative proportions of $R$ and $P$ faults can be explained in terms of Coulomb-Mohr theory. Problems related to the interpretation of the experimental Riedel shear orientations have been discussed by Moore et al. (1989) and are summarized briefly here. From the Coulomb-Mohr shear-failure criterion combined with the generally accepted notion that experimental (e.g., Mandl et al., 1977) and natural (e.g., Sylvester, 1988) strike-slip faults deform by simple shear, the angle that the Riedel shears make with the average orientation of the fault zone should equal one-half the angle of internal friction $(\phi)$ of the material being tested. For the illite-rich gouge examined by Moore et al. (1989), however, values of $\phi$ calculated from plots of normal versus shear stress do not agree with those obtained from the maximum Riedel angles. Use of an average of all the measured Riedel angles in a given sample rather than the maximum value produces an even worse fit in most cases. It is also not clear whether the $R$ shear orientations in the samples are the cause or a result of the sliding behavior.

The origin of $P$ shears is not completely understood. As has been described in previous sections, $P$-shears should be secondary structures and generally subordinate in their occurrence relative to the primary $R$ shears, based on a number of laboratory studies (Morgenstern and Tchalenko, 1967; Tchalenko, 1970; Naylor et al., 1986; Mandl, 1988). The illite gouge run products that contain many more $R$ than $P$ shears appear to be consistent with these theoretically predicted and experimentally observed relationships. Where present, the $P$ shears in such samples are restricted in their occurrence to short segments that connect two $R$ shears or an $R$ and a boundary shear. Examination of a set of illite samples that show different amounts of slip (Moore, unpublished data) supports the suggestion that $P$ shears may form later than $R$ shears in such samples. 
Bartlett et al. (1981) reported the possible concurrent rather than sequential development of $R$ and $P$ shears in laboratory strike-slip fault zones that they generated in initially intact layers of limestone. The concurrent formation of $P$ and $R$ shears would apparently preclude both types of shear from being explained by Coulomb-Mohr theory (Bartlett et al., 1981). Alternatively, Naylor et al. (1986) suggest that the $P$ shears in the limestone layers could be secondary rather than primary and therefore consistent with Coulomb-Mohr theory. They reason that because of the greater elastic stiffness of the limestone compared to the unconsolidated materials used in most faulting experiments, the limestone will accommodate only very minor displacements on the $R$ shears before $P$ shears are required to form.

Although most experimental occurrences of $P$ shears can be assigned to a secondary origin, first generation or primary arrays of en echelon $P$ fractures are commonly found in nature (Gamond, 1987). Several of the en echelon $P$ faults along the San Andreas (see Figure 3d-3g of Wallace, 1973) appear to be examples of such primary arrays, because they form the principal (or only) mapped traces of those areas. Similarly, the $P$ shears in the illite samples sketched in Figure 12 look to be the primary shears in those parts of the samples in which they predominate, whereas the short $R$ segments connecting the $P$ shears appear to be secondary. At present, no interpretation in terms of stress can be proposed to explain the occurrence of primary $P$ faults (Gamond, 1987), although some natural en echelon $P$ faults have been suggested to form where dilatation of the fault zone is possible (Vialon, 1979; Gamond, 1983). Dilatation cannot be invoked to explain $P$-shear development in our experimental illite samples, however, because the experiments were run under high effective pressures, for which dilatancy would be considerably suppressed. It may be significant that the illite samples containing many $P$ shears were all ones that had been heated to $400^{\circ} \mathrm{C}$ or, in lesser numbers, to $600^{\circ} \mathrm{C}$. The clay-rich gouge layers in these high-temperature experiments became lithified during the runs (e.g., Moore et al., 1983, 1986a), making them similar to the intact limestone layers studied by Bartlett et al. (1981), which may also contain primary $P$ shears. In contrast, all of the run products of the room-temperature and $200^{\circ} \mathrm{C}$ illite gouge experiments, in which the clay layers remained unconsolidated, were samples which contained only minor, obviously secondary $P$ shears. Primary $P$ shears, if they can occur, may perhaps only form in originally intact rock.

One final point should be made regarding the comparison of experimental and San Andreas fault zone structures. In this study, the faulting patterns of both the creeping and locked sections of the San Andreas have been correlated with the texture $\underline{c}$ and $\underline{\mathbf{d}}$ samples of Table 1. All of the experimental samples in these two textural categories show localization of shear to a greater or lesser extent, which is consistent with the development of faults in the seismogenic zone. In contrast, the texture $\underline{a}$ and $\underline{b}$ gouge layers are characterized by pervasive shear, which may be more typical of faulting at depths below the seismogenic zone. The point to be made here is that if an experimental study is being conducted to duplicate faulting processes in the seismogenic zone, then the experiments should be run under conditions that will produce localized shear (texture $c$ or d) rather than pervasive shear (texture a or b). All laboratory friction studies, therefore, should routinely include textural examinations of the run products, to determine the applicability of the results. 


\section{SUMMARY}

(1) Recent textural examinations of layers of fault gouge deformed during triaxial friction experiments had revealed some physical differences between samples that slide stably and ones that show stick-slip motion. Specifically, the gouge layers with pervasively developed deformation fabrics slide stably, whereas the ones with localized shear show stick-slip motion if the Riedel shears in the samples make relatively high angles with the boundary of the gouge layer. In order to determine whether the experimental results are of general significance to fault zones, faulting patterns in the creeping and locked portions of the San Andreas from Point Arena to Cajon Pass, California were compared. For consistency with the experimental studies, the examined length of the San Andreas fault was subdivided into 52 geometrically-defined segments of uniform average trend. The orientations of individual fault traces within each segment were then measured and compared with the average trend.

(2) The segments defined in this study were informally grouped into straight sections and intervening bend areas. A straight section is a group of segments in which the maximum bend between adjoining segments is less than $5^{\circ}$; in contrast, the difference in orientation between adjoining segments of the bend areas is as much as $20^{\circ}$. In addition, the fault zone is generally narrower and the average segment length greater in the straight sections than they are in the bends. The average segment length is also greater in the creeping straight section than in the locked straight sections.

(3) The orientations of Riedel-type traces in the San Andreas fault zone showed patterns consistent with the experimental results, in that the maximum Riedel angle of the creeping segments is $14^{\circ}$, whereas the maximum Riedel angle in most of the locked segments is greater than $15^{\circ}$. The locked section between Tejon Pass and Cajon Pass has maximum Riedel angles comparable to those of the creeping section, however.

(4) $P$-type en echelon faults predominate over $R$-type arrays in the segments of the creeping section, whereas $R$-type faults predominate in the locked segments. The ratio $P / R$ is approximately 1.38 for the creeping segments as a group and 0.63 for all the locked segments grouped together. This latter difference is also consistent with the experimental results, and the combination of $P / R$ ratios and Riedel angles serves to distinguish the creeping segments from the locked segments, including those locked segments located between Tejon Pass and Cajon Pass.

(5) The physical correlations that can be made between experimental samples and San Andreas fault segments that show equivalent types of motion suggest the possibility that deformation textures developed in the laboratory samples may help to explain the causes of earthquakes and of fault creep. The appropriateness of this correlation needs to be tested in further studies, however, along with the possible merits of several alternative hypotheses for the origin of the San Andreas fault patterns.

(6) The segments of both the creeping and locked sections of the San Andreas have been correlated texturally with the experimental samples showing localized shear. Pervasively deformed laboratory gouge samples may be more representative of conditions in 
natural faults at depths below the seismogenic zone. Experimental studies should therefore include textural descriptions of the run products in order to determine the applicability of the results. 


\section{REFERENCES}

Aviles, C.A., Scholz, C.H., and Boatwright, J., 1987. Fractal analysis applied to characteristic segments of the San Andreas fault. Journal of Geophysical Research 92: 331-344.

Bakun, W.H., Stewart, R.M., Bufe, C.G., and Marks, S.M., 1980. Implication of seismicity for failure of a section of the San Andreas fault. Seismological Society of America Bulletin 70: 185-201.

Barka, A.A. and Kadinsky-Cade, K., 1988. Strike-slip fault geometry in Turkey and its influence on earthquake activity. Tectonics 7: 663-684.

Bartlett, W.L., Friedman, M., and Logan, J.M., 1981. Experimental folding and faulting of rocks under confining pressure. Part IX. Wrench faults in limestone layers. Tectonophysics 79: 255-277.

Bilham, R., and Williams, P., 1985. Sawtooth segmentation and deformation processes on the southern San Andreas fault, California. Geophysical Research Letters 12: 557-660.

Brown, R.D., Jr., 1970. Map showing recently active breaks along the San Andreas and related faults between the northern Gabilan Range and Cholame Valley, California. U.S. Geological Survey Miscellaneous Geologic Investigations Map I-575.

Brown, R.D., Jr., 1972. Active faults, probable active faults, and associated fracture zones, San Mateo County, California. U.S. Geological Survey Miscellaneous Field Studies Map MF-955.

Brown, R.D., Jr., and Wolfe, E.D., 1972. Map showing recently active breaks along the San Andreas fault between Point Delgada and Bolinas Bay, California. U.S. Geological Survey Miscellaneous Geologic Investigations Map I-692.

Byerlee, J., Mjachkin, V., Summers, R., and Voevoda, O., 1978. Structures developed in fault gouge during stable sliding and strike-slip. Tectonophysics 44: 161-171.

Clark, M.M., 1984. Map showing recently active breaks of the San Andreas fault and associated faults between Salton Sea and Whitewater River, Mission Creek, California. U.S. Geological Survey Miscellaneous Geologic Investigations.Map I-1483.

Cloos, H., 1928. Experimente zur inneren Tektonik. Zentralblatt für Mineralogie, Geologie, und Palaeontelogie, Abt. B.: 609-671.

Eaton, J.P., O'Neill, M.E., and Murdock, J.N., 1970. Aftershocks of the 1966 ParkfieldCholame, California, earthquake: A detailed study. Seismological Society of America Bulletin 60: 1151-1197. 
Gamond, J.F., 1983. Displacement features associated with fault zones: A comparison between observed examples and experimental models. Journal of Structural Geology 5: 33-45.

Gamond, J.F., 1987. Bridge structures as sense of displacement criteria in brittle fault zones. Journal of Structural Geology 9: 609-620.

Hope, R.A., 1969. Map showing recently active breaks along the San Andreas and related faults between Cajon Pass and Salton Sea, California. U.S. Geological Survey OpenFile Map.

Jackson, R.E., and Dunn, D.E., 1974. Experimental sliding friction and cataclasis of foliated rocks. International Journal of Rock Mechanics and Mining Science and Geomechanical Abstracts. 11: 235-249.

Lindh, A.G., and Boore D.M., 1981. Control of rupture by fault geometry during the 1966 Parkfield earthquake. Seismological Society of America Bulletin 71: 95-116.

Logan, J.M., Friedman, M., Higgs, N., Dengo, C., and Shimamoto, T., 1979. Experimental studies of simulated gouge and their application to studies of natural fault zones. Proceedings of Conference VIII: Analysis of Actual Fault Zones in Bedrock, U.S: Geological Survey Open-File Report 79-1239: 305-343.

Logan, J.M., Higgs, N.G., and Friedman, M., 1981. Laboratory studies on natural gouge from U.S. Geological Survey Dry Lake Valley No. 1 well, San Andreas fault zone. In: N.L. Carter, M. Friedman, J.M. Logan, and D.W. Stearns (eds.), Mechanical $\bar{B}$ ehavior of Crustal Rocks, American Geophysical Union Monograph 24: 121-134.

Logan, J.M., and Rauenzahn, K.A., 1987. Frictional dependence of gouge mixtures of quartz and montmorillonite on velocity, composition, and fabric. Tectonophysics 144: 87-108.

Mandl, G., deJong, L.N.J., and Maltha, A., 1977. Shear zones in granular material: An experimental study of their structure and mechanical genesis. Rock Mechanics 9: 95-144.

Mandl, G., 1988. Mechanics of Tectonic Faulting. Elsevier, New York, 407 p.

Moore, D.E., Summers, R., and Byerlee, J.D., 1983. Strengths of clay and non-clay fault gouge at elevated temperatures and pressures. Proceedings 24th U.S. Symposium on Rock Mechanics: 489-500.

Moore, D.E., Summers, R., and Byerlee, J.D., 1986a. The effects of sliding velocity on the frictional and physical properties of heated fault gouge. In: Chi-Yuen Wang (ed.), Internal Structure of Fault Zones, Pure and Applied Geophysics 124: 31-52. 
Moore, D.E., Summers, R., and Byerlee, J.D., 1986b. Strength measurements of heated illite gouge at low and high pore pressures. U.S. Geological Survey Open-File Report 86-578: $28 \mathrm{p}$.

Moore, D.E., Summers, R., and Byerlee, J.D., 1988. Relationship between textures and sliding motion of experimentally deformed fault gouge: Application to fault zone behavior. Proceedings 29th U.S. Symposium on Rock Mechanics: 103-110.

Moore, D.E., Summers, R., and Byerlee, J.D., 1989. Sliding behavior and deformation textures of heated illite gouge. Journal of Structural Geology: 11: 329-342.

Morgenstern, N.R., and Tchalenko, J.S., 1967. Microscopic structures in kaolin subjected to direct shear. Géotechnique 17: 309-328.

Mount, V.S., and Suppe, J., 1987. State of stress near the San Andreas fault: Implications for wrench tectonics. Geology 15: 1143-1146.

Naylor, M.A., Mandl, G., and Sijpesteijn, C.H.K., 1986. Fault geometries in basementinduced wrench faulting under different initial stress states. Journal of Structural Geology 8: 737-752.

Okubo, P.G., and Aki. K., 1987. Fractal geometry in the San Andreas fault system. Journal of Geophysical Research 92: 345-355.

Paterson, M.S., and Weiss, L.E., 1966. Experimental deformation and folding in phyllite. Geological Society of America Bulletin 77: 343-374.

Reasenberg, P., and Ellsworth, W.L., 1982. Aftershocks of the Coyote Lake, California earthquake of August 6, 1979: A detailed study. Journal of Geophysical Research 87: 10637-10655.

Riedel, W., 1929. Zur Mechanik geologischer Brucherscheinungen. Zentralblatt für Mineralogie, Geologie, und Palaeontologie, Abt. B: 354-368.

Rogers, T.H., 1973. Fault trace geometry within the San Andreas and Calaveras fault zones - A clue to the evolution of some transcurrent fault zones. In: R.L. Kovach and A. Nur (eds.), Proceedings of the Conference on Tectonic Problems of the San Andreas Fault System. Stanford University Publications in Geological Science 13: 251-258.

Ross, D.C., 1969. Map showing recently active breaks along the San Andreas fault between Tejon Pass and Cajon Pass, southern California. U.S: Geological Survey Miscellaneous Investigations Series Map I-553. 
Rutter, E.H., Maddock, R.H., Hall, S.H., and White, S.H., 1986. Comparative microstructures of natural and experimentally produced clay-bearing fault gouges. In: ChiYuen Wang (ed.), Internal Structure of Fault Zones. Pure and Applied Geophysics 124, 3-30.

Sanderson, D.J., and Marchini; W.R.D., 1984. Transpression. Journal of Structural Geology 6: 449-458.

Sarna-Wojcicki; A.M., Pampeyan, E.H., and Hall, N.T., 1975. Map showing recently active breaks along the San Andreas fault between the central Santa Cruz Mountains and the northern Gabilan Range, California. U.S. Geological Survey Miscellaneous. Field Studies Map MF-650.

Savage, J.C., Prescott, W.H., and Gu, G., 1986. Strain accumulation in southern California, 1973-1984. Journal of Geophysical Research 91: 7455-7473.

Segall, P., and Pollard, D.D., 1980. Mechanics of discontinuous faults. Journal of Geophysical Research 85: 4337-4350.

Segall, P., and Pollard, D.D., 1983. Nucleation and growth of strike-slip faults in granite. Journal of Geophysical Research 88: 555-568.

Sharp, R.V., 1971. Map showing recently active breaks along the San Jacinto fault zone between the San Bernardino area and Borrego Valley, California. U.S. Geological Survey Miscellaneous Geologic Investigations Map I-675.

Sharp, R.V., and Silver, L.T., 1971. Quaternary displacement on the San Andreas and Punchbowl faults at the San Gabriel Mountains, southern California. Geological Society of America Abstracts with Programs 3: 191.

Sharp, R.V., 1979. Implications of surficial strike-slip fault patterns for simplification and widening with depth. In: Proceedings of Conference VIII, Analysis of Actual Fault Zones in Bedrock. U.S: Geological Survey Open-File Report 79-1234: 66-78.

Sibson, R.H., 1985. Stopping of earthquake ruptures at dilational fault jogs. Nature 316: 248-251.

Sibson, R.H., 1986. Rupture interaction with fault jogs. Geophysical Monograph 37: 157-167.

Summers, R., and Byerlee, J., 1977. Summary of results of frictional sliding studies, at confining pressures up to $6.98 \mathrm{~kb}$, in selected rock materials. U.S. Geological Survey Open-File Report 77-142: 129 p. 
Sylvester, A.G., 1988. Strike-slip faults. Geological Society of America Bulletin 100: 16661703.

Tchalenko, J.S., 1970. Similarities between shear zones of different magnitudes. Geological Society of America Bulletin 81: 1625-1640.

Vedder, J.G., and Wallace, R.E., 1970. Map showing recently active breaks along the San Andreas and related faults between Cholame Valley and Tejon Pass, California. U.S: Geological Survey Miscellaneous Geologic Investigations Map I-574.

Vialon, P., 1979. Les déformations continues-discontinues des roches anisotropes. Eclogae geologicae Helvetiae 72: 531-549.

Wallace, R.E., 1973. Surface fracture patterns along the San Andreas fault. In: Robert L. Kovach and Amos Nur (eds.), Proceedings of the Conference on Tectonic Problems of the San Andreas Fault System. Stanford University Publications in Geological Science 13: 248-250.

Wallace, R.E., and Morris, H.T., 1986. Characteristics of faults and shear zones in deep mines. Pure and Applied Geophysics 124: 107-125.

Weaver, C.S., and Hill, D.P., 1978. Earthquake swarms and local crustal spreading along major strike-slip faults in California. Pure and Applied Geophysics 117: 51-64.

Wesnousky, S.G., 1988. Seismological and structural evolution of strike-slip faults. EOS (Transactions, American Geophysical Union 69: 1455.

Wesson, R.L., 1988. Predicted variation of stress orientation with depth near an active fault: Application to the Cajon Pass scientific drillhole, southern California. Geophysical Research Letters 15: 1009-1012.

Woodburne, M.O., 1975. Cenozoic stratigraphy of the Transverse Ranges and adjacent areas, southern California. Geological Society of America Special Paper 162, 91 p.

Zoback, M.D., Zoback, M.L., Mount, V.S., Suppe, J., Eaton, J.P. Healy, J.H., Oppenheimer, D., Reasenberg, P., Jones, L., Raleigh, C.B., Wong, I.G., Scotti, O, and Wentworth, C., 1987. New evidence on the state of stress of the San Andreas fault system. Science 238: 1105-1111. 